\title{
Exiting prison with complex support needs: the role of
} housing assistance 
Title

Exiting prison with complex support needs: the role of housing assistance

\section{Authors}

Chris Martin, The University of New South Wales Rebecca Reeve, The University of New South Wales Ruth McCausland, The University of New South Wales Eileen Baldry, The University of New South Wales Pat Burton, University of Tasmania Rob White, University of Tasmania Stuart Thomas, RMIT University

\section{ISBN}

978-1-922498-28-1

\section{Key words}

Ex-prisoners, incarceration, criminal justice, mental health, cognitive disability, post-release, desistance, reintegration, homelessness, social housing, temporary accommodation, transitional accommodation, private rental, comparative interrupted time series analysis, cost-benefit analysis, linked administrative data.

\section{Series}

AHURI Final Report

\section{Number}

361

\section{ISSN}

1834-7223

\section{Publisher}

Australian Housing and Urban Research Institute Limited Melbourne, Australia

DOI

10.18408/ahuri7124801

\section{Format}

PDF, online only

\section{URL}

https://www.ahuri.edu.au/research/final-reports/361

\section{Recommended citation}

Martin, C., Reeve, R., McCausland, R., Baldry, E., Burton, P., White, R. and Thomas, S. (2021) Exiting prison with complex support needs: the role of housing assistance, AHURI Final Report No. 361, Australian Housing and Urban Research Institute Limited, Melbourne, https://www.ahuri.edu.au/research/final-reports/361, doi: 10.18408/ahuri7124801.

\section{Related reports and documents}

Inquiry into enhancing the coordination of housing supports for individuals leaving institutional settings

https://www.ahuri.edu.au/housing/research-in-progress/ enhancing-the-coordination-of-housing-supports-forindividuals-leaving-institutional-settings

\section{AHURI}

The Australian Housing and Urban Research Institute (AHURI) is a national independent research network with an expert not-for-profit research management company, AHURI Limited, at its centre.

AHURI's mission is to deliver high-quality research that influences policy development and practice change to improve the housing and urban environments of all Australians.

Using high-quality, independent evidence and through active, managed engagement, AHURI works to inform the policies and practices of governments and the housing and urban development industries, and stimulate debate in the broader Australian community.

AHURI undertakes evidence-based policy development on a range of priority policy topics that are of interest to our audience groups, including housing and labour markets, urban growth and renewal, planning and infrastructure development, housing supply and affordability, homelessness, economic productivity, and social cohesion and wellbeing.

\section{Acknowledgements}

This material was produced with funding from the Australian Government and state and territory governments. AHURI Limited gratefully acknowledges the financial and other support it has received from these governments, without which this work would not have been possible.

AHURI Limited also gratefully acknowledges the contributions, both financial and in-kind, of its university research partners who have helped make the completion of this material possible.

The authors gratefully acknowledge Dr Elizabeth McEntyre and Mr Damian Griffis, the project's Aboriginal Reference Group; Dr Sian Thompson, who assisted with the project's ethics applications; Mr Nicholas Winley, the MHDCD Databank data manager; and everyone who participated in the interviews.

\section{Disclaimer}

The opinions in this report reflect the views of the authors and do not necessarily reflect those of AHURI Limited, its Board, its funding organisations or Inquiry Panel members. No responsibility is accepted by AHURI Limited, its Board or funders for the accuracy or omission of any statement, opinion, advice or information in this publication.

\section{AHURI journal}

AHURI Final Report journal series is a refereed series presenting the results of original research to a diverse readership of policy-makers, researchers and practitioners.

\section{Peer review statement}

An objective assessment of reports published in the AHURI journal series by carefully selected experts in the field ensures that material published is of the highest quality. The AHURI journal series employs a double-blind peer review of the full report, where anonymity is strictly observed between authors and referees.

\section{Copyright}

(C) Australian Housing and Urban Research Institute Limited 2021

This work is licensed under a Creative Commons Attribution-NonCommercial 4.0 International License, see http://creativecommons.org/licenses/by-nc/4.0/. 


\section{Contents}

List of tables $\quad$ iv

List of figures

Acronyms and abbreviations used in this report

Executive summary $\quad 1$

1. Introduction $\quad 7$

1.1 Policy context

\begin{tabular}{l}
1.2 Existing research and concepts \\
\hline 19
\end{tabular}

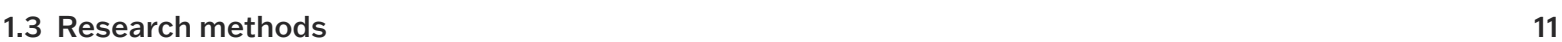

2. A statistical picture of prisoners and complex support needs

2.1 The prisoner population

2.2 Prisoner mental health, disability and suffering $\quad 20$

2.3 Prisoners, ex-prisoners and housing

$\begin{array}{ll}2.4 \text { Summary } & 24\end{array}$

3. Policies and programs relevant to post-release housing pathways $\quad 25$

$\begin{array}{ll}3.1 \text { Homelessness services } & 26\end{array}$

$\begin{array}{lr}3.2 \text { Social and affordable housing } & 27\end{array}$

$\begin{array}{ll}\text { 3.3 Disability services } & 30\end{array}$

$\begin{array}{ll}3.4 \text { Post-release services } & 31\end{array}$

3.4.1 New South Wales

3.4 .2 Victoria

3.4.3 Tasmania $\quad 33$

3.5 Summary

4. Pathways after prison: what do ex-prisoners and agency representatives tell us?

4.1 Pre-release planning and assistance $\quad 35$

4.1.1 Pre-release planning around post-release housing, homelessness and reintegration support 36

4.1.2 Pre-release planning around post-release mental health and disability support

4.2 Post-release temporary and transitional accommodation $\quad 40$

4.2.1 Temporary accommodation 41

4.2.2 Transitional accommodation 42

4.2.3 Specialist Homelessness Services (SHS)

4.2.4 Boarding houses

4.2.5 Engaging with housing and other service providers

$\begin{array}{lr}4.3 \text { Long-term housing } & 48\end{array}$

4.3.1 Private rental housing $\quad 48$

4.3.2 Social housing $\quad 50$

4.3.3 Specialist Disability Accommodation (SDA) 51

4.3.4 The road home

4.4 Summary $\quad 53$ 
5.1 Linked administrative data: the MHDCD Databank

5.2 Descriptive statistics $\quad 56$

$\begin{array}{ll}5.3 \text { Comparative interrupted time series (CITS) analysis } & 57\end{array}$

5.3.1 Police incidents

5.3.2 Court appearances $\quad 60$

5.3.3 Time in custody 65

5.3.4 Time on supervised community orders

5.3 .5 Justice costs

5.4 Cost-benefit analysis $\quad 73$

5.4 .1 Cost of providing public housing

$\begin{array}{ll}5.5 \text { Summary } & 75\end{array}$

6. Two case studies of the costs and benefits of housing assistance after prison 77

$\begin{array}{ll}6.1 \text { Jason } & 78\end{array}$

$\begin{array}{ll}6.2 \text { Debra } & 80\end{array}$

6.3 Case study costings $\quad 82$

$\begin{array}{ll}6.3 .1 \text { Jason } & 82\end{array}$

$\begin{array}{ll}\text { 6.3.2 Debra } & 84\end{array}$

6.4 Summary

7. Policy development options $\quad 86$

$\begin{array}{lr}\text { References } & 88\end{array}$

Appendix 1. Interview topic guide-agency representatives

Appendix 2. Interview topic guide-ex-prisoners 96 


\section{List of tables}

Table 1: Interviewees

Table 2: 'Greatest need' applications and allocations, and priority housing wait times, NSW, Victoria and Tasmania

Table 3: Private rental assistance, Temporary Accommodation and social housing allocations, NSW, 2018-19 30

Table 4: MHDCD datasets and date ranges

Table 5: Characteristics of the public housing and comparison groups 57

Table 6: Police incidents regression output 58

Table 7: Finalised court appearances regression output $\quad 60$

Table 8: Proven court appearances regression output 62

Table 9: Proven offences regression output 64

Table 10: Table 10: Days in custody regression output $\quad 66$

Table 11: Days of community supervision regression output 68

Table 12: Justice costs regression output $\quad 71$

Table 13: Criminal justice cost savings per person from providing public housing for ex-prisoners 73

Table 14: Cost-benefit scenario 1: Public housing compared with private rental 74

Table 15: Cost-benefit scenario 2: Public housing compared with homelessness 74

Table 16: Cost-benefit scenario 3: Public housing compared with private rental and homelessness

(50:50 weighting)

Table 17: Jason's institutional contacts, by age and agency

Table 18: Jason's institutional costs, by age and agency

Table 19: Debra's institutional contacts, by age and agency

Table 20: Debra's institutional costs, by age and agency 


\section{List of figures}

Figure 1: Average predicted number of police incidents per annum, for people with rental assistance only following exit from prison

Figure 2: Average predicted number of police incidents per annum, before and after receiving public housing following exit from prison

Figure 3: Jason's institutional costs, by age and agency

Figure 4: Debra's institutional costs, by age and agency

Figure 5: Prisoner populations and imprisonment rates, Australia, NSW, Victoria and Tasmania, 2010-20 16

Figure 6: Unsentenced prisoners, Australia, NSW, Victoria and Tasmania, 2010-20 17

Figure 7: Female prisoners, Australia, NSW, Victoria and Tasmania, 2010-20

Figure 8: Indigenous prisoners, Australia, NSW, Victoria and Tasmania, 2010-20 19

Figure 9: Prison conditions: average hours out of cells, prison design capacity utilisation, and assaults on prisoners per 100 prisoners, NSW, Victoria and Tasmania, 2009-19

Figure 10: People exiting custody seeking assistance from homelessness services, Australia, NSW, Victoria, Tasmania, 2011-19

Figure 11: Public housing, community housing and Indigenous housing dwellings, Australia, NSW, Victoria, Tasmania, 2010-19

Figure 12: Real per capita social housing expenditure, Australia, NSW, Victoria, Tasmania, 2019

Figure 13: Average predicted number of police incidents per annum, for people with rental assistance only following exit from prison

Figure 14: Average predicted number of police incidents per annum, before and after first receiving public housing following exit from prison

Figure 15: Average predicted number of finalised court appearances per annum, for people with rental assistance only following exit from prison

Figure 16: Average predicted number of finalised court appearances per annum, before and after receiving public housing following exit from prison

Figure 17: Average predicted number of proven court appearances per annum, for people with rental assistance only following exit from prison

Figure 18: Average predicted number of proven court appearances per annum, before and after receiving public housing following exit from prison

Figure 19: Average predicted number of proven offences per annum, for people with rental assistance only following exit from prison

Figure 20: Average predicted number of proven offences per annum, before and after receiving public housing following exit from prison

Figure 21: Average predicted number of days in custody per annum, for people with rental assistance only following exit from prison

Figure 22: Average predicted number of days in custody per annum, before and after receiving public housing following exit from prison

Figure 23: Average predicted days on supervised community order per annum, for people with rental assistance only following exit from prison

Figure 24: Average predicted days on supervised community order per annum, before and after receiving public housing following exit from prison

Figure 25: Average criminal justice costs, for people with rental assistance only following exit from prison 72

Figure 26: Average criminal justice costs, before and after receiving public housing following exit from prison 72

Figure 27: Jason's institutional costs, by age and agency

Figure 28: Debra's institutional costs, by age and agency 


\section{Acronyms and abbreviations used in this report}

\begin{tabular}{|c|c|}
\hline AHURI & Australian Housing and Urban Research Institute Limited \\
\hline ABS & Australian Bureau of Statistics \\
\hline AlHW & Australian Institute of Health and Welfare \\
\hline AOD & Alcohol and other drug \\
\hline BOCSAR & Bureau of Crime Statistics and Research (NSW) \\
\hline CITS & Comparative interrupted time series \\
\hline $\mathrm{CHP}$ & Community housing provider \\
\hline cosp & Community Offender Support Program \\
\hline CRC & Community Restorative Centre (NSW) \\
\hline DCJ & Department of Communities and Justice (NSW) \\
\hline DHHS Vic. & Department of Health and Human Services Victoria \\
\hline DSP & Disability Support Pension \\
\hline IRR & Incidence rate ratio \\
\hline JLO & Justice Liaison Officer \\
\hline MHDCD & Mental Health Disorders and Cognitive Disabilities Databank \\
\hline NDIA & National Disability Insurance Agency \\
\hline NDIS & National Disability Insurance Scheme \\
\hline NGO & Non-government organisations \\
\hline NPAH & National Partnership Agreement on Homelessness \\
\hline NRAS & National Rental Affordability Scheme \\
\hline NSW & New South Wales \\
\hline RoGS & Report on Government Services \\
\hline SDA & Specialist Disability Accommodation \\
\hline SHS & Specialist homelessness services \\
\hline SHSC & Specialist Homelessness Services Collection \\
\hline TA & Temporary Accommodation (NSW) \\
\hline UNSW & The University of New South Wales \\
\hline
\end{tabular}




\section{Executive summary}

Key points

- Imprisonment in Australia is growing and ex-prisoner housing need is growing; but at the same time, housing assistance capacity is declining.

- Without real options and resources, prisoner pre-release planning for accommodation is often last-minute. Insecure temporary accommodation is stressful, and diverts ex-prisoners and agencies from addressing other needs, undermining desistance from offending.

- Ex-prisoners with complex support needs who receive public housing have better criminal justice outcomes than comparable ex-prisoners who receive private rental assistance only. Public housing 'flattens the curve' of average predicted police incidents (down $8.9 \%$ per year), time in custody (down $11.2 \%$ per year), justice system costs per person (down $\$ 4,996$ initially, then a further $\$ 2,040$ per year), and other measures.

- In dollar terms, housing an ex-prisoner in a public housing tenancy generates, after five years, a net benefit of between $\$ 5,200$ and $\$ 35,000$, relative to the cost of providing them with assistance in private rental and/or through homelessness services.

- The evidence strongly supports the need for much greater provision of social housing to people exiting prison, particularly for those with complex support needs. 
One of the classic metaphors for exiting prison is 'going home'. However, more than half of people exiting Australian prisons either expect to be homeless or don't know where they will be staying when they are released.

The connection between imprisonment and homelessness presents special risks for people with complex support needs: that is, people leaving prison who have a mental health condition and/or a cognitive disability. People with complex support needs are often excluded from community-based support and services because they are deemed 'too difficult', and so end up entangled in the criminal justice system.

Post-release housing assistance is a potentially powerful lever in arresting the imprisonment-homelessness cycle, and breaking down the disabling web of punishment and containment in which people with complex support needs are often caught.

\section{Key findings}

\section{Imprisonment is growing ...}

Over the past decade, Australian prisoner populations and imprisonment rates have grown - notwithstanding a dip in numbers during the COVID-19 pandemic. Just over 41,000 people were in prison at the time of the 2020 prison census. Men continue to make up the large majority (92\%) of prisoners, but in most jurisdictions rates of growth in the imprisonment of women have been somewhat higher than for men. Indigenous people continue to be hugely over-represented in prisons, with an imprisonment rate more than thirteen times that of non-Indigenous people, and still rising.

\section{... ex-prisoner housing need is growing ...}

A wide range of factors associated with disadvantage and support needs are highly prevalent among people in prison, particularly: mental health conditions (40\%), cognitive disability (33\%), problematic alcohol or other drug use (up to 66\%), and past homelessness (33\%). However, prisons are not mere aggregators of disadvantage: they are inherently afflictive. All prisoners experience suffering, and this compounds disadvantage and complicates other support needs.

We estimate that there were approximately 65,000 releases from prison in 2019, and one in seven of these resulted in a request for assistance from a specialist homelessness service. Ex-prisoners have been the fastest growing client category for specialist homelessness services (SHS) over the past decade.

\section{... but housing assistance capacity is declining.}

Homelessness services and social housing are strained after a decade of declining policy priority and, in the case of social housing, declining real per capita expenditure. Ex-prisoners are a priority group in homelessness policy, and have been since the short-lived period of homelessness policy reform in the late 2000s. This is reflected in the increase in ex-prisoners accessing SHS, and a wider commitment to inter-agency work and Housing First principles; however, the necessary housing is lacking. The diminishing social housing sector has tightened its targeting, and sought to increase the ways it can assist clients to access private rental housing.

Disability service provision has been transformed in more profound ways, by the introduction of the National Disability Insurance Scheme (NDIS). In the shift to person-centred funding for disability supports, the states and territories have withdrawn from many forms of service provision-including, in some cases, services targeted at people in contact with the criminal justice system. However, there are signs, acknowledged by the National Disability Insurance Agency (NDIA), that such people are not reaching the NDIS.

There are also state-funded transitional support and accommodation services specifically for ex-prisoners but, relative to need, their capacity is tiny. 


\section{Pathways after prison: ex-prisoner and agency perspectives}

For this study, we interviewed people working in housing, disability and reintegration support agencies, state corrective services representatives, and ex-prisoners, in New South Wales (NSW), Victoria and Tasmania. The standout point made by all interviewees was the dearth of housing options for people exiting prison.

Many agency interviewees spoke about the significant histories of abuse, neglect, trauma and institutionalisation experienced by the cohort they work with, and how these factors lead to significant and ongoing challenges in terms of clients' desistance from offending and reintegration with the community. They indicated that access to a range of supports, currently rationed to the highest priority cases, should be provided much more widely.

Interviewees reported that prisoner pre-release planning for housing and post-release support is constrained by high workloads and limited services. Without the necessary resources to plan (including long-term accommodation options), these arrangements are often left until very shortly before release.

After release, the road to permanent housing for ex-prisoners can be long, and beset by pitfalls.

They could easily be waiting a couple of years, realistically. For them that's a long time, and so far off in the distance it's difficult to conceive of. And a long time in which things could go wrong in their lives - to be homeless or back in prison, all sorts of things. And the longer the time, the less chance you've got that they'll be in a place to be offered something. (Victorian community housing provider)

The general consensus among interviewees was that insecure temporary accommodation is stressful and diverts ex-prisoners and support agencies from addressing other needs, undermining desistance from offending.

Of necessity, ex-prisoners and support agencies work at accessing private rental housing, but barriers-primarily unaffordability - make this route challenging, and impossible for many. Respondents acknowledged that the social housing pathway has its own challenges, but they generally felt that, combined with ongoing support, it is the best long-term prospect.

\section{Pathways after prison: linked data analysis}

The research team conducted a comparative interrupted time series (CITS) analysis of post-release housing assistance and criminal justice outcomes for ex-prisoners with complex support needs. The Mental Health Disorders and Cognitive Disabilities (MHDCD) Databank at the University of New South Wales (UNSW) holds linked, de-identified administrative data from NSW state government agencies. From this dataset we selected 623 people who received public housing after exiting prison and 612 people who received rental assistance only.

The figures below show the average predicted number of police incidents per annum for the 'rental assistance only' group, and for the 'public housing' group. For the latter group, the difference made by public housing (received at year 0 ) to the trend in predicted incidents over time is stark: public housing 'flattens the curve'. 
Figure 1: Average predicted number of police incidents per annum, for people with rental assistance only following exit from prison

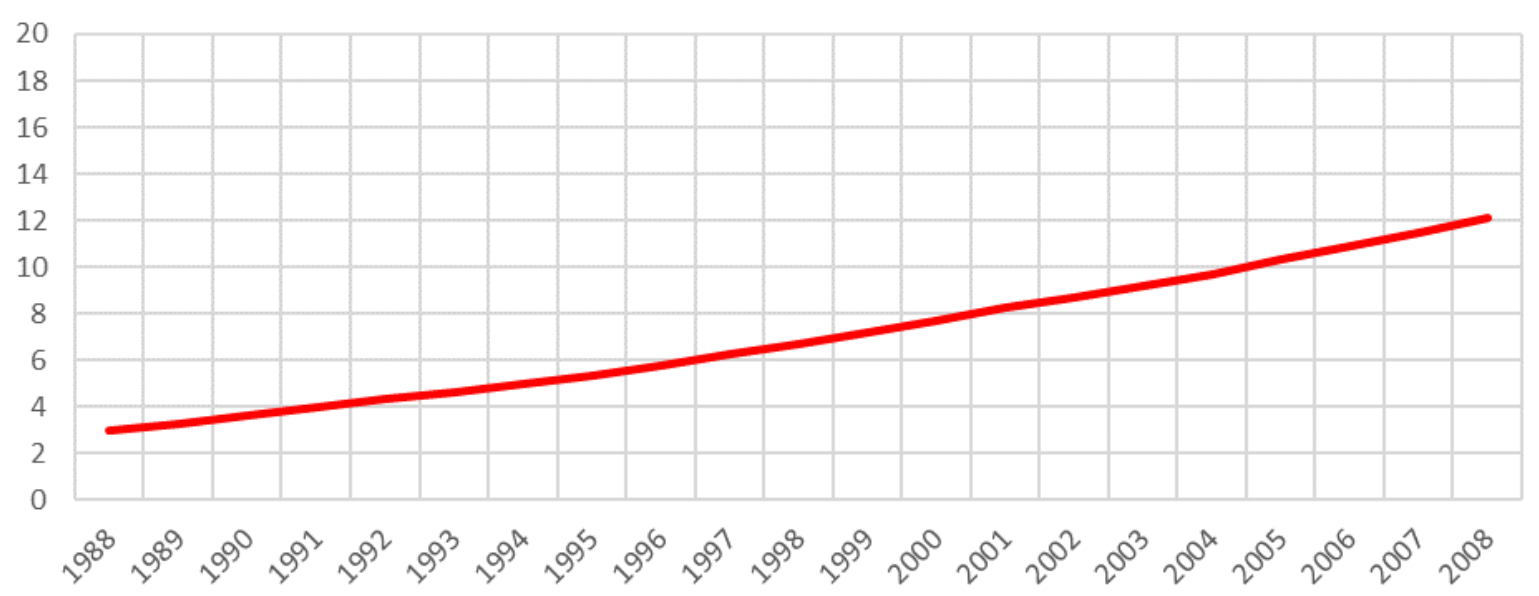

Source: The authors, drawing on MHDCD data (2020).

Figure 2: Average predicted number of police incidents per annum, before and after receiving public housing following exit from prison

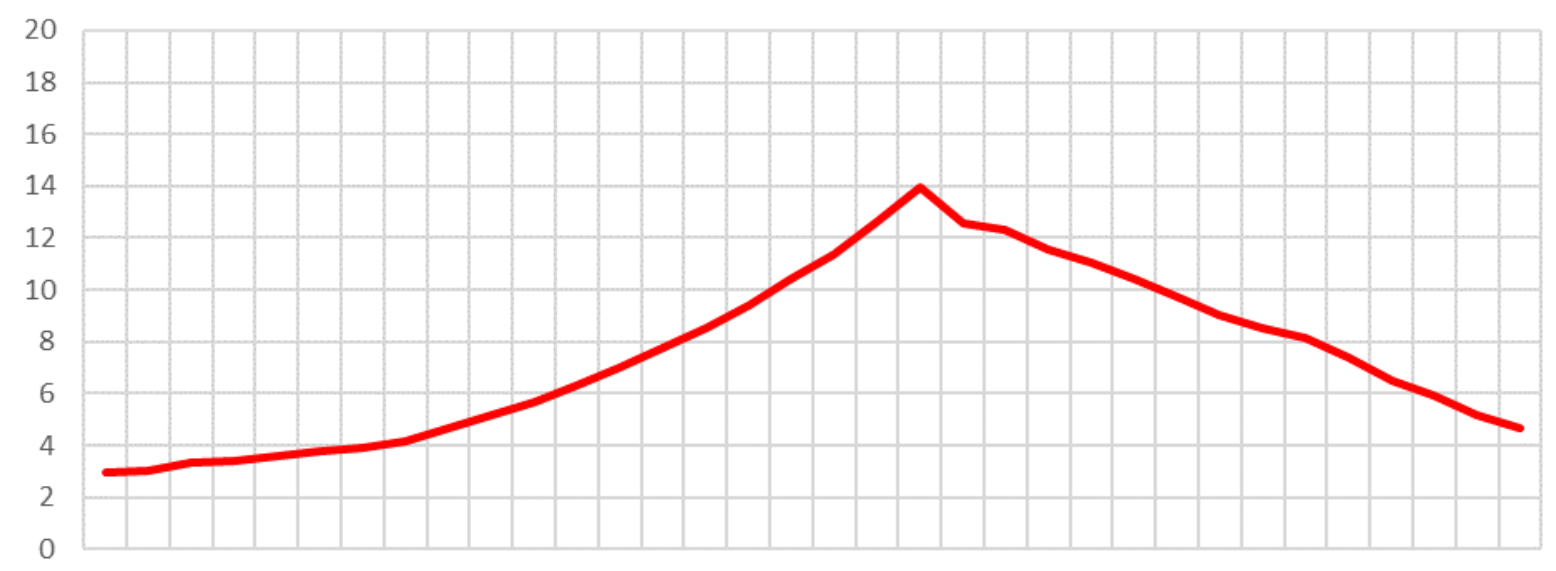

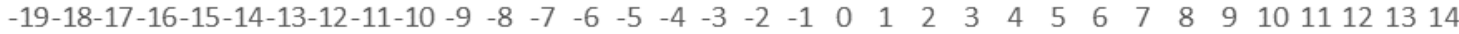

Note: Public housing received at year 0.

Source: The authors, drawing on MHDCD data (2020).

The trend shows a reduction in police incidents of 8.9 per cent per year after receiving public housing. We found similar downward trends when considering other criminal justice measures for this group.

- Court appearances: down 7.6 per cent per year.

- Proven offences: down 7.6 per cent per year.

- Time in custody: down 11.2 per cent per year.

- Time on supervised orders: after an initial increase, down 7.8 per cent per year.

- Justice costs per person: down \$4,996 initially, then a further \$2,040 per year. 
Our research identified that, for most of these measures, women, Indigenous people and people with multiple diagnoses experience similar improvements to people outside those subgroups. Age (i.e. each additional year of age at first prison exit) is associated with a small additional improvement for most measures.

Fewer interactions with the criminal justice system means cost savings to the justice system. We found that, when housing costs are taken into consideration, public housing generates a net benefit of $\$ 5,200$ to $\$ 35,000$ per person over five years, relative to the cost of providing assistance to an ex-prisoner in private rental or through homelessness services.

The cohort's median time from first prison exit to public housing is five years (mean 5.9). Were public housing received sooner following exit from prison, the benefits to the individual and society would be expected to occur sooner and therefore be even greater.

\section{Two case studies}

Two case studies - 'Jason' and 'Debra'-were drawn from the MHDCD Databank in order to illustrate the role that social housing can play in the trajectories and experiences of people with cognitive disability and complex needs who are in contact with the criminal justice system.

- Jason's consecutive public housing tenancies from age 23 were found to be associated with a dramatic reduction in his costly interactions with the criminal justice system, some of which related to violent offences against women.

- Debra had several public housing tenancies between the ages of 37 and 45. During that time, she maintained periods of up to 18 months without contact with the criminal justice system, providing significant cost savings. The provision of more support around Debra's mental health and other needs may have helped avoid her repeated crisis-related contact with police and emergency hospital admissions, and assisted her to maintain her tenancies, reducing the cost to Debra and the state.

- Both Jason and Debra waited for housing after release from custody, during which time they frequently reoffended.

Calculating the cost of Jason and Debra's institutional contacts (i.e. interactions with the criminal justice system and other agencies) highlights the economic, as well as social, benefits of providing social housing and support for people released from custody - both in the short and longer term.

Figure 3: Jason's institutional costs, by age and agency
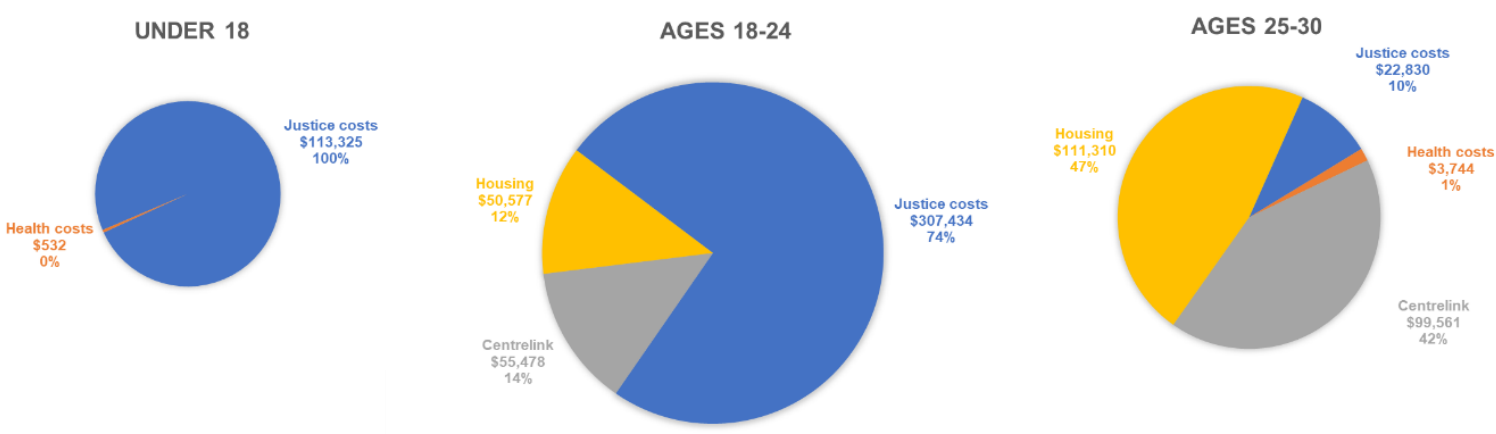

Note: Jason received public housing from age 23

Source: The authors, drawing on MHDCD data (2020). 
Figure 4: Debra's institutional costs, by age and agency
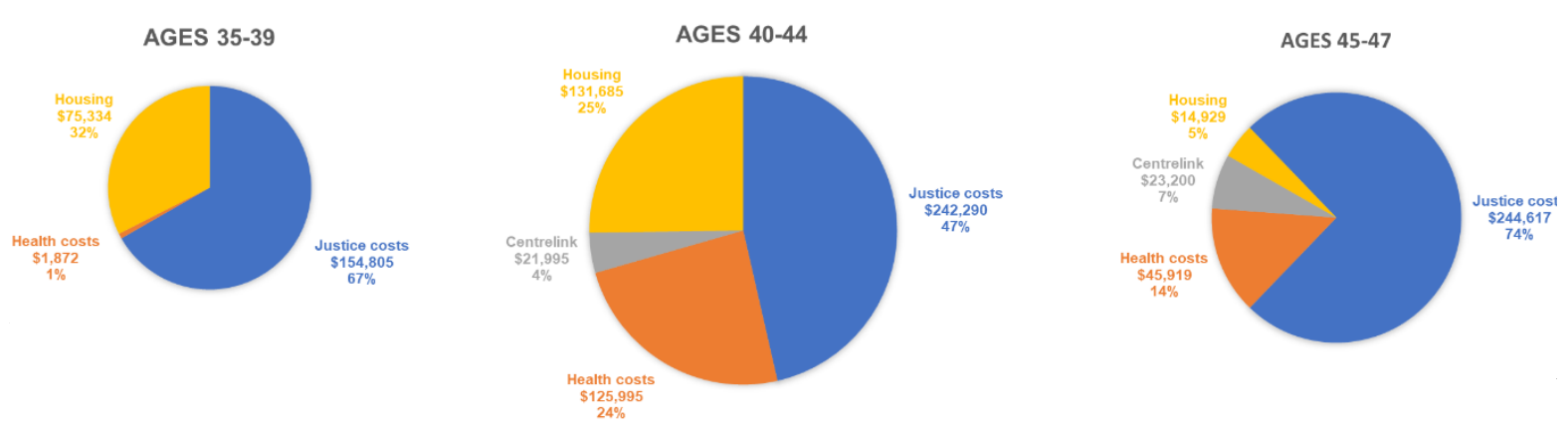

Note: Debra received public housing, intermittently, from age 37 to 45.

Source: The authors, drawing on MHDCD data (2020).

\section{Policy development options}

The evidence strongly supports the need for much greater provision of social housing to people exiting prison, particularly for those with complex support needs. Relatively secure, affordable public housing is a steady 'hook for change' that a person exiting prison can hold onto as they make changes in their circumstances, and in themselves, to desist from offending. It is also a stable base from which to receive and engage with support services.

Our linked data analysis looked specifically at public housing, because we could not identify in the data assistance from community housing providers and Indigenous NGOs. We see no reason why the beneficial effects of public housing for ex-prisoners would not also be realised in community housing or Indigenous housing, provided they offer secure, affordable tenancies and associated conditions (e.g. access to transfers), like public housing.

\section{The study}

The research focussed on NSW, Victoria and Tasmania, and employed a mixed-methods approach. It comprised four components.

- Reviews of published statistics on prisoners and their support and housing needs, and current policies and programs relevant to post-release pathways.

- Interviews with 41 people, including: corrective services representatives; housing, disability, and reintegration services workers (government and NGO); and six ex-prisoners with complex support needs. Interviews were conducted in NSW, Victoria and Tasmania.

- CITS analysis of linked administrative data from the MHDCD Databank at UNSW.

- Two cost-benefit analyses: one based on the CITS analysis, and the second based on two case studies drawn from de-identified linked administrative data.

The MHDCD Databank at UNSW holds de-identified linked data for about 2,713 people who were in prison in NSW at some point between 2001 and 2008. The data is provided by NSW state government agencies-including the Bureau of Crime Statistics and Research (BOCSAR), Police, Corrective Services, Justice Health and other health areas, Juvenile Justice (now Youth Justice), Legal Aid, Disability, Housing and Community Services - and relates to each person's contact with agencies before, during and after their time in prison, giving a whole-of-life picture of institutional involvement.

This research was conducted as part of the Australian Housing and Urban Research Institute (AHURI) Inquiry into enhancing the coordination of housing supports for individuals leaving institutional settings. The Inquiry includes research on exits from residential rehabilitation facilities (Duff, Hill et al. forthcoming) and exits from out-of-home care (Martin, Cordier et al. forthcoming). 


\section{Introduction}

One of the classic metaphors for exiting prison is 'going home' (e.g. Western 2018; Petersilia 2009). However, more than half of people exiting Australian prisons either expect to be homeless or don't know where they will be staying when they are released (AlHW 2019a).

For some individuals, imprisonment will have ended their previous housing arrangement, such that they cannot go back. For others, prison will have interrupted a period of homelessness: one-third of all people entering prison do so from a situation of homelessness (AlHW 2019a). With more than half of prisoners also having been in prison previously (ABS 2019), a picture emerges of a vicious, costly cycle of imprisonment and homelessness.

The apparent connections between imprisonment and homelessness present special risks for people with complex support needs: that is, people leaving prison who have a mental health condition and/or a cognitive disability. People with these conditions are over-represented in prison: about 40 per cent of people entering prison have been diagnosed with a mental health condition, and 33 per cent may have some degree of cognitive impairment (AIHW 2019a; NSW Justice Health 2017; Thomas, Spittal et al. 2015). As Baldry characterises it, people with complex support needs are often seen as 'too difficult' and are excluded from community-based support and services, and so end up 'enmeshed in the criminal justice system' (Baldry 2014: 376).

Post-release housing assistance is a potentially powerful lever in arresting the imprisonment-homelessness cycle, and breaking down the disabling web of punishment and containment in which people with complex support needs are often caught.

\subsection{Policy context}

A little over a decade ago, the Australian Government's white paper on homelessness, The Road Home, identified prisoners as a group that is especially vulnerable to homelessness. The paper, which envisaged a reduction in homelessness generally, put forward a national objective of 'no exits into homelessness' from custodial settings (FaHCSIA 2008: 27). Pursuit of this objective over the ensuing years has been rocky, as homelessness and social housing have again slipped from the national policy agenda (as discussed in more detail in our policy review in Chapter 3).

However, ex-prisoners remain an identified priority group in the homelessness policy statements and action plans of state governments, including the three jurisdictions in focus in the present research: NSW (NSW Government 2018), Victoria (DHHS Vic. 2018) and Tasmania (DHHS Tas. 2015). Recently, the NSW Government reaffirmed its objective of 'no exits into homelessness' from government services, including prisons (DCJ 2020).

Regarding ex-prisoners with complex support needs, the advent of the NDIS represents a major change in disability service policy and provision, and has the potential to significantly shape post-release pathways. How the NDIS and its agencies relate to ex-prisoners, and to people with complex support needs-and, for that matter, to other government and non-government agencies - is still fluid (this is also discussed in Chapter 3 ). 
The challenge of addressing the housing and support needs of people exiting prison is heightened by the continued growth of the prison population. Over the past decade, prisoner numbers and imprisonment rates in Australia have increased-notwithstanding a notable dip in numbers during the COVID-19 emergency. At the time of the most recent prison census, just over 41,000 people were incarcerated in prisons across Australia (ABS 2020a). From the data reviewed in this research (Chapter 2), we estimate that about 65,000 prison discharges occurred in 2019.

While governments commit to objectives of crime prevention in high-level strategies and agencies (Clancey, Fisher et al. 2016), there has been little formal commitment to reducing imprisonment rates or prison populations. However, some targets have been set for decreasing reoffending by ex-prisoners. The NSW Government has adopted, as a Premier's Priority, the aim of 'reducing recidivism in the prison population', and is targeting a 5 per cent reduction, by 2023, in the number of individuals reoffending after leaving prison (NSW Government 2020). Similarly, Tasmania's Corrections Plan, Breaking the Cycle, highlights a reduction in reoffending as a current goal (Department of Justice Tas. 2011). There has also been some policy action in relation to Indigenous people, who, because of past and continuing colonisation and racism, are hugely over-represented in prisons (see Chapter 2). The National Agreement on Closing the Gap includes a target to reduce the rate of Indigenous incarceration by at least 15 per cent by 2031 (Australian Government 2020). The Victorian Aboriginal Justice Agreement: Burra Lotjpa Dunguludja also includes commitments to reduce the number of Indigenous people entering and returning to prison (VAJAC 2020).

High and rising imprisonment rates are, however, registering in state government budgets. Across Australia, real net expenditure on prisons increased 44 per cent over the 2010-19 period (18\% in NSW, 102\% in Victoria and $41 \%$ in Tasmania: SCRGSP (2020) Table 8A.2). The high costs of imprisonment and reoffending-in terms of public expenditure, and in terms of the victims of crimes and the wasted lives of offenders - are also being debated and challenged outside government. The Jailing is Failing campaign by the Justice Reform Initiative is a prominent example, backed by high-profile patrons from across political parties and the legal, academic, Indigenous and community sectors (Justice Reform Initiative 2020).

\subsection{Existing research and concepts}

\section{The homelessness-imprisonment connection}

There is strong evidence linking imprisonment and homelessness. However, the nature and complexity of the connection is less thoroughly examined. As a result, assessments of policies and programs that act on postrelease pathways may not take in to account all the factors and contexts that influence effectiveness.

Almost twenty years ago, landmark AHURI research by Baldry, McDonnell et al. (2003) revealed a strong connection between post-release housing instability and homelessness, and reoffending and reincarceration. In that research, homelessness was found to be one of two predictors of reincarceration (the other being illegal drug use). Examining a cohort of ex-prisoners in NSW and Victoria, the study found that about half moved residence twice or more in the first nine months post-release. Of those frequent movers, almost 60 per cent had returned to prison during that nine-month period - a reincarceration rate three times that of the less-frequent movers (i.e. those with more stable housing).

In a large-scale study of Queensland ex-prisoners by Thomas, Spittal et al. (2015), 21 per cent of the cohort examined had a history of unstable housing (i.e. prior to imprisonment), and 61 per cent of this group (compared with 55\% of the whole cohort) were reincarcerated within three years. Ex-prisoners prescribed mental health medications, and ex-prisoners screened as having an intellectual disability, comprised, respectively, 30 per cent and 31 per cent of the cohort, with reincarceration rates of 58 per cent and 62 per cent. 
On further analysis, the authors found that an ex-prisoner's risk of reincarceration was 8 per cent higher when they had a history of unstable housing, 28 per cent higher when they were prescribed mental health medications, and 15 per cent higher when they had an intellectual disability (Thomas, Spittal et al. 2015: 8). They also observed a high rate of reincarceration for Indigenous ex-prisoners (71\%), but found that the risk of reincarceration associated with Indigeneity is somewhat attenuated when associated health and disadvantage factors are taken into account -highlighting that Indigenous over-imprisonment derives from social and economic marginalisation as well as from discrimination in criminal justice institutions (2015: 10).

The imprisonment-homelessness connection is also evident from research that focusses on homeless populations in Australia. Analysis by Bevitt, Chigavazira, et al. (2015) of Journeys Home (the six-wave longitudinal survey of people who are homeless or at risk of homelessness) showed that of the various adverse histories reported by participants, a history of imprisonment uniquely predicted current homelessness: individuals who had been in prison before the survey period experienced homelessness during the survey period at 1.5 times the rate of others, and primary homelessness (rough sleeping) at 2.4 times the rate of others (2015: 68). Ex-prisoners also spent more time homeless (1.4 times longer than others; and twice as long in primary homelessness) (2015: 73). Of those people who had recently been in prison, 42 per cent were homeless at the next survey wave (twice the average rate), with 10 per cent in primary homelessness (three times the average rate) (2015: 70).

International research also shows the imprisonment-homelessness connection. In New Zealand, Morrison and Bowman (2017) found that just under half (47\%) of a cohort of dischargees did not have stable accommodation on release. At 4-6 months post-release, only 41 per cent of individuals released into unstable accommodation were more securely housed, while 20 per cent were homeless and 39 per cent were back in prison. Reviewing the United States (US) research literature, LeBel observed the consistent finding that 'released prisoners without stable housing are more likely to return to prison' (LeBel 2017: 893). Using linked data from homeless shelters and prison authorities in New York, Metraux and Culhane (2004) found that 11 per cent of ex-prisoners accessed shelters shortly after release, and that this group was 17 per cent more likely than other ex-prisoners to be reincarcerated within two years of release. For ex-prisoners who had a history of homelessness before prison, rates both of homeless shelter access and of reincarceration were higher still (2004: 148). The authors concluded: 'efforts to prevent homelessness among released prisoners should focus on the transitional period occurring right after prison and should focus on people who demonstrate a history of unstable housing' (2004: 153).

In a Boston study (Western, Braga, et al. 2015), 20 per cent of dischargees reported that they had been homeless or marginally housed prior to imprisonment. After release, rates of homelessness or marginal housing were 38 per cent in the first week, and still 35 per cent after six months-and rates were twice as high for ex-prisoners with a mental illness or addiction as for those without (Western, Braga et al. 2015: 1526-27). The authors observed high levels of reported social anxiety on release (40\%) and noted the importance of adaptive 'de-prisonisation' activities: cleaning a room or residence, getting new clothes, welcome home parties. From further statistical analysis they identified the 'first two months as a critical period in the progress of social integration', with homelessness and marginal accommodation highly associated with isolation immediately post-release and with poor integration later (2015: 1532).

\section{Desistance and housing pathways}

When considering the empirical dimensions of the imprisonment-homelessness connection and the role of housing assistance, a useful conceptual framework is offered by the literature on 'desistance' (Anderson and McNeill 2019; Graham and White 2015; McNeill 2006; Maruna 2001; Laub and Sampson 2001). Desistance scholarship seeks to explain:

how and why people stop offending and change, offering empirical and practical insights into how services, structures and social relations within and beyond the criminal justice system can be reconfigured to successfully support change (Graham and White 2015: 12). 
The key proposition of the desistance literature is that desistance from offending is a process — rather than an event or decision - whereby individuals who had previously engaged persistently in offending actively maintain lawful behaviours and refrain from offending (Maruna 2001: 26). As such, the process of desistance may, for some, involve lapses and relapses into offending, while others maintain a more complete cessation (Graham and White 2015: 12). Furthermore, desistance is a process that takes place largely or entirely outside prisons and other criminal justice institutions. Desistance scholars look instead 'to forces like the labor market, to the family, and to the offender himself or herself' as the shapers of the process (Maruna 2001: 28). Indeed, many aspects of imprisonment appear to disrupt or work against desistance, whether by exposing offenders to the influence of other offenders or, through its inherently punitive conditions, by harming prisoners or provoking their adaptation of survival behaviours, either of which may lead to further offending in the outside world (Maruna and Toch 2005: 152-154; Irwin and Owen 2005).

Streams of the desistance literature emphasise different institutions and mechanisms bearing on the process of desistance (Anderson and McNeill 2019: 600; Graham and White 2015: 12-13). Some highlight the social bonds made through employment, intimate relationships and friendship groups, and the informal social controls these bonds exert on individuals (e.g. Laub and Sampson 2001). Others focus on the experiences and subjectivities of people desisting, and their formation of a new non-offending identity (e.g. Anderson and MacNeill 2019; McNeill 2006; Maruna 2001). As Graham and White observe (2015: 13), these are complementary perspectives, and studies of desistance as a subjective process need to attend to the individual's external environment, including systemic and structural arrangements, and whether it affords 'hooks for change' onto which the individual might latch (Anderson and McNeill 2019: 601; Giordano, Cernkovich et al. 2002).

The conceptual framework of desistance resonates with key concepts in housing studies. In Clapham's conceptualisation of 'housing pathways', housing is conceived of as the basic site for individuals' engagement in diverse social relations and in identity-making, and as a crucial mediator of socio-economic structure, material conditions and individual agency (Clapham 2002; also Easthope 2014, 2004). In Australia, this sort of conceptualisation has informed AHURI research into private rental housing and the extent to which individuals and households can exercise autonomy, find self-fulfilment and make a home as renters (Hulse, Milligan et al. 2011; Easthope 2014; Martin, Hulse et al. 2018). These studies suggest that making a home in private rental is challenging, because the Australian private rental sector is legally and structurally insecure; additionally, low-income private renters face deepening problems of affordability and access as the low-cost rental stock continues to decline (Hulse, Reynolds et al. 2019).

Compared to private rental, social housing (i.e. public and community housing) in Australia is more secure and affordable. AHURI research provides evidence that new social housing tenants enjoy a range of associated 'non-shelter outcomes', including: increased participation in health programs and healthier diet; more support from neighbours; improved school performance by children; and less stress (Phibbs and Young 2005). Recently, social housing policy-makers have sought to reduce the security historically associated with social housing, and effect 'pathways' out of the sector and into the 'independence' of the private rental market (Flanagan, Levin et al. 2020). However, as the authors show, social housing tenants value its relative security and invest strongly in it, deriving 'profound ontological security' from their tenancies (2020: 1).

\section{Housing assistance costs and benefits}

From a social justice perspective, housing for people who would otherwise be homeless, associated 'non-shelter outcomes' and desistance from offending are self-evidently beneficial outcomes of government expenditure, and should be pursued as ends in and of themselves. However, as observed by Parsell, Petersen et al. (2017: 1535), in recent years both policy-makers and advocates have increasingly presented arguments for expenditure on assistance in terms of achieving a further end: reduced total financial costs to governments, through offsetting savings achieved in other areas of government operations. While this line of argument risks mistakenly downplaying the fiscal capacity of governments to increase expenditure for the public benefit (Flanagan, Martin et al. 2019: 21-22), it can bolster the case for policies and programs beyond their social justice imperative. 
While there is a substantial body of research in the US on housing assistance costs and benefits realised in other areas, including the criminal justice system (Parsell, Petersen et al. 2017; Culhane 2008), there is rather less research in Europe and Australia-although The Road Home makes the argument that housing assistance delivers 'whole-of-government savings' (FaHCSIA 2008: 10; Parsell, Petersen et al. 2017). Research for AHURI by Zaretsky and Flatau (2013) employed survey data from clients of homelessness services to estimate changes in their use of other services (e.g. emergency hospital visits) and contacts with the criminal justice system, and potential cost reductions in those areas. They estimated homelessness services generally achieved net savings in other areas, but the distribution of costs and benefits varied significantly between client groups. They also cautioned that their findings were limited by the study's short-term timeframe for assessing costs and benefits, and its reliance on survey data.

Using linked administrative data over a 24-month period for a cohort of 41 formerly homeless residents of a Housing First supportive housing project in Brisbane, Parsell, Petersen et al. calculated that the housing service, at an average cost of $\$ 14,329$ per resident per annum, achieved an average reduction in other government service costs of $\$ 27,429$ per resident per annum, of which almost $\$ 3,000$ related to criminal justice sector costs (2017: $1543-47)$. In other words, it cost the government about $\$ 13,000$ less to assist a person with supportive housing than to interact with them while homeless.

In a series of research reports, several members of the present research team have produced cost-benefit analyses of linked administrative data from longer time periods, to show the long-term costs relating to people who have complex support needs and are in contact with the criminal justice system and other agencies in NSW (Baldry, Dowse et al. 2012; McCausland, Baldry et al. 2013; Reeve, McCausland et al. 2017; McCausland, Reeve et al. forthcoming). Those analyses used a case study approach, showing individual's institutional costs over periods of up to multiple decades, with a high degree of granularity that revealed turning points in the person's life course: for example, a period of homelessness associated with highly costly contacts with the criminal justice system, or a period of stable accommodation and support with little criminal justice contact. The present research follows this line of research further, using the same linked administrative data source (the MHDCD Databank at UNSW, discussed further below) and undertaking cost-benefit analyses of newly derived case studies from that source, as well as an innovative cost-benefit analysis of comparable groups within the cohort.

\subsection{Research methods}

\section{Research questions}

Four research questions guided the present study.

1. What policy settings and programs are relevant to the housing pathways of ex-prisoners with complex support needs?

2. What do criminal justice workers, housing workers and ex-prisoners say about the coordination and delivery of housing assistance?

3. What does the linked administrative data tell us about the role of housing assistance in the pathways of ex-prisoners with complex needs?

4. What criminal justice costs and benefits result from current housing assistance settings, and what are the priority areas for further investment? 


\section{Research methods}

To answer these research questions, we employed the following mix of research methods.

- Reviews of published statistics and policies

- Interviews

- CITS analysis of linked administrative data

- Cost-benefit analysis

Reviews of published statistics and policies

We reviewed the major published statistical sources-including the Prisoners in Australia series by the Australian Bureau of Statistics (ABS 2020a), the Health of Australian Prisoners study by the Australian Institute of Health and Welfare (AlHW 2019a), and Specialist Homelessness Services Collection (SHSC) data (AlHW 2019b)-to track trends in the prisoner population and generate a current profile of prisoners and their housing and other support needs. Chapter 2 presents the results.

We also reviewed the current state and recent history of policies and programs relevant to post-release pathways. Encompassing developments over the past decade in homelessness, social housing, disability services and postrelease specific programs, this review is presented in Chapter 3.

\section{Interviews}

We conducted interviews in NSW, Victoria and Tasmania with representatives of a range of stakeholder agencies, and with people with complex support needs who had exited prison, to garner their perspectives on post-release pathways. In total, 47 individuals participated in the interviews (see Table 1). Agency representatives were recruited, by invitation, from relevant agencies selected by the research team on the basis of the organisation's knowledge of the housing, disability and criminal justice sectors. Ex-prisoner interviewees were recruited from reintegration services selected by the research team. The COVID-19 pandemic presented challenges to this component of the research-especially in Victoria, where we were unable to recruit ex-prisoner participants.

Table 1: Interviewees

\begin{tabular}{|c|c|c|c|c|c|}
\hline Interviewee category & NSW & Victoria & Tasmania & National & Total \\
\hline Ex-prisoners & 3 & & 3 & & 6 \\
\hline State corrective services & 3 & 1 & 7 & & 11 \\
\hline State housing authority & 1 & 1 & 1 & & 3 \\
\hline State disability agency & 1 & & & & 1 \\
\hline Reintegration service & 5 & 2 & 6 & & 13 \\
\hline Community housing provider & & 3 & 2 & & 5 \\
\hline Homelessness organisation & 1 & & 1 & & 1 \\
\hline Intellectual disability organisation & 1 & 1 & & & 2 \\
\hline Mental health organisation & 1 & & & & 1 \\
\hline Alcohol and other drug organisation & & & 1 & & 1 \\
\hline Disability sector professional & & & & 1 & 1 \\
\hline National Disability Insurance Agency & & & & 1 & 1 \\
\hline
\end{tabular}

Source: The authors.

Interviews were conducted according to the approvals given by the UNSW Human Research Ethics Committee (HC190603 and HC190620), using a topic guide in a semi-structured approach. The perspectives of interviewees are presented and discussed in Chapter 4. 
Comparative interrupted time series (CITS) analysis of linked administrative data

We analysed the post-release pathways of people exiting prison with complex support needs using the linked administrative data in the MHDCD Databank at UNSW. The Databank, established by research team member Eileen Baldry through an Australian Research Council Linkage Project (LP0669246), contains linked administrative data for about 2,713 people who were in prison in NSW at some point between 2001 and 2008. The data is sourced from BOCSAR, NSW Police, NSW Corrective Services, NSW Justice Health and other health areas, Juvenile Justice (now Youth Justice), Legal Aid, Disability, Housing and Community Services, and relates to each person's contact with agencies before, during and after their time in prison, giving a whole-of-life picture of institutional involvement.

From the MHDCD Databank we selected two groups--ex-prisoners who had received a public housing tenancy after release, and ex-prisoners who had been eligible for public but instead received assistance with private rental housing - and conducted a CITS analysis. The analysis shows the impact, in terms of criminal justice outcomes, of providing ex-prisoners with public housing compared with other forms of housing assistance. The CITS analysis is presented in Chapter 5.

Cost-benefit analysis

We conducted two cost-benefit analyses for the present research. The first considered the predicted cost savings to the criminal justice system from providing public housing, and other forms of housing assistance, to ex-prisoners. This analysis is presented along with the CITS analysis in Chapter 5.

The second cost-benefit analysis took a different approach, using case studies. From the MHDCD Databank, we extracted de-identified data about two individuals, for presentation as case studies and cost-benefit analysis, this time showing the estimated lifetime costs associated with these specific cases. The case studies and cost-benefit analysis are presented in Chapter 6.

\section{The limits of this research regarding Indigenous people and pathways}

Indigenous people in Australia disproportionately experience both imprisonment and homelessness. Research in these areas, therefore, may also disproportionately affect Indigenous people, through the investigative processes of the research and the interpretation of data.

The present research was not designed or conducted by Indigenous people, nor was it under the control of Indigenous organisations and communities. On advice from the NSW Aboriginal Health and Medical Research Council, and from the Aboriginal Reference Group convened for the project, we have conducted the research subject to the express limitation that it not investigate, or purport to speak to, post-release experiences specific to Indigenous people.

Indigenous people are included in the MHDCD cohort and the CITS analysis, but not in the case studies. Indigenous people were included in the invitations used to recruit participants for the interviews, and three interviewees (two agency representatives and one ex-prisoner) indicated that they are Indigenous. However, we did not recruit Indigenous interviewees specifically, nor ask about Indigenous-specific experiences. In our analysis, we go only as far as to observe where the data indicates that the Indigenous experience is different, so as to 'prepare the ground' for further specific Indigenous-controlled research into that different experience. 


\section{A statistical picture of prisoners and complex support needs}

- Over the past decade, the Australian prisoner population has grown, as have imprisonment rates.

- Males continue to make up the large majority of prisoners, but in most jurisdictions the growth rates for the imprisonment of women have been somewhat higher than for men. Indigenous people are hugely over-represented in prisons, and their imprisonment rate continues to increase.

- A wide range of factors relating to disadvantage and support needs are highly prevalent among people in prison, particularly regarding mental health conditions, alcohol and other drug (AOD) use, cognitive disability, and past homelessness. But prisons are not mere aggregators of disadvantage: imprisonment is inherently afflictive. All prisoners experience suffering and this compounds disadvantage and complicates other support needs.

- An estimated 65,000 discharges (including sentenced and unsentenced prisoners) occurred in 2019. Less than half of prison dischargees expect to be housed in their own home (owned or rented) on release. Growth in post-release housing need is registering with homelessness services, where ex-prisoners have been the fastest growing client category over the decade. 
This chapter presents a statistical picture of prisoners, ex-prisoners and complex support needs, utilising the major publicly available data sources.

\subsection{The prisoner population}

At the time of the 2020 prisoner census (conducted on 30 June) there were just over 41,000 people in prisons across Australia-equivalent to 202 prisoners per 100,000 of the adult population (ABS 2020a). Over the course of 2020, there was a notable decrease in the prisoner population, deriving from much reduced entries to prison at the height of the COVID-19 pandemic in the June and September quarters (ABS 2020b), due to lockdowns and law court closures. The longer-term trend, however, has shown significant growth in the national prisoner population and imprisonment rate. Over the decade up to and including 2020, the prisoner population increased by 40 per cent and the imprisonment rate by 16 per cent-even taking into account the unusual numbers of the last year. If we consider the decade to 2019 (i.e. discounting 2020 as an anomaly), we see that the prisoner population increased by 47 per cent and the imprisonment rate by 25 per cent (ABS 2020a).

Of the three jurisdictions considered in this research, NSW had 12,700 prisoners as of 30 June 2020 (up 14\% over 10 years), Victoria had 7,100 (up 62\%) and Tasmania had just under 670 (up 25\%) (ABS 2020a). Victoria's extraordinary growth in numbers over the decade is from a relatively low base, and its imprisonment rate (134 per 100,000 adults) is still below the national average. However, Victoria also had the largest reduction in rate of imprisonment during 2020, due to the effects of COVID-19. Prior to the COVID-19 emergency, the state had been on track to double its prisoner population over the decade. Tasmania's imprisonment rate (154 per 100,000) is a little higher than Victoria's; NSW's rate (197 per 100,000) is just under the national rate. Both NSW and Tasmania began the decade with declining prisoner numbers and imprisonment rates, but from 2013 to 2020 these have been growing. Figure 5 shows the prisoner populations and imprisonment rates for Australia, NSW, Victoria and Tasmania for the decade to 2020. 
Figure 5: Prisoner populations and imprisonment rates, Australia, NSW, Victoria and Tasmania, 2010-20

Aus

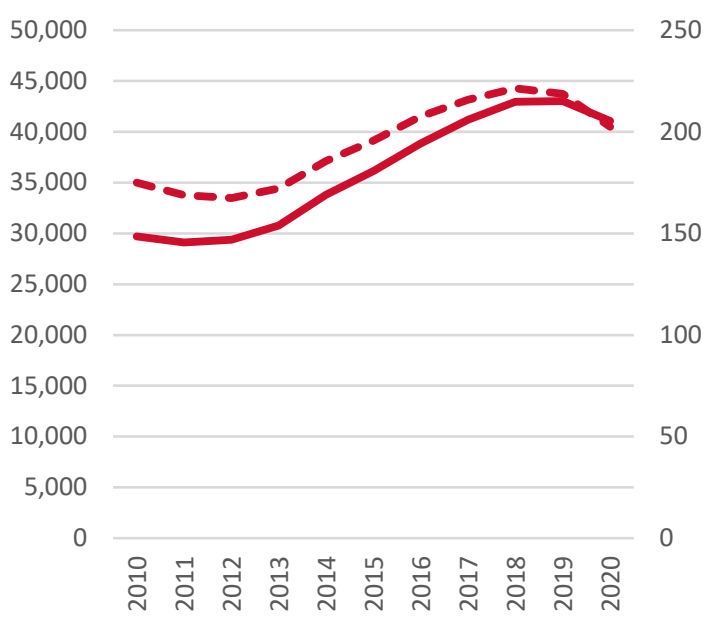

Vic

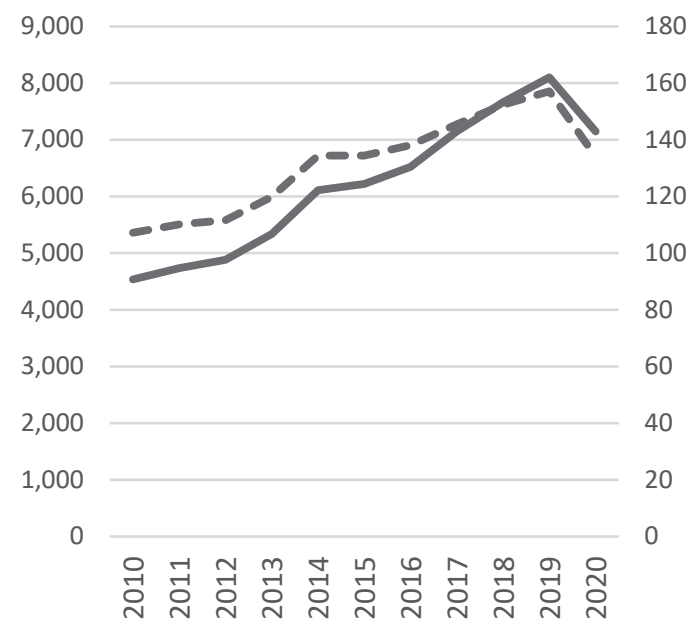

NSW

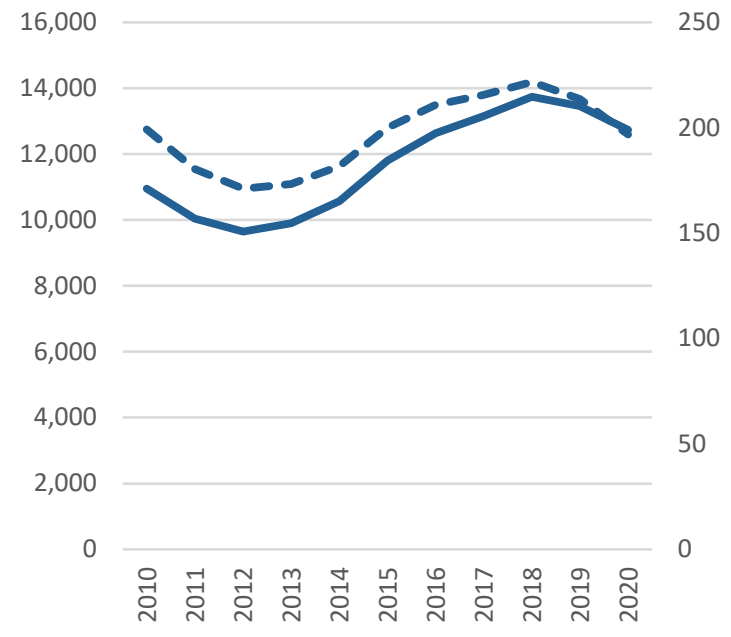

Tas

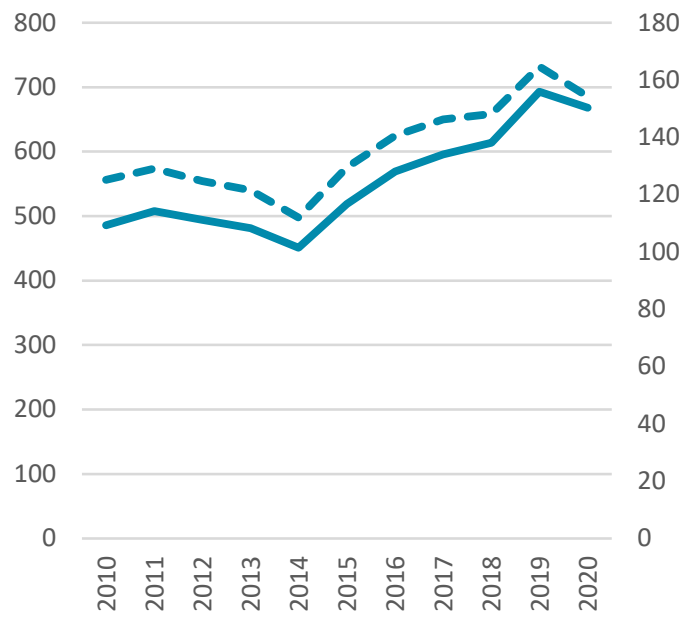

Key: Solid line, left-hand scale = prisoners (number); dash line, right-hand scale = imprisonment rate (per 100,000 adults). Source: The authors, drawing on ABS data (ABS 2020a).

At the time of the 2020 census, 68 per cent of Australian prisoners were under sentence and 32 per cent were unsentenced (i.e. on remand pending trial or sentencing). Unsentenced prisoners are a major driver of growth in the total prisoner population: their number has more than doubled over the past decade. All three jurisdictions considered here recorded strong growth in the number and proportion of unsentenced prisoners-especially Victoria, where the number tripled and the proportion almost doubled (see Figure 6). The median time spent on remand for Australian prisoners is 3.4 months, with Tasmania lower (1.9 months) and NSW and Victoria around the national median (3.6 and 3.0 months, respectively). Being on remand constitutes full-time imprisonment in maximum security, so can disadvantage prisoners, in regard to housing and social connections, in the same ways as for sentenced prisoners. 
Figure 6: Unsentenced prisoners, Australia, NSW, Victoria and Tasmania, 2010-20

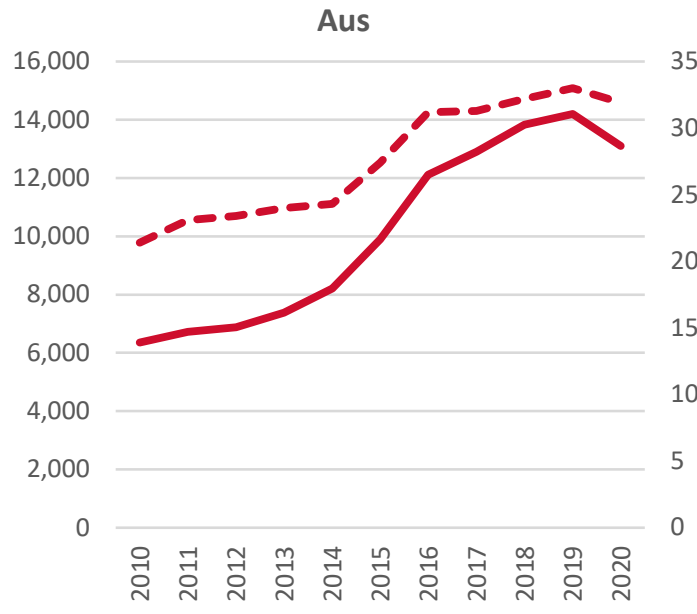

Vic

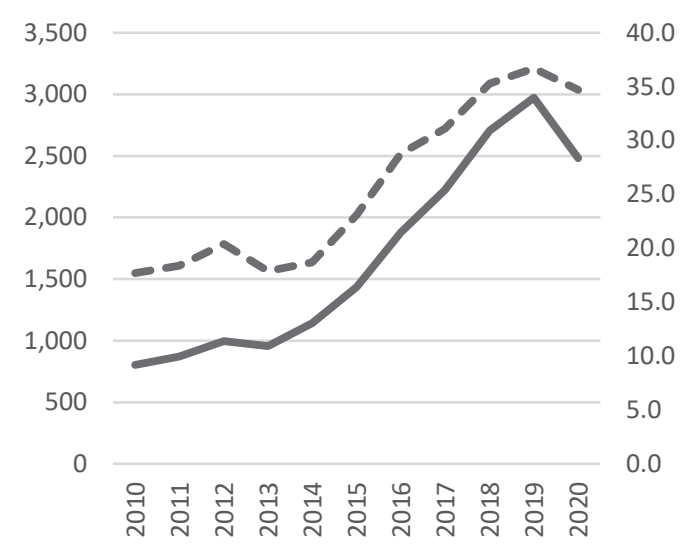

NSW

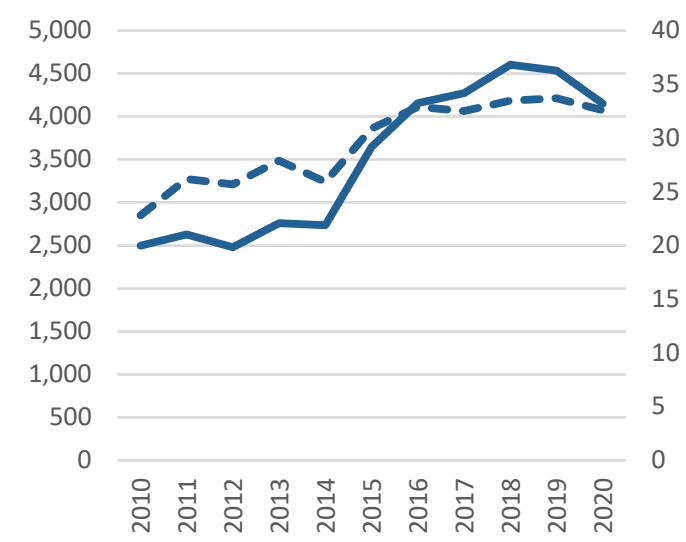

Tas

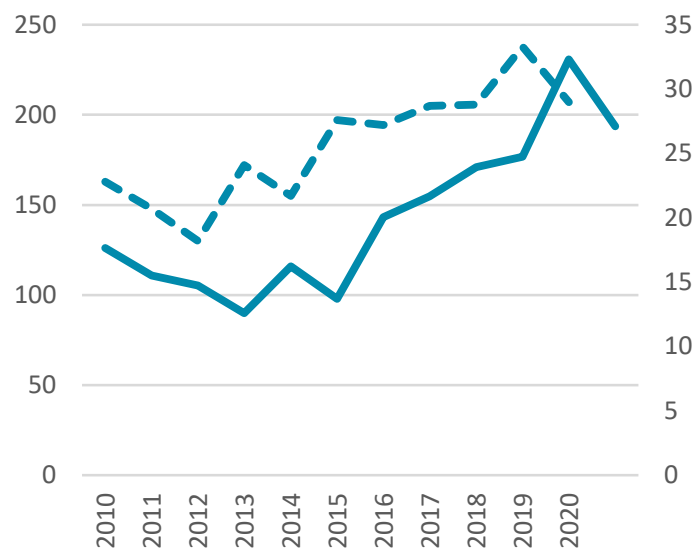

Key: Solid line, left-hand scale = unsentenced prisoners (number); Dash line, right-hand scale = unsentenced prisoners as a proportion of all prisoners.

Source: The authors, drawing on ABS data (ABS 2020a).

The very large majority of Australian prisoners are male (92\%) - because of this, the trends discussed here largely reflect trends regarding male prisoners. In 2020, female prisoner numbers and imprisonment rates were well above their levels of a decade previously (up $41 \%$ and $18 \%$, respectively-somewhat higher than growth rates for males) (see Figure 7). However, in most jurisdictions, for most of the decade, growth in female prisoner numbers and imprisonment rates were even higher (64\% and 34\%, respectively, for the decade to 2019), with the 2020 reduction in entries to prison especially pronounced for women (ABS 2020b). This pattern is most evident in Victoria, where female prisoner numbers had doubled over the decade to 2019, but dropped sharply in 2020. Tasmania's very small population of female prisoners fluctuates around the national growth trend. NSW is unusual for having slowed growth over the past couple of years, ending the decade to 2020 with a lower female imprisonment rate. 
Figure 7: Female prisoners, Australia, NSW, Victoria and Tasmania, 2010-20

Aus

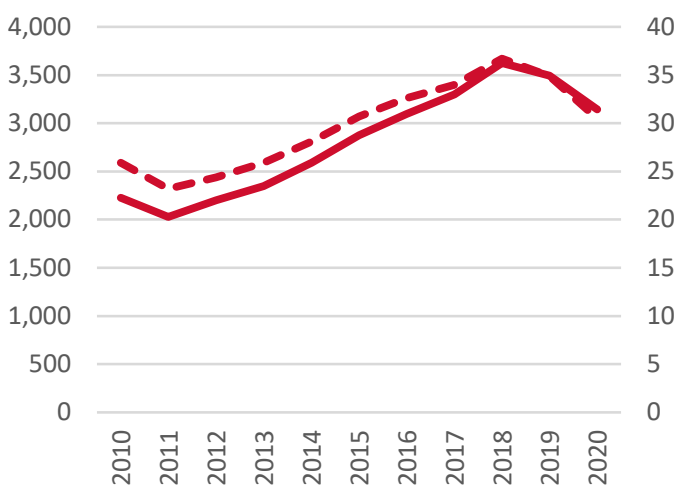

Vic

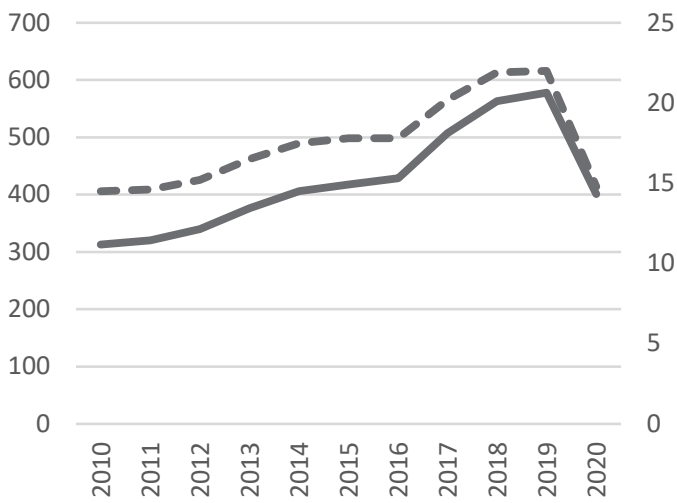

NSW

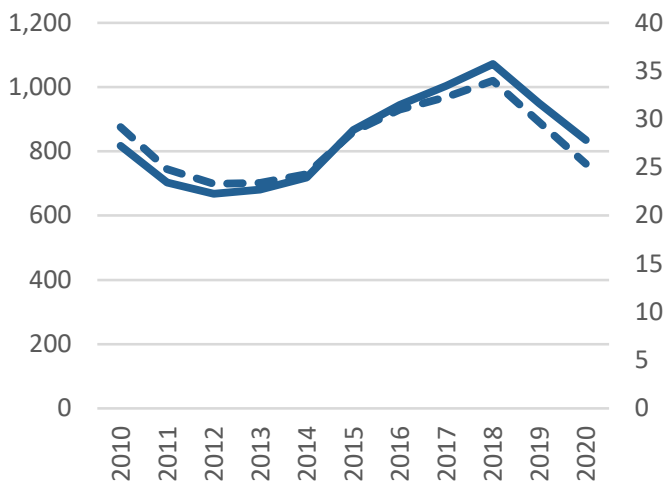

Tas

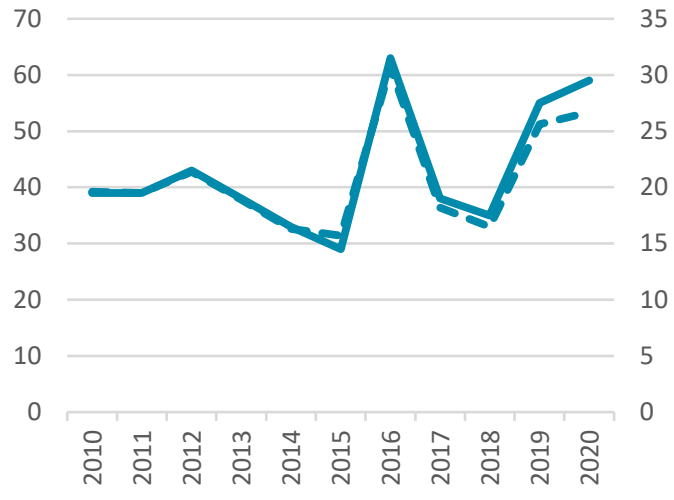

Key: Solid line, left-hand scale = female prisoners (number); dash line, right-hand scale = female imprisonment rate (per 100,000 adults). Source: The authors, drawing on ABS data (ABS 2020a).

Indigenous people are hugely over-represented in the Australian prisoner population (see Figure 8). Although constituting only about 2.4 per cent of the general adult population, Indigenous people represented 29 per cent of prisoners at the time of the 2020 census (up from 26\% in 2010) (ABS 2020a). The rate of imprisonment of Indigenous people has increased by 35 per cent since 2010 (to 2,081 per 100,000 adults in 2020), which is more than 13 times the imprisonment rate of non-Indigenous people. Furthermore, the growth in the Indigenous imprisonment rate is more than double the growth in the non-Indigenous imprisonment rate (up $14 \%$ ). ${ }^{1}$ Indigenous prisoner numbers were less affected by the 2020 reduction in prison entries (ABS 2020b).

In Victoria, the number of Indigenous prisoners has tripled (to 722), and the proportion almost doubled (to 10\%), over the decade. Tasmania's Indigenous prisoner population has also grown strongly, doubling in number and almost doubling as a proportion of all prisoners (to 22\%), while NSW has broadly tracked the national proportion and growth trends.

1 These imprisonment rates are calculated on an age-standardised basis: that is, they account for the differences in age profiles of the Indigenous and non-Indigenous populations. 
Figure 8: Indigenous prisoners, Australia, NSW, Victoria and Tasmania, 2010-20

Aus

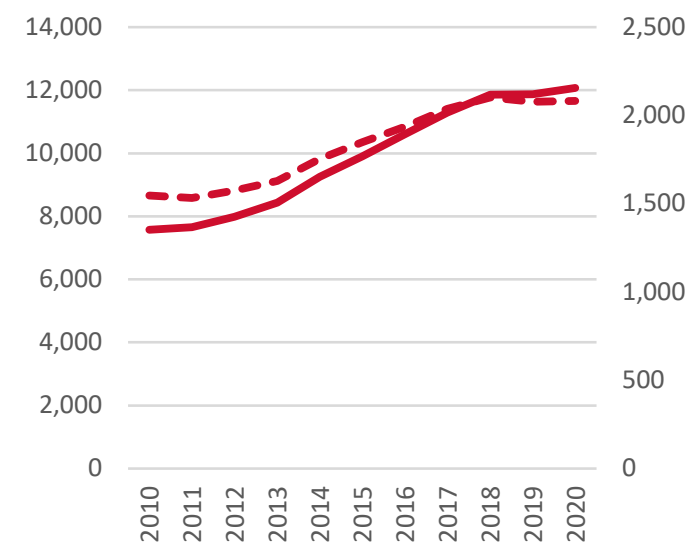

Vic

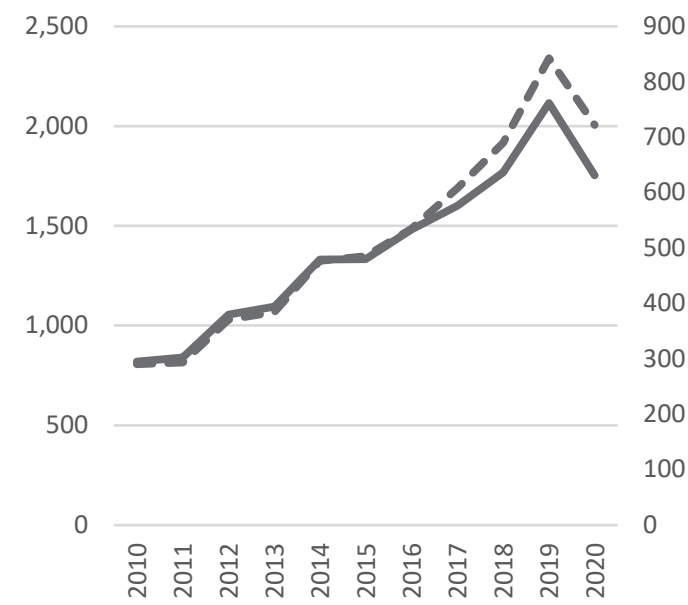

NSW

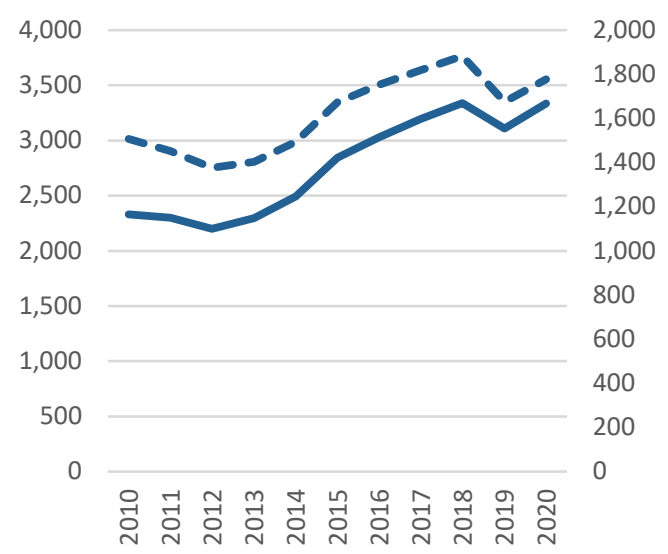

Tas

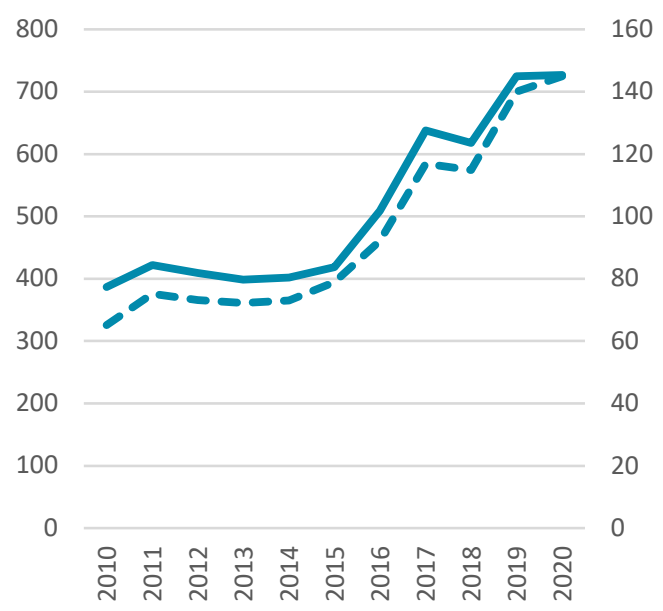

Key: Solid line, left-hand scale = Indigenous prisoners (number); dash line, right-hand scale = Indigenous imprisonment rate (per 100,000 adults, age standardised).

Source: The authors, drawing on ABS data (ABS 2020a).

Most Australian prisoners (60\%) have been in prison previously (ABS 2020a). This rate has drifted up over the decade (from 55\% in 2010). Our three jurisdictions vary around the national rate: NSW (54\%), Victoria (51\%) and Tasmania (67\%).

There is no published data that gives the total number of people released from prisons in Australia each year. NSW and Victoria, which together represented about half of all Australian prisoners at the time of the 2020 census, recorded just over 19,700 and 13,000 discharges, respectively, in 2019 (BOCSAR 2020; Corrections Victoria 2020). On this basis we estimate there were about 65,000 discharges from all Australian prisons in 2019. However, the number of individuals discharged may be less, because a person may be imprisoned and released multiple times in a year. 


\subsection{Prisoner mental health, disability and suffering}

The main source of data about the support needs of prisoners, particularly regarding mental health and disability, is the National Prisoner Health Data Collection (NPHDC), published in The health of Australia's prisoners series by the AIHW. Not all states and territories have participated in each iteration of the collection, and the latest, from 2018, does not include data from NSW (AIHW 2019a). The NSW state government has, however, published its own Network Patient Health Survey of data collected in 2015 (NSW Justice Health 2017). The two sources collect and present data somewhat differently, so we refer to them here as the 'national data' and the 'NSW data', respectively.

According to the 2018 national data, 40 per cent of prisoners had been diagnosed at some point with had a mental health condition (AlHW 2019a: 28). Of recent prison entrants, 24 per cent were taking some form of psychiatric medication at entry - with a higher rate for women (40\%) and a lower rate for Indigenous entrants (20\%) (2019a: 38-39). Eighteen per cent were referred on entry to mental health services delivered in prison -again, with a higher rate for women (30\%) and a lower rate for Indigenous prisoners (14\%) (2019: 42). Sixteen per cent of prisoners received psychiatric medication while in custody (28\% of women). The 2015 NSW data tells a similar story, albeit with an even higher prevalence of mental health diagnoses: 63 per cent of prisoners surveyed had a mental health diagnosis, and 47 per cent had been diagnosed with two or more mental illnesses (NSW Justice Health 2017). Almost half (49\%) of NSW prisoners had received some form of psychiatric care prior to prison, with a higher rate for women (55\%), and almost half of those not previously treated received a diagnosis in prison.

In the national data, 26 per cent of prison entrants had a 'high' or 'very high' level of psychological distress score, with a higher rate for women (52\%) (AlHW 2019a: 35). ${ }^{2}$ Among prisoners soon to be discharged, 14 per cent scored 'high' or 'very high'; again, with a higher rate for women (22\%). Indigenous prisoners scored lower, with 20 per cent of entrants and 8 per cent of dischargees recorded as highly distressed. For both entrants and dischargees, distress was commonly associated with 'family or relationships in the community': this was the most common reason for entrants (52\%), followed by their current imprisonment (43\%); and the second-most common reason for dischargees (40\%), after their upcoming release (41\%) (2019a: 37-38). The NSW data recorded experiences of trauma, rather than distress, and showed that almost two-thirds of prisoners (65\%) had experienced or witnessed at least one traumatic event (the most common example: someone being killed or seriously injured) (NSW Justice Health 2017: 58).

In the national data, 21 per cent of prison entrants had a history of self-harm, with a higher rate for women (31\%) (AIHW 2019a: 43). In the NSW data, 31 per cent of prisoners reported suicidal ideation, 18 per cent had attempted suicide, and 12 per cent had self-harmed (NSW Justice Health 2017: 61-62).

Nationally, one-third (34\%) of prison entrants were 'at high risk of alcohol-related harm' in the 12 months prior to entry (AIHW 2019a: 101). Two-thirds (65\%) reported using illicit drugs in the year before entry-most commonly methamphetamine (43\%), followed by cannabis (40\%). One in six dischargees (16\%) reported using illicit drugs while in prison (2019a: 98). In the NSW data, two-thirds (67\%) of prisoners reported consuming alcohol in the year before entry, with 67 per cent of that group consuming alcohol 'in a hazardous or harmful manner'. Thirteen per cent of prisoners had been diagnosed with an alcohol disorder. Eighty-six per cent of prisoners reported some level of other drug use during their lifetime. Of this group, 57 per cent reported being daily cannabis users in the year before entry; 42 per cent daily methamphetamine users; and 16 per cent daily amphetamine users (NSW Justice Health 2017: 63-65).

2 Scores based on the Kessler 10 scale. 
Nationally, 29 per cent of prison entrants had a disability or chronic health condition (AlHW 2019a: 57). In the NSW data, 46 per cent of prisoners reported having two or more chronic illnesses; 34 per cent had some level of difficulty with learning; 25 percent had difficulty with task management; and 22 per cent had difficulty with communication, personal relationships and community life, respectively (NSW Justice Health 2017: 48). Both in the national and NSW data, just under one-third of prisoners had experienced a head injury causing unconsciousness in their lifetime (AIHW 2019a: 106; NSW Justice Health 2017: 50).

These data show the range of factors relating to vulnerability and support needs that are aggregated in prisons. But there is another factor that these reports do not address: the experience of being imprisoned itself. Every individual who has been in prison has experienced punishment and suffering. This is so even in a prison that is entirely law-abiding - that is to say, abiding by the United Nations Standard Minimum Rules for the Treatment of Prisoners (the Nelson Mandela Rules). As the rules acknowledge:

Imprisonment and other measures that result in cutting off persons from the outside world are afflictive by the very fact of taking from these persons the right of self-determination by depriving them of their liberty. Therefore the prison system shall not, except as incidental to justifiable separation or the maintenance of discipline, aggravate the suffering inherent in such a situation. (UNOCD 2015: Rule 3).

The Nelson Mandela Rules are reflected in the Guiding Principles for Corrections in Australia (CSAC 2018), adopted by all states and territories, and in the specific standards applied to NSW and Tasmanian prisons, which expressly acknowledge the 'suffering inherent in imprisonment' (NSW Inspector of Custodial Services 2020a: 142.4; Office of the Custodial Inspector Tasmania 2018: 143.4). The NSW standards acknowledge:

the impact of imprisonment is likely to be stressful and potentially harmful to [prisoners'] mental and emotional health: isolation from family and social networks; loss of privacy; loss of personal control, identity and power to act; austere surroundings; and overt or covert aggression and bullying by other inmates. In addition, for many inmates there may be a lack of work or purposeful activity, heightened levels of uncertainty (particularly for remand inmates) and concerns about the outside world. (NSW Inspector of Custodial Services 2020a: 90).

Victoria's Correctional Management Standards (Corrections Victoria 2014) refer to the Guiding Principles and the Nelson Mandela Rules, but do not reiterate the acknowledgement of inherent suffering in prison.

According to the standards' calibration of non-aggravated suffering, prisoners may be kept in individual cells of 8.75 square metres or shared cells of 12.75 square metres (NSW: 20.4; Tas: 20.4); they may be kept in cells for up to 12 hours (Vic: 12.2.1) or 14 hours a day (NSW: 142.7; Tas: 143.7) and kept indoors for up to 22 hours per day (Tas: 100.1) or 23 hours per day (NSW: 100.1; Vic: 12.2.1). Prisoners are subject to random and targeted searches, including strip-searches (NSW: 40.9; Tas: 40.9; Vic: 8.2.2); and their visitors are searched too (NSW: 40.2; Tas: 40.9; Vic: 8.2.5).

Other forms of suffering and harm that the Nelson Mandela Rules and prison standards guard against, but which are persistent in prisons, include overcrowding and violence. Some measures of these conditions are reported in the annual Report on Government Services (RoGS) (see Figure 9); however, that data should not obscure the larger point, which is that everyone in prison suffers, and the experience is itself a factor in the complexity of ex-prisoners' support needs.

3 On the harms of strip-searches, especially for people who have suffered abuse and violence, see Gregoire (2020); NSW Inspector of Custodial Services (2020b); and Victorian Ombudsman (2017). 
Figure 9: Prison conditions: average hours out of cells, prison design capacity utilisation, and assaults on prisoners per 100 prisoners, NSW, Victoria and Tasmania, 2009-19

Hours out of cells per day (average)

15

10

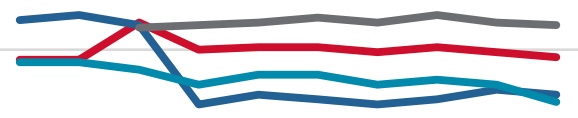

5

0

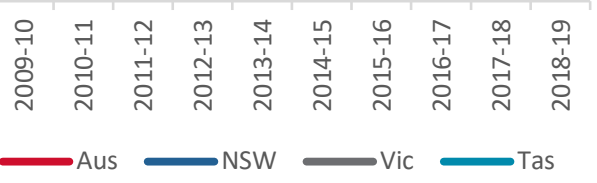

Assaults on prisoners, per 100 prisoners

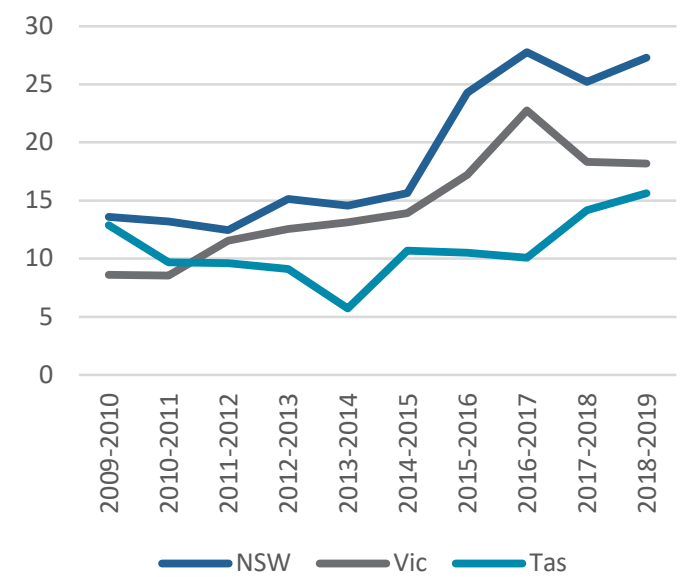

Prison design capacity utilisation

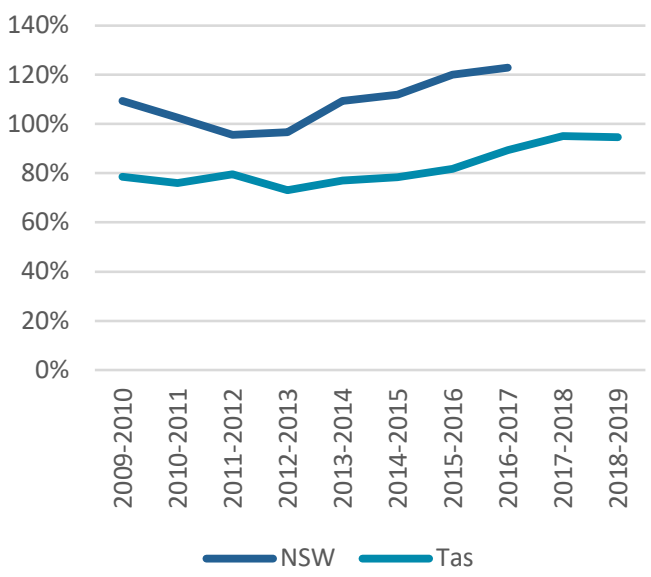

Note: Victorian data for hours out of cells before 2011-12, and prison design capacity utilisation (all years) was not available. NSW data for prison design capacity utilisation after 2016-17 was not available. Australian totals for prison design capacity utilisation and assaults on prisoners was not available. Prison design capacity utilisation refers to the intended number of prisoners a facility was designed for, compared with the number it actually holds.

Source: The authors, drawing on SCRGSP data (2020: Tables 8A.13, 8A.14 and 8A.17).

\subsection{Prisoners, ex-prisoners and housing}

The national and NSW data, discussed above, also includes some data about housing, before and after prison. Another relevant data source on housing is the SHSC data collated and reported by AIHW (2019b).

In the national data (AIHW 2019a), one-third (33\%) of prison entrants were previously homeless, with 28 per cent living in short-term or emergency accommodation and 5 per cent sleeping rough or in improvised shelter in the four weeks prior to entering prison. Female prison entrants had a slightly higher rate of sleeping rough prior to entry (7\%). Particularly high rates of prior homelessness were recorded for Indigenous prison entrants (43\%) and young adults (18-24 years) (39\%), while older prison entrants (55+ years) had a very high rate of sleeping rough (15\%). 
In the NSW data (NSW Justice Health 2017), 15 per cent of prisoners were homeless in the six months prior to imprisonment, with more than 6 per cent recorded as having 'no fixed accommodation' (10\% for women). The NSW data also gave some details about prisoners' prior housing tenure: 36 per cent were renting privately, 15 per cent were in public housing, and 3 per cent were in boarding houses. Almost one-quarter of female prisoners (23\%) previously lived in public housing. One-third (33\%) of prisoners moved at least once in the six months prior to imprisonment (2017: 29).

At the other end of their time in prison, the national data (AlHW 2019a) showed the expectations of dischargees about their post-release housing: less than half (46\%) expected to be housed in their own home (owned or rented) after release, while 44 per cent expected to be in short-term or emergency accommodation, while 2 per cent expected to be sleeping rough (and 8\% did not know how they would be housed). Short-term or emergency accommodation figured particularly strongly in the plans of Indigenous dischargees (52\%), and 18-24 year olds (50\%), while women (59\%) and dischargees aged 55 years and over (60\%) were more likely to expect to go to their own home.

The SHSC data (AIHW 2019b) shows that just over 9,100 adults in 2018-19 sought assistance from homelessness services across Australia because they were exiting custody_comprising about 4.6 per cent of all adults seeking $\mathrm{SHS}$ assistance in that period (see Figure 10). Although the ex-prisoner cohort makes up a relatively small proportion of SHS clients, it is the fastest growing, increasing 67 per cent over eight years (2011-12 to 2018-19). ${ }^{4}$ The number of SHS cases involving a person exiting custody was equivalent to 14 per cent of all estimated prison discharges for the 2018-19 year.

4 'Custody' in the SHSC data includes adult prison, juvenile detention and immigration detention. We have filtered the data by age to remove juvenile dischargees, but cannot remove the probably small number of immigration detention dischargees. 
Figure 10: People exiting custody seeking assistance from homelessness services, Australia, NSW, Victoria, Tasmania, 2011-19

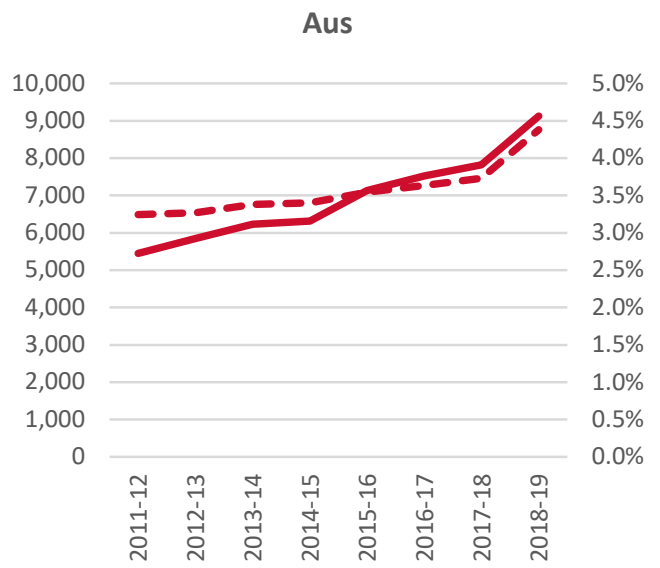

Vic

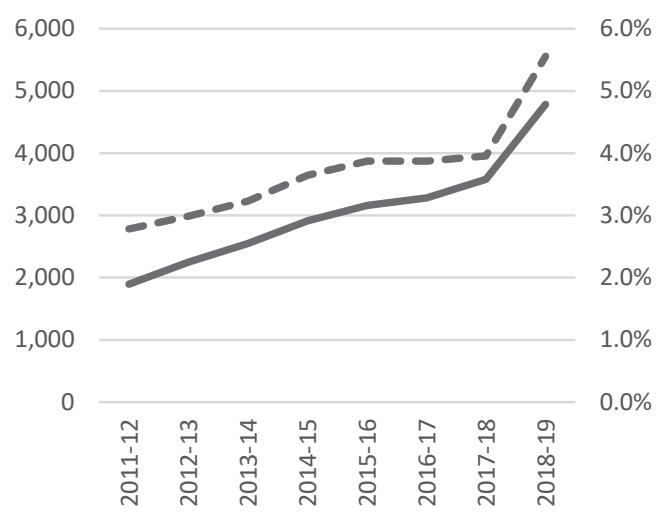

NSW

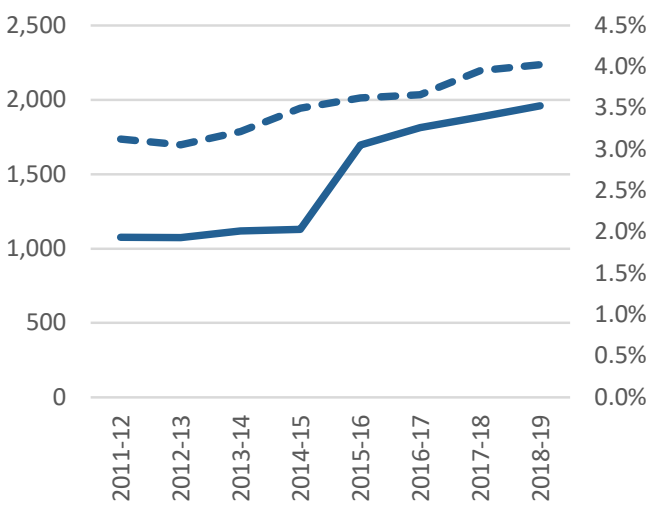

Tas

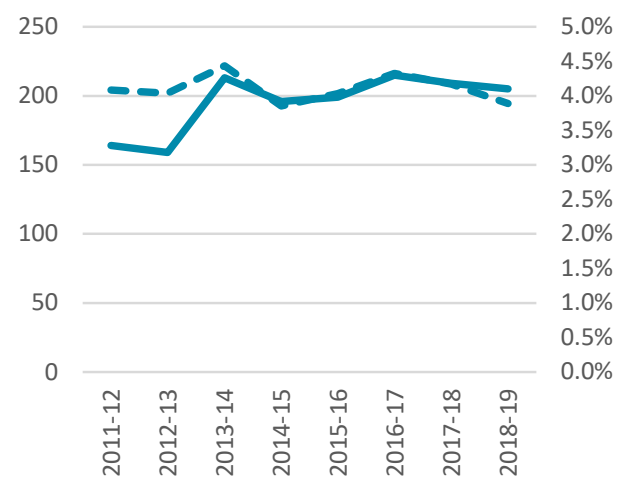

Key: Solid line, left-hand scale = adult SHS clients exiting custody (number); dash line, right-hand scale=adult SHS clients exiting custody as a proportion of all clients (\%).

Source: The authors, drawing on AlHW data (AlHW 2019a).

\subsection{Summary}

Over the past decade, Australian prisoner populations and imprisonment rates have grown — notwithstanding a dip in numbers during the COVID-19 pandemic. Just over 41,000 people were in prison at the time of the last prison census (2020). Men remain the large majority (92\%) of prisoners, but in most jurisdictions rates of growth in the imprisonment of women have been somewhat higher than for men. Indigenous people continue to be hugely over-represented in prisons, with an imprisonment rate more than 13 times the non-Indigenous imprisonment rate, and still rising.

The published statistics show that a wide range of factors relating to disadvantage and support needs are highly prevalent among people in prison, particularly regarding mental health conditions (40\%), cognitive disability (33\%), problematic alcohol or other drug use (up to 66\%), and past homelessness (33\%). But prisons are not mere aggregators of disadvantage: imprisonment is inherently afflictive, and all prisoners experience suffering.

Almost all of these people will at some point be released from prison, and we estimate about 65,000 releases occurred in 2019. As prison populations and imprisonment rates have grown, so too has the need for housing assistance post-release - and this is registering with homelessness services, where ex-prisoners have been the fastest growing client category over most of the past decade. The published statistics indicate that less than half of prisoners released will 'go home' to their own rented or owned housing, and about one in seven will end up seeking assistance from a homelessness service. 


\section{Policies and programs relevant to post-release housing pathways}

- Over the past decade, imprisonment rates have grown and ex-prisoners' housing assistance needs have grown, but housing assistance capacity has declined. Homelessness services and social housing are strained after a decade of declining policy priority and, in the case of social housing, declining real per capita expenditure.

- In homelessness policy, ex-prisoners remain a priority group. This is reflected in the increase in ex-prisoners' accessing SHS and a wider commitment to inter-agency work and Housing First principles; but the necessary housing is lacking. The diminishing social housing sector has tightened its targeting, and sought to increase the ways it can assist clients to access private rental housing.

- The NDIS has transformed disability service provision, but there are acknowledged deficiencies regarding ex-prisoner access to the scheme, and contestation of the division of responsibilities by other agencies.

- States fund a range of transitional programs specifically for ex-prisoners, some of which provide accommodation. Relative to need, their capacity is tiny, and in some jurisdictions there has been considerable instability in programs and funding. 
People exiting prison may, at least notionally, access housing assistance from mainstream agencies, such as the state and territory housing authorities and SHS. They may also access assistance through ex-prisoner-specific programs delivered by corrections agencies and mainstream agencies, and by specialist non-government organisations (NGOs) committed to assisting people in the criminal justice system. Some of those specialist organisations are longstanding - for example, the Victorian Association for the Care and Resettlement of Offenders (VACRO) was established in 1872- but the programs funding them frequently change and the level of funding is very low, relative to need. The past 10-15 years have been especially uncertain, even turbulent, in terms of program change.

At the same time, wider shifts in homelessness, social housing and disability policy have significantly changed the post-release landscape for people exiting prison and the agencies working with them. In this chapter, we review recent developments in policies and programs for housing and other assistance, both mainstream and specialist, with particular focus on NSW, Victoria and Tasmania.

\subsection{Homelessness services}

Just over a decade ago, homelessness policy was significantly reprioritised by the Australian Government: first through its 2008 white paper, The Road Home, and then through the 2009 National Partnership Agreement on Homelessness (NPAH). The white paper's headline objective was to halve homelessness by 2020; another was that there should be "'no exits into homelessness" from statutory, custodial care and hospital, mental health and drug and alcohol services' (FaHCSIA 2008: 27). The NPAH, a three-year matched funding agreement between the Australian and state and territory governments, set interim targets for these objectives, including a 20 per cent reduction in total homelessness, and a 25 per cent reduction in exits from institutions into homelessness services, by 2013.

More than 180 new initiatives by state and territory agencies and SHS were funded across Australia, with a focus on Housing First and Street to Home (assertive outreach) models and inter-agency coordination of support to maintain tenancies. A significant share of these initiatives were directed to the 'exiting institutions' priority cohort (16\% in NSW, 12\% in Victoria, 22\% in Tasmania) (ANAO 2013). Since the SHSC began gathering data in 2011, SHS assistance to ex-prisoners has increased-rather than decreased, as intended in the NPAH_in part because of the new inter-agency model, but also because the permanent housing required to make good the promises of 'Housing First' and 'no exits' was never sufficiently supplied (Bullen and Baldry 2019).

Following a change of government in 2013, doubt was cast on further Commonwealth funding for homelessness services by the Abbott government's proposed federation reforms. The uncertainty of short-term funding extensions undermined job security, organisational capacity and program delivery in the SHS sector (Pawson, Parsell et al. 2018: 51), even as real per capital expenditure across both levels of government rose (SCRGSP 2020: Table 19A.1). Herault and Johnson assessed the reform opportunity of 2009 as 'by and large, wasted' (2016: 138).

Commencing in 2018, the National Housing and Homelessness Agreement (NHHA) has restored some certainty to the funding of homelessness services, but it lacks the reforming imperative of the 2008 white paper and the $\mathrm{NPAH}$. The NHHA nominates 'people exiting institutions into homelessness' as a 'national priority homelessness cohort', and requires states and territories to address this and other cohorts in their homelessness strategies. However, the agreement does not commit to 'no exits', nor to targets for an overall reduction in homelessness. At the state level, policy-making and action on homelessness have recently been stepped up by several governments, with a focus on reducing rough sleeping_-perhaps, as suggested by Pawson, Parsell et al. (2020: 36), because this is the most visible and politically embarrassing aspect of a policy problem that had languished for years. 


\subsection{Social and affordable housing}

Concurrent with its 2008 reprioritisation of homelessness policy, the Australian Government undertook major initiatives in social and affordable housing policy. First, the National Rental Affordability Scheme (NRAS), commencing in 2008, sought to foster a new sector of discount-to-market rental properties, offering 50,000 subsidy packages for new housing built by private investors and community housing providers (CHPs) (Pawson, Milligan et al. 2020: 281). Next, in response to the global financial crisis, the government's 2008 Nation Building Economic Stimulus Plan included the Social Housing Initiative (SHI), which built almost 20,000 new social housing properties between 2009 and 2012-a rate of construction approximately double the annual rate for the previous 15 years (Pawson, Milligan et al. 2020: 95). Most SHI properties were transferred to the community housing sector and, in some cases, made available to NPAH initiatives (Phillips and Parsell 2012: 26).

These social and affordable housing initiatives were, however, short-lived. The SHI ended in 2012 and new social housing construction dropped even lower than its previous level. After the 2013 change in government, the NRAS was closed early to new projects (in 2014), with only three-quarters of the originally envisaged number of affordable rental properties built. The proposed federation reforms cast a similar pall over social housing as over homelessness services.

Since 2018, the NHHA has kept the Australian Government involved in the financing of social housing, but not sufficiently to grow the sector. The level of funding committed to social housing is indexed to sector wage rates, not to population growth; nor is it linked to the deficit of social housing relative to need that has deepened over decades (Lawson, Pawson et al. 2018). Without the assurance of Commonwealth funds to subsidise the operation of additional social housing stock, most states and territories have not made substantial commitments to growth. The exception is Victoria, where the state government has very recently announced a substantial program of new social housing construction (Victorian Government 2020)—albeit off the lowest social housing expenditure per capita in Australia. 
Figure 11: Public housing, community housing and Indigenous housing dwellings, Australia, NSW, Victoria, Tasmania, 2010-19

Aus

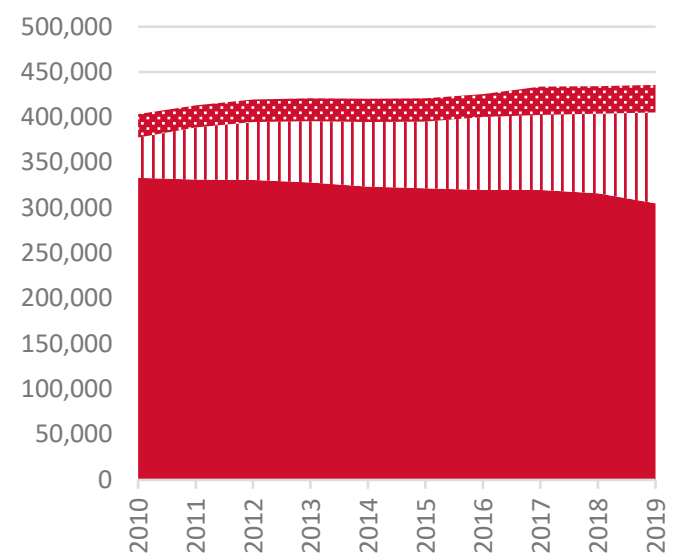

Vic

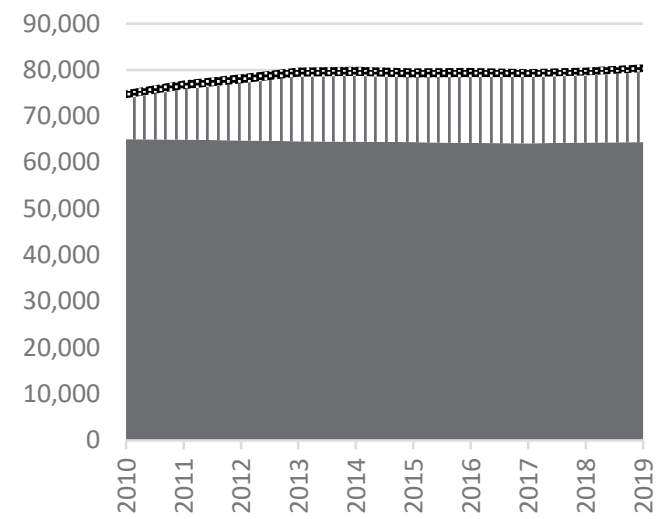

NSW

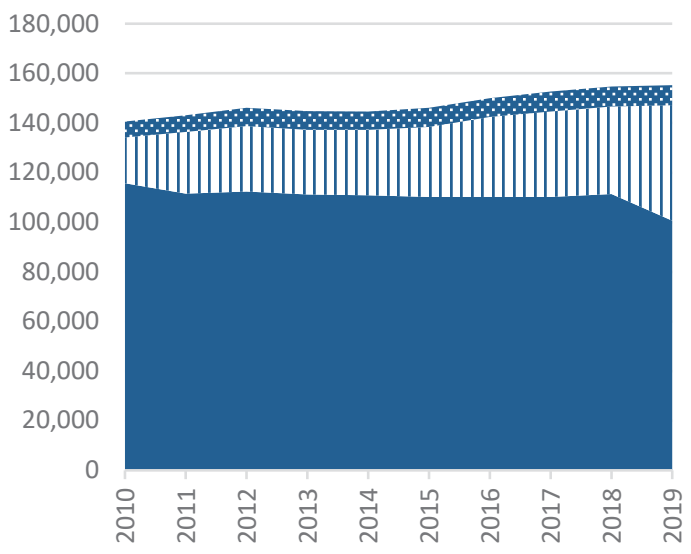

Tas

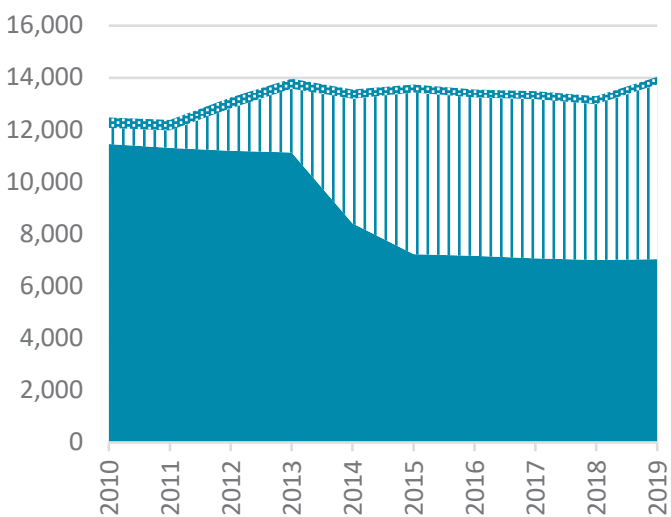

Key: Solid colour = public housing; white with stripes = community housing; colour with dots = Indigenous housing (state owned and managed + community).

Note: Indigenous community housing values for 2019 were not available: values for 2018 have been used instead.

Source: The authors, drawing on SCRGSP data (2020). 
Figure 12: Real per capita social housing expenditure, Australia, NSW, Victoria, Tasmania, 2019

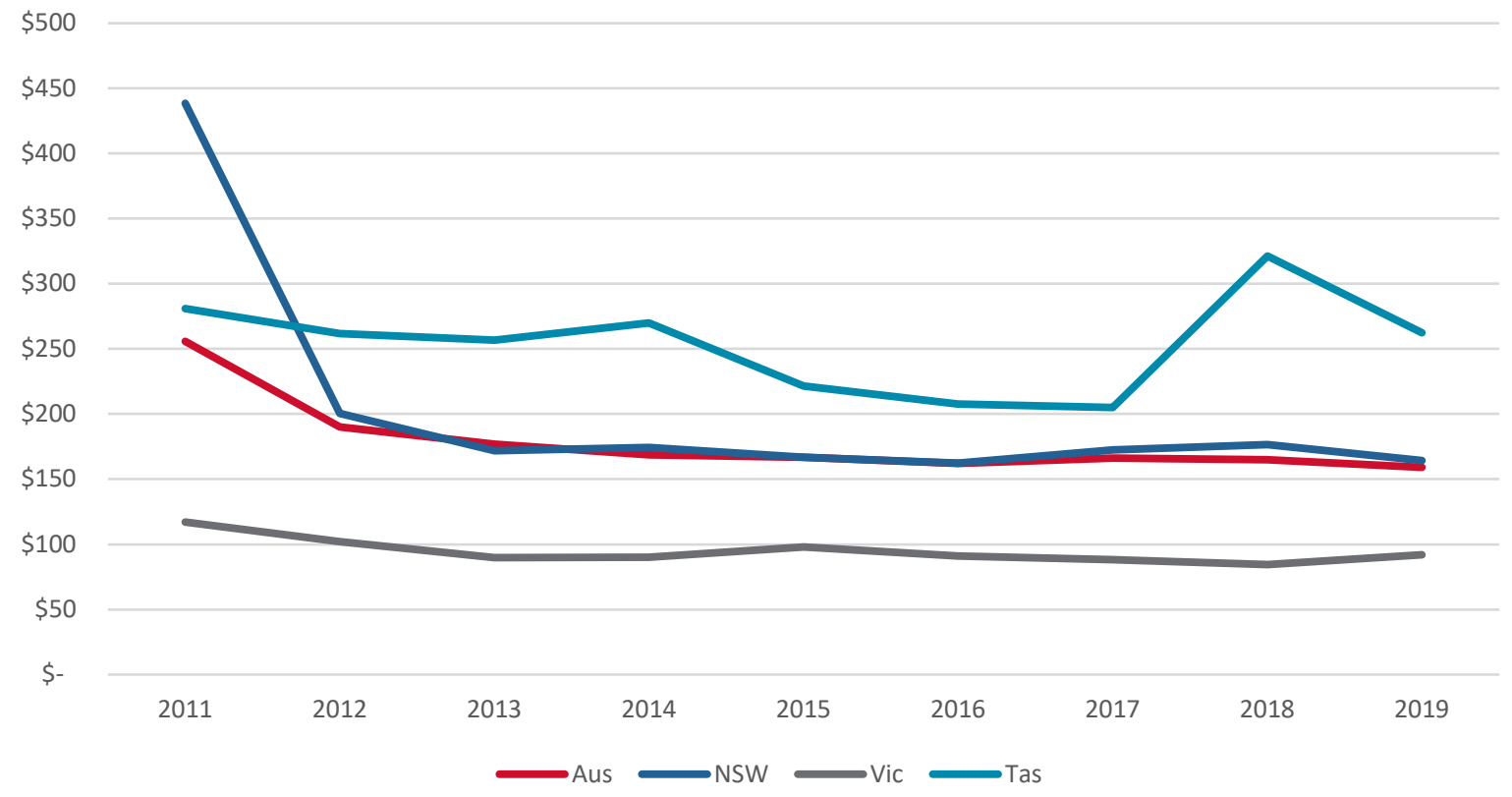

Source: The authors, drawing on SCRGSP data (2020: Table 18A.1).

The continued decline of social housing has been accompanied by significant changes in how the sector operates. Community housing's share of the sector has grown relative to public housing (see Figure 11), through stock transfers and some new development. Policy-makers have attempted to harness the perceived benefits of community housing, including providers' claimed superiority in delivering client services, and the additional rent revenues from community housing tenants' eligibility for Commonwealth Rent Assistance (Pawson, Martin et al. 2016). In Tasmania, in particular, community housing has grown to comprise almost half the social housing sector. Indigenous social housing growth, on the other hand, has been much more modest, and the sector has struggled to build, or even maintain, capacity (Milligan, Pawson et al. 2017; Milligan, Martin et al. 2016).

The sector is also increasingly targeted to applicants in 'greatest need', particularly those who are homeless or in unsafe housing. The social housing policies of all states and territories make provision for allocations on a priority basis, outside the usual 'wait-turn' basis. However, even people approved for priority housing may wait a long time (see Table 2). In Victoria, the average wait is almost one year, and in Tasmania it is longer. NSW has a relatively short average wait time for priority housing, just over three months, because it is more stringent: DCJ Housing gives priority status to relatively few applicants.

Table 2: 'Greatest need' applications and allocations, and priority housing wait times, NSW, Victoria and Tasmania

\begin{tabular}{lrrr}
\hline & NSW & Victoria & Tasmania \\
\hline ‘Greatest need' applications (\% of total applications) & $11 \%$ & $53 \%$ & $72 \%$ \\
\hline ‘Greatest need' allocations (\% of total allocations) & $56 \%$ & $90 \%$ & $99 \%$ \\
\hline Priority housing wait times (average) & 3.2 months & 11.6 months & 14.3 months \\
\hline
\end{tabular}

Note: Figures refer to public housing, not community housing or Indigenous housing, because in the RoGS data some recent transfers of existing tenancies from public housing to community housing are recorded as new community housing allocations, which reduces the 'greatest need' proportion of community housing allocations. NSW does not include households with very high rents in the definition of 'greatest needs'. NSW and Victorian average wait times are for 2018-19; Tasmanian average wait time is for $2019-20$.

Source: The authors, drawing on data from: DCJ (2019, 2020); DHHS Tas. (2020); DHHS Vic. (2019); SCRGSP (2020: Tables 18A.5 and 18A.15). 
Aside from prioritisation, social housing providers have responded to the sector's decline by providing more (and thinner) forms of assistance that facilitate client access to private rental housing and temporary accommodation (e.g. in motels and caravan parks). For example, in NSW, DCJ Housing offers a suite of 'private rental assistance products' to eligible people, including: bond loans, grants of advance rent, private rental subsidies for hard-toplace priority applicants, time-limited tapering Rent Choice subsidies, tenancy guarantees (non-cash sureties additional to rental bonds), and non-financial tenancy facilitation and brokerage services. It also offers a Temporary Accommodation (TA) program that provides homeless people with a few nights' accommodation in a motel or caravan park, up to 28 nights per year. In NSW, instances of these forms of assistance now far outnumber social housing allocations (see Table 3). In Victoria and Tasmania, non-government housing and homelessness agencies use brokerage funds from their respective state governments to provide similarly thin, but more readily applied, assistance.

Table 3: Private rental assistance, Temporary Accommodation and social housing allocations, NSW, 2018-19

\begin{tabular}{lrrrr}
\hline & 2018 Q3 & 2018 Q4 & 2019 Q1 & 2019 Q2 \\
\hline Private rental assistance (total instances) & 10,723 & 10,717 & 11,608 & 12,671 \\
\hline Temporary Accommodation (TA) (total instances) & 6,865 & 7,553 & 8,460 & 7,477 \\
\hline Social housing allocations (total new allocations) & 2,712 & 2,243 & 2,131 \\
\hline
\end{tabular}

Source: DCJ (2019).

No state or territory has eligibility criteria for priority or 'wait-turn' housing, or other forms of assistance, specifically relating to people exiting prison, so ex-prisoners must demonstrate eligibility according to the usual income, assets and priority need criteria. Some special provisions apply, however, where the person leaving prison formerly lived in social housing. Firstly, where a social housing tenant is serving a short sentence, they may be able to keep their tenancy on foot while in prison. In NSW and Victoria, public housing operational policies generally allow tenancies to remain on foot, at a nominal rent, if the tenant is in prison for not more than six months (and HousingVic may allow longer by special consideration). In Tasmania, the policy is to allow tenancies to remain on foot for eight weeks, but longer may be allowed by special consideration. Secondly, where a person relinquishes a social housing tenancy while in prison, operational policies may provide for them to be readmitted to the housing register on a priority basis. In DCJ Housing policies, this is known as 'tenancy reinstatement'. The Department of Health and Human Services Victoria (DHHS Vic.) also gives priority to individuals who relinquished their social housing tenancy during an absence. Finally, there are formal referral and application pathways between prisons and housing agencies that facilitate applications for assistance as a prisoner nears release. The operation of these pathways is discussed in more detail in Chapter 6.

\subsection{Disability services}

Like homelessness and social housing policy, disability services policy also received new attention from governments about a decade ago, although in this area there has been less reversion and more enduring change to the institutions and even the philosophy of disability service provision.

In the National Disability Strategy 2010-2020, governments committed to a human rights based disability policy reform agenda. Observing the historic shift in the 1980s and 1990s, from segregated institutional management to community-based service provision, the strategy indicated a further shift to a 'person-centred' approach, with 'individualised, self-directed funding and supports' (National Disability Strategy 2010: 13).This approach underpins the NDIS, established 2013, in which eligible people with disability enrol as participants, make a funded plan with a support coordinator to address their needs, and then purchase those supports from service providers. 
The NDIS has transformed the role of the states and territories in regard to disability service provision. Where previously state and territory governments provided block grants to service providers, including their own agencies and NGOs, they now contribute to the pool of funds administered by the NDIA to support individual participants. As a result, many state and territory disability agencies and programs have been wound up, and assets (for example, group homes) leased or transferred to the NGO sector. To guard against a wider range of state and territory agencies cutting their provision of services to people with disability (i.e. cost-shifting to the NDIS), the intergovernmental agreement for the scheme sets out, in its Applied Principles and Tables of Support (APTOS), a detailed division of responsibilities between the NDIS and other service systems, including social housing, homelessness, mental health and criminal justice.

NDIS plans do not include funding for housing costs, except for the small minority of participants with extreme functional impairment or very high support needs, for whom funds for Specialist Disability Accommodation (SDA) may be provided. Some properties for SDA recipients are purpose-built on the basis of this funding stream, while others are older, 'legacy' properties that have been designated as SDA. Many more NDIS participants are instead eligible for Supported Independent Living, which funds personal support services-recipients may be living in rental housing supplied by the support provider (often boarding houses or similar), or in private or social housing.

According to the APTOS, social housing providers and homelessness services continue to be responsible for providing accessible long-term housing and homelessness-specific services to people with disability (COAG 2015: Table 8). Regarding the criminal justice system, management of offenders under supervision remains a criminal justice agency responsibility, as do 'offence specific interventions which aim to reduce specific criminal behaviours', while the NDIS is responsible for providing 'supports to address behaviours of concern (offence related causes) and reduce the risk of offending and reoffending such as social, communication and self-regulation skills' (COAG 2015: Table 10). Plainly, these guidelines leave open the potential for differing interpretations as to where the line lies.

In 2017, following participant representations and consultations, the NDIA acknowledged that the NDIS was not sufficiently accessible to people with complex supports needs, homeless people, and people with repeat contacts with the criminal justice system (NDIS 2018). To address this, the NDIA established a new 'complex support needs pathway' for access to the NDIS, involving specialist planners and support coordinators, and created a new Justice Liaison Officer (JLO) role to 'provide a single point of contact for workers within state and territory justice systems to coordinate support for NDIS participants' (Disability Reform Council 2019).

\subsection{Post-release services}

Services specifically supporting people in their transition from prison and reintegration into the community have not been the subject of a national policy or reform agenda of their own, although they have been shaped by developments in other policy areas. Here, we briefly review recent developments and current programs in NSW, Victoria and Tasmania.

\subsubsection{New South Wales}

NSW Corrective Services_-now a division of the NSW Department of Communities and Justice (DCJ)—operates the Funded Partnerships Initiative (FPI), which funds support and, in some cases, accommodation for people exiting prison on parole or extended supervision orders, and who are assessed as being at a medium to high risk of reoffending. The FPI consists of a number of service streams, with all programs accessed by referral from community corrections officers.

One stream is Transitional Support Accommodation, which provides 12 weeks' accommodation and casework support (delivered by NGOs at seven locations throughout NSW), with capacity to support about 50 people in total. Another stream is the Extended Reintegration Service, delivered by the Community Restorative Centre (CRC), which provides up to nine months' accommodation and intensive casework for ex-prisoners with mental health conditions and/or intellectual disability. The program takes about 20 clients per year. 
A third FPI stream is Initial Transitional Support (ITS), which grants ex-prisoners up to 12 weeks' casework support (provided by NGOs in 26 locations across the state). ITS does not include accommodation, and assistance with finding accommodation is the most common casework task. In a review of 200 accommodation-related cases, just 35 ITS clients ended up in stable housing (public or private), while 19 were housed with family and friends, and 13 were in 'ongoing transitional' arrangements (Morony 2018).

NSW Corrective Services also directly operates two post-release accommodation facilities at Long Bay and Campbelltown, known as Community Offender Support Programs (COSPs). From 2008-14, another 10 COSPs were in operation throughout the state, but these were closed for being too costly, and the funding focus was shifted to the FPI (Needham 2013; Corrective Services 2013). The remaining two facilities have 45 and 26 beds, respectively, and offer accommodation and casework support for up to three months. They have been particularly significant in accommodating sex offenders (NSW Inspector of Custodial Services 2020b, 2020c; Corrective Services NSW 2013).

Outside the Corrective Services division, DCJ funds three transitional and post-release services delivered by the CRC: the Transitional and Post-release Service-Penrith and Blue Mountains, which provides up to 12 months' casework support and, in some cases, accommodation from the local CHP; the Women's Transitional and Postrelease Service, which provides up to 12 months' casework support; and the Transitional Boarding House Support service, which provides case work support, and assistance placing people (in practice, men) in boarding houses in Sydney's inner west. The CRC previously provided other transitional services with accommodation, but these were defunded in 2014; now, two larger SHS contract with the CRC for the provision of specialist casework for ex-prisoners.

Until recently, NSW Ageing, Disability and Home Care (ADHC) operated the Community Justice Program (CJP), which provided a range of services, including accommodation, to people with intellectual disability who had spent time in custody. These services ranged from accommodation in specially constructed group homes with 24-hour 'intensive residential support', to accommodation in 'supported living' units with support at hand, to drop-in support delivered at a client's non-CJP residence (e.g. social housing). In 2015 (its tenth year of operation), the CJP had 300 clients, seven 'intensive residential support' group homes and 12 'supported living' complexes, managed by disability NGOs and ADHC (NSW Treasury 2015). However, with the roll-out of the NDIS, CJP clients were enrolled in NDIS plans, the residential assets leased to NGOs, and all staff transferred to NGOs (except for a small complement of clinicians remaining in DCJ).

\subsubsection{Victoria}

Victoria's framework for the provision of reintegration services is the Corrections Victoria Reintegration Pathway, which provides programs from entry to prison through to post-release. Pre-release programs include ReGroup, in which prisoners make post-release plans and receive information and application forms for housing assistance. For people assessed as having high-level transitional needs, the ReConnect program provides intensive postrelease casework support for up 12 months, delivered by one of three NGOs: VACRO, the Australian Community Services Organisation (ACSO) and Jesuit Social Services. For priority cases, ReConnect can also grant access to the Corrections Victoria Housing Program (CVHP), which provides transitional accommodation managed by community housing providers.

The CVHP has been evaluated positively, with a 2013 report finding reduced recidivism for medium- and high-risk ex-prisoners in the program, and what the authors referred to as a 'positive cost-benefit' (Ross, Diallo et al. 2013). Placements, however, are very limited: in 2015, there were 47 CVHP properties (40 owned by Corrections Victoria, plus seven community housing properties to which Corrections Victoria had nomination rights), with an estimated capacity to accommodate just 1.7 per cent of people exiting prison that year (Victorian Ombudsman 2015: 107).

The Corrections Victoria Brokerage Program provides financial assistance to help individuals secure longer-term housing. Corrections Victoria also funds a range of other post-release mentoring and support programs for particular community groups. 
In addition to the Corrections Victoria Reintegration Pathway programs, the DHHS operates the Forensic Disability Program. Like NSW's erstwhile CJP, the Forensic Disability Program provides support and, in select cases, accommodation to people with cognitive impairment and a high risk of involvement in the criminal justice system; but unlike the CJP, the Victorian scheme is continuing in the NDIS era. A total of eleven Specialist Forensic Disability Accommodation services are managed by the DHHS and non-government service providers. Furthermore, the Victorian Aboriginal Legal Service has recently partnered with Aboriginal Housing Victoria to develop two post-release residential facilities, as well as provide post-release casework services (Aboriginal Housing Victoria 2019).

Finally, in response to the additional challenges presented by the COVID-19 pandemic, a pilot project-involving Corrections Victoria, private security company G4S, and Jesuit Social Services - is repurposing the former Maribyrnong detention centre into a residential facility. Commenced in June 2020, the project targets men who have experienced homelessness and are leaving custody with no fixed address. A dedicated housing officer will support participants to secure longer-term housing, and provide help with budgeting and other daily living skills.

\subsubsection{Tasmania}

Tasmania has recently established a specialist throughcare service, Beyond the Wire, to provide pre- and post-release support to people exiting prison and at risk of homelessness. Delivered by a network of NGOs led by the Salvation Army, the service has access to the Prisoner Rapid Rehousing program, a dedicated pool of 12 properties owned by community housing providers or head leased by CHPs from the private sector. Most of these organisations are also partners in Housing Connect, Tasmania's one-stop application point for social housing and homelessness services.

Beyond the Wire is the latest in a series of post-release support programs in Tasmania: the seventh, in fact, in 20 years of short-lived pilots, defunding and 'program churn' (Herrlander Birgerson 2018). Unlike Victoria or, previously, NSW, Tasmania does not have a disability-specific criminal justice support and accommodation program, and state-provided supported accommodation for people with disability was wholly transferred to the NDIS.

\subsection{Summary}

It is difficult to properly assess the overall capacity of post-release-specific accommodation programs, because the data about them is presented variously as stocks of properties or beds, and flows of clients. However, it is evident that compared to the volume of people discharged from prisons, the shared capacity of these programs is tiny.

The capacity of mainstream housing assistance sectors - homelessness services and social housing-is also strained. A decade of growth in prisoner populations and rates of imprisonment has coincided with declining policy priority for both the homelessness and social housing sectors and, in the case of social housing, declining real per capita expenditure. In homelessness policy, ex-prisoners remain a priority group-a hangover from the short-lived period of reform in the late 2000s. This is reflected in the increase in ex-prisoners' accessing SHS, and a wider commitment to inter-agency work and Housing First principles; but the necessary housing is lacking. The diminishing social housing sector has tightened its targeting, and sought to increase the ways it can assist clients to access private rental housing.

Disability service provision has been transformed in more profound ways, by the introduction of the NDIS. In the shift to person-centred funding for disability support provision, the states and territories have withdrawn from service provision-including, in some cases, accommodation and support services targeted at people in contact with the criminal justice system (e.g. the NSW CJP). However, there are signs, acknowledged by the NDIA, that such people are not reaching the new scheme. 


\section{Pathways after prison: what do ex-prisoners and agency representatives tell us?}

- Housing is crucial to desistance, reintegration and the delivery of support for people with complex needs, but there is a dearth of housing options for ex-prisoners.

- Pre-release planning is constrained by heavy workloads, and referrals to transitional accommodation and support are tightly prioritised and rationed. The lack of accommodation options means that referrals and housing arrangements are often left until very shortly before release.

- Ex-prisoners face a fraught pathway through various forms of temporary accommodation-motels, caravan parks, SHS facilities and private boarding houses - with some also accessing transitional accommodation.

- Temporary accommodation can be a useful stopgap for dischargees, but having to rely on it is highly stressful.

- The accommodation offered by homelessness services varies. Large congregate services and shared spaces, in particular, are identified as posing risks to residents.

- There is a high level of dissatisfaction with private boarding houses but, out of necessity, use is still made of them.

- For ex-prisoners with complex support needs, the challenges associated with accessing private rental are formidable, and often impossible to overcome.

- The social housing pathway has challenges of its own, and there is a tendency for support services to drop away after a tenancy commences. However, social housing provides affordability and security, and space for personal fulfilment and engagement with support. 
Where Chapter 3 reviewed the post-release terrain in terms of the main policies and programs in the area, this chapter presents and discusses the perspectives of people on the ground. To gain these perspectives, we conducted interviews in NSW, Victoria and Tasmania, with representatives from the criminal justice system; housing, homelessness, disability and reintegration services; and ex-prisoners. Our approach was to find common themes, rather than highlight every difference between the jurisdictions; but notable divergences and issues of specific concern are noted.

Participants were categorised by organisation/service type (with ex-prisoners forming a separate category), as indicated below. The letters in parenthesis are used, along with the relevant jurisdiction and a number, where we quote individual interviewees.

- State corrective services (CS)

- State housing authorities (HA)

- State disability agencies (SD)

- Homelessness organisations (HL)

- Community housing providers $(\mathrm{CH})$

- Reintegration services (R)

- Mental health organisation (MH)

- Intellectual disability organisation (ID)

- National Disability Insurance Agency (NDIA)

- Ex-prisoners $(X)$

\subsection{Pre-release planning and assistance}

Across our three jurisdictions, the common official position is that planning for release begins on entry to prison, with more specific case planning and referrals to transitional programs commencing 6-12 months before the date when the prisoner may be released on parole. It is important to note, however, that prisoners released without parole (i.e. at expiry of sentence) receive no assistance; and those being released directly from remand also receive no support. In regard to prisoners approaching parole, interviewees highlighted that the important action happens - or rather, is left to happen - in the couple of weeks, or even days, prior to release.

Two general points stand out from the interviews. The first is the dearth of accommodation options available to prisoners post-release. Every interviewee highlighted this lack. The agency representatives viewed it as a basic constraint on their planning and service provision. For five of the six ex-prisoner interviewees, it was an ongoing part of their post-release experience: four were currently living in transitional accommodation (one after initial homelessness); while the fifth had been couch surfing since release.

The second stand-out point is the broad consensus among agency interviewees that the large majority of people leaving prison have complex support needs. Many spoke about the significant histories of abuse, neglect, trauma and institutionalisation experienced by the cohort they work with, and how these factors lead to significant and ongoing challenges with respect to clients' desisting from offending and reintegrating with the community. In practice, pre-release planning and post-release service provision involved prioritising a very small number of people and rationing resources-but generally agency interviewees thought support should be provided much more widely. 


\subsubsection{Pre-release planning around post-release housing, homelessness and reintegration support}

For corrective services officers, housing is a particularly important consideration when planning for prisoners' release on parole-as they make case plans, and prioritise and select prisoners for referral to transitional programs (such as NSW's Funded Partnership Initiatives and COSPs, the Corrections Victoria Housing Program, and Tasmania's Beyond the Wire and Prisoner Rapid Rehousing programs). Depending on the program, officers aim to make contact with support services and undertake some initial planning work 6-12 weeks prior to release, though in practice it is often less. As noted in Chapter $\square 3$, only a few of these transitional programs directly provide accommodation, so even prisoners who have been put in contact with a reintegration service still need to arrange accommodation.

In NSW and Victoria, a prisoner assessed as moderate- to high-risk of reoffending generally needs a 'known address' to be eligible for parole, so these prisoners are prioritised in referrals to transitional programs; corrections officers 'know not to try to place everyone' (NSW CS1). Low-risk prisoners, on the other hand, may be paroled on the basis of a referral to DCJ's Link2Home referral service or one of the Housing Access Points in Victoria's state-wide network, where they will receive assistance and further referrals. In Tasmania, parole generally requires 'stable and suitable accommodation' (Tasmanian Government 2020).

In all three jurisdictions, most interviewees were critical of the way pre-release planning is conducted. A Tasmanian corrections officer reflected that, over their long career, the prison population has 'easily doubled and the amount of reintegration officers has not grown with that ... yeah, there's just not enough to go around, so there's not any planning' (Tas CS6). Victorian corrections and reintegration interviewees also pointed to the increased prisoner numbers and pressure on officers and other workers. A NSW reintegration service interviewee observed that corrections officers 'have massive caseloads - hundreds of people-and their focus is on group work, and it is hard to spend time with individuals' (NSW R5). Another reintegration worker characterised the process as 'a big line of different people who come and see an inmate before they are released ... It's a big machine, more than individual help' (NSW R1). Another commented:

It's really hit and miss ... Within each jail there are massive differences between workers as well. There's no set, guaranteed, 'This is what's going to happen'. It's pot luck, almost. Regarding housing, there's not much that goes on pre-release, on the corrective services side. They definitely don't see that as their role. (NSW R5)

A NSW homelessness organisation interviewee also observed variability across the corrections system, pointing out that only a few prisons have established relations with local homelessness services and community housing providers, granting them access to prisoners and broadening the scope for pre-release planning and relationship building.

Like, [a certain prison] had a good arrangement, where housing providers could access prisoners and they could do some planning work. That's just down to the workers in the system thinking there's value in allowing others access, and the governor supporting that. It depends on the governor and the culture of the prison-and the housing workers too. The main frustration of the homelessness services is [not] being able to access people in a timely way and work with them as soon as they can. People get moved around jails for random reasons, and you can't form a relationship with someone when they move. So there's a whole lot of barriers to providing proper support. (NSW HL1)

Victorian and Tasmanian interviewees gave the impression that connections between prisons and non-government housing and homelessness organisations were generally better in those states than in NSW. One example of close collaboration was provided by a Victorian community housing worker, whose role involved working designated days at a prison, offering appointments to prisoners in need of help with social housing applications and other referrals. 
4. Pathways after prison: what

do ex-prisoners and agency

representatives tell us?

Tasmania's general requirement that parolees must have a stable address presents additional challenges for prisoners. It is possible to use the address of a homelessness service for this purpose, but it is difficult, as it requires both that the service hold a place for the parolee and that the Parole Board approve the arrangement (Tas CS7). A Tasmanian reintegration service worker said parole applications were discouraged by lack of accommodation options.

Many [prisoners] give up and say they will serve their sentence out, even though they would likely be granted parole if it weren't for their lack of accommodation to go to after release. (Tas R5)

Between workload pressures on corrections officers, restricted access and late referrals to transitional programs, and frustrated access to other support services, for many prisoners pre-release planning happens very shortly before release and in a necessarily limited way. The NSW housing authority interviewee summarised the approach and objectives of the Link2Home referral service.

From a Housing perspective, we only engage with people a couple of weeks before they get out ... We're working with Corrective's as quickly as we can to work out the person's needs. So, the trajectory is short-term accommodation, working with us to get a sense of where you want to live, your need, medical evidence, and working towards getting them approved for priority housing. (NSW HA1)

Interviewees gave different views on this model of late pre-release planning. The NSW housing authority interviewee saw benefits in it.

You might think, 'Surely if we engage [with prisoners] six months out, we'd get better housing outcomes'. We didn't. We did [a pilot] over nine months, roughly, with a quasi-control group, and the numbers are limited, but ... what we found is that a lot of the clients who had the pre-planning disengaged... We're probably better off waiting until someone is very close to release until we seriously start assessing and planning housing assistance ... All the pre-planning doesn't really yield any value. (NSW HA1)

Notably, the interviewee placed a significant qualification on this view: 'If the pre-planning meant you got a social housing property immediately coming out of jail: different story. But that doesn't exist' (NSW HA1).

A Tasmanian corrections interviewee expressed a positive view of the late-planning approach of Housing Connect workers, within limits.

If we've requested it, a support worker will usually make contact with the individual before they're released and talk through what their options might be ... They do a really good job of informing both the client and the worker within the prison of what's happening.' (Tas CS2)

The Victorian community housing interviewee, who worked regularly at a jail, said they tried, as a late measure, to lodge a social housing application for each prisoner they saw, and regarded this as 'a good start for them' (Vic CH2).

The more common view, however, was that this sort of late pre-release work is really too little too late, and that more time and different skills are needed to establish rapport and trust with prisoners, provide information in a useful way, and consider all available options. A NSW reintegration service interviewee said prisoners themselves 'were all about pre-planning':

They want information, they want communication, and they want someone to sit down and show them what they need to do-because they don't know, and there isn't that person in the prison doing that with them. (NSW R1) 
4. Pathways after prison: what

do ex-prisoners and agency

representatives tell us?

This interviewee ran a very short pre-release information program for prisoners who had missed out on other transitional programs, and described their interaction with prisoners nearing release.

We talk though everything regarding reintegration, from their release day - how to get clothes if they've just got their greens-to housing. The majority are homeless. We talk through the Link2Home program, and although the participants have been doing this for years-like, they've been cycling in and out-the majority don't know about the Link2Home program. All this information is not shared easily, and they can be quite shocked: 'What, I get 28 nights free each year? Wow, that's life changing.' ... We take in with us the Housing application, and show participants the application. Many have one, and have had one for many years, and every time they go in it is suspended. So we talk about how to get on the [Housing wait] list, and get on the priority list. The majority are like, 'Oh I've been on 10 years, 15 years.' (NSW R1)

The same interviewee commented that, unlike corrections and housing authority officers, reintegration workers are caseworkers and counsellors trained to open conversations. It is difficult, draining work, both for prisoners and workers.

They are very open with us: a woman might say, 'I have four kids and we're homeless' or, 'I was sexually abused as a child'. No one holds anything back ... Sharing information with them is quite tricky, because their head is still in prison, and the stuff I'm talking about is outside. So, it gets quite emotional, and you've got to understand and have empathy and talk through that stuff, and most come around. (NSW R1)

The Victorian corrections and reintegration service interviewees similarly highlighted the emotion and stress of pre-release planning. One worried about how much prisoners were asked to take on in the short period before release:

They're given so much information ... You can imagine how jumbled that gets when you've got someone telling you about Centrelink, housing, accessing your kids? They get these lengthy lists of all these things they have to do ... and people wonder why they fail. (Vic R1)

The Victorian community housing interviewee, who set up prisoners with a social housing application as they were released, had a similar worry.

The problem comes when they're released. With that application, they're supposed to have some kind of support worker, but a lot of these guys don't have the capacity to follow through on an application ... We hope they'll present at a homelessness service, but that's an unknown for us. (Vic $\mathrm{CH} 2)$

As a release date approaches and nothing substantial has been arranged, it can appear-from a reintegration services point of view - that no planning at all has taken place, and that the intended post-release 'trajectory' has misfired at the start.

It's not coordinated. We'll get a prison ringing up on the day of release saying, 'Can you pick this woman up?'- on the day of release, when they knew it was coming months in advance. There's no planning. No planning about how [the prisoner will] get from the gate to wherever the next step is. (NSW R2)

Similarly, a Tasmanian ex-prisoner interviewee, who lived in a roof-top tent on his car on release, felt he got 'nothing, nothing from the prison':

You basically get kicked out the door and kicked in the guts and they say, 'Go do whatever you need to do, see ya.' (Tas X1) 
4. Pathways after prison: what

do ex-prisoners and agency

representatives tell us?

\subsubsection{Pre-release planning around post-release mental health and disability support}

Aside from housing, interviewees also discussed pre-release planning for post-release mental health and disability support. Some interviewees spoke highly of corrective services' procedures for screening and identifying mental health conditions and disability, particularly intellectual disability. However, the common view was that planning is not comprehensive, with relatively few cases, typically only the most severe or complex, receiving plans that integrate support provision across the transition from prison to the community.

As with housing, pre-release support planning is, at best, 'hit and miss', said the NDIA interviewee, and 'often, people can be discharged from prison quite quickly, and they haven't had an assessment done or tested their access to the [NDIS]'. This interviewee observed that opportunities for NDIS assessments and access requests were not being acted on by corrective services officers. The NDIA interviewee viewed the new JLOs as the key to effecting change here, but noted that JLOs were 'struggling' to get into prisons. The interviewee indicated that the JLOs' main efforts, currently, were in identifying potential NDIS participants very shortly before release, for follow up and access afterwards.

The JLOs are fairly new, and we struggle to get them into the system, but they are the key. In their weekly [contact], they'll be saying, 'Who's going out this week, do they need support?' We can do the active connection once they're discharged. That's still hit and miss at the moment ... But if we can get in early, and get [the prisoner] across what we can and can't do, and get them to a support coordinator, they're in a much better position. It's still pretty hit and miss, and not as smooth as it could be, but there is a plan. (NDIA1)

NSW and Victorian corrections interviewees similarly observed some access to supports being effected pre-release, but this was patchy. In particular, the Victorian corrections interviewee characterised the facilitation of access to NDIS services as dependent upon a particular officer seeing a need and deciding to tackle the issue (Vic CS 1).

The main obstacle to NDIS access, as the NDIA interviewee saw it, was prison authorities not appreciating the specific role and limits of the NDIS.

Some of the prisons just say, 'You can't come in, you just need to fund what we're telling you to fund, and we don't even know what their disability is'. Just, 'Fund their housing, fund their mental health treatment' - the whole range of things. (NDIA1)

This stance may be partly the result of misapprehensions or misunderstandings about the NDIS, and partly the result of political contestation by states and territories regarding the division of responsibilities between the NDIS and state-funded services. The NDIA interviewee described prisoners' lack of access to the NDIS as 'a constant point of tension with the states and territories'.

You can have your workers on the ground doing a whole of system response, but higher up the pecking order it's about taxpayers' dollars, and about funding; it's about Treasury, and it's about a cost shift: 'How can I get someone else to do the gig here?' (NDIA1)

This tension was especially evident in NSW, where the state has removed itself completely from post-release disability service provision, and less so in Victoria, where the government still has, through the Forensic Disability Program, 'skin in the game in the justice space' (NDIA1).

The intellectual disability organisation interviewee from NSW similarly observed that relations between corrective services and the NDIA were 'fraught', but felt that the JLOs were making a 'significant improvement' and 'better links between gaol and the NDIS' (NSW ID1). This interviewee also agreed that the NSW government's withdrawal from disability service provision meant that ex-prisoners now face 'much bigger challenges to getting the support services they need and the accommodation they need.' 
4. Pathways after prison: what

do ex-prisoners and agency

representatives tell us?

However, this interviewee, and others, saw problems with the NDIS and NDIA, too. In particular:

The expertise within the NDIS, at pretty much all levels, to respond to this particular group has been lacking a hell of a lot. So, unless you've had a savvy advocate on your side, this population has really struggled with the NDIS. (NSW ID1)

The Victorian corrections interviewee agreed that NDIS participants needed 'very good advocates'. According to the intellectual disability organisation interviewee from NSW, the problem was 'being addressed to a certain degree by recent developments [the JLOs and the complex support pathways], but only to a certain degree' (NSW ID1).

This interviewee was also critical of the NDIS effecting a shift away from more intensive case management, characterising the approach of NDIS support coordinators as 'case management "lite"' (NSW ID1).The state disability agency interviewee similarly saw a lack of expertise and case management skills in the NDIA: 'They've thrown the baby out with the bath water, and they need to bring back people who understand disability and some case management.' On the collaboration between state clinicians and case managers, NDIA planners and prisoners, the interviewee said, 'Sometimes it means watching a train crash happen-but we've never just watched, we get involved and assist' (NSW SD1).

The Victorian corrections representative highlighted that the length of time taken to complete NDIS assessments was a problem - though this issue might also reflect the inadequate time and resources given to post-release planning within prison authorities' own processes.

\subsection{Post-release temporary and transitional accommodation}

As our interviewees made clear, people leaving prison without pre-existing housing very rarely go straight into a long-term tenancy. 'It's about getting someone from A to C, and what's the B?', explained the NSW housing authority interviewee. For the Victorian community housing interviewee, 'A to C' could be a long journey and one beset by pitfalls.

They could easily be waiting a couple of years, realistically. And for them that's a long time, and so far off in the distance it's difficult to conceive of. And a long time in which for things could go wrong in their lives - to be homeless or back in prison, all sorts of things. And the longer the time, the less chance you've got that they'll be in a place to be offered something. What they do in the meantime: they couch surf, stay with family, stay in motels, stay in cars/stolen cars, stay with friends, sleep rough, all those things. (Vic $\mathrm{CH} 2)$

This interviewee said prison itself could become an accommodation option for homeless ex-prisoners: 'l've had guys say to me, they've deliberately reoffended to come back to prison, because they have nowhere to live' (Vic $\mathrm{CH} 2$ ). Similarly, a Tasmanian Corrective Services interviewee said:

So then, people want to come back to custody because they've then got a roof over their head.

They don't have to worry; they're getting fed, they can stay warm. (Tas CS2)

In this section we consider interviewees' perspectives on four accommodation options:

- temporary accommodation in motels

- transitional accommodation specifically for ex-prisoners

- accommodation, and other assistance, provided by SHS

- boarding houses. 
4. Pathways after prison: what

do ex-prisoners and agency

representatives tell us?

We also examine the issue of maintaining relations and 'engagement' between ex-prisoners, housing assistance providers and other support services.

First, to set the context for this process, it is useful to consider a typical release day, as recounted by one of the reintegration service interviewees. It can be a hectic, gruelling day.

One, there's no transport for them from Corrections to Housing. That's the first barrier. Corrections' duty of care, they keep telling us, ceases at the gate. And they [prisons] can be quite isolated ... You have to walk quite a distance to catch the bus, and have been given an Opal card [travel fare] to catch the bus, and know where it is going. They may have been released in their prison greensso they are feeling like a target-or in clothes that don't fit them, and with their belongings in a seethrough plastic bag. Then they have to walk a distance. They may be released not at a peak time, so they may be sitting for 45 minutes, with no food or water or phone or nothing to get into Penrith to get to Housing.

You can already see how it makes it difficult, and then add in levels of trauma, being in custody for a long time, issues around drugs and alcohol and mental health-'Are people watching me, what's happening?'-and lack of communication skills with others.

Then they get into Housing; they haven't eaten since breakfast and it's now afternoon, they don't have money to buy food, and they have to sit in Housing and be patient, because they've got their ticket. They don't know the system, so they have to wait to speak to a housing officer at a desk and have that interaction: 'You need this paper, this paper, this paper'; 'I don't have that, I don't have a birth certificate, I'm just out of custody'. Then: 'This is the [TA] address, you have to get yourself there.' No maps, no directions, nothing-just find the location.

For a lot of women, and men too, the TA is shared accommodation, and it's a lot of people they don't know - they're walking again into a new situation, and its triggering. And if their communication skills aren't there, they have no meds, they're hungry, they have to navigate that.

And get to a bank for money.

And get to parole-on their first day, sometimes they have to report to parole as well.

And Centrelink! In one day! (NSW R2)

\subsubsection{Temporary accommodation}

Temporary accommodation is often the first form of housing assistance that ex-prisoners experience on release, and the form to which they might continually return. This is accommodation in motels and, in some suburbs and regional centres, caravan parks. In NSW it is paid for and arranged by DCJ, for a couple of nights at a time, up to a total of 28 nights in a year. In Victoria and Tasmania, Housing Access Point and Housing Connect services arrange and pay for temporary accommodation using funds from their respective state governments - they offer a little more flexibility, usually a week's accommodation at a time, but subject to budgets.

Interviewees generally appreciated the availability of temporary accommodation. Reintegration workers said they made sure their clients knew to ask for temporary accommodation. Housing workers, particularly in Victoria and Tasmania, said it meant they were able to 'put most people up'. They could use temporary accommodation to creatively solve problems: one worker described paying for a taxi fare and hotel accommodation to get a female ex-prisoner experiencing domestic violence out of a small town (Vic $\mathrm{CH} 1$ ). Another Victorian homelessness worker saw temporary accommodation as providing an 'opportunity' to identify and link clients with additional support services (Vic $\mathrm{CH} 3)$. 
4. Pathways after prison: what

do ex-prisoners and agency

representatives tell us?

However, interviewees also emphasised that having to rely on temporary accommodation was immensely stressful for clients.

TA is two or three nights at a time, and that stresses people out. In two or three days, they don't know what they're doing. (NSW HA1)

They have to go through the whole thing of turning up at a Housing office, waiting, and then people lose their cool, they get anxious. It's very difficult, the process. (NSW R4)

A Victorian homelessness worker who made a high volume of temporary accommodation referrals was dissatisfied with the quality of hotel accommodation offered, and characterised clients as being 'squashed in this bandaid system, where we're just holding people in these hotels in this pattern' (Vic CH3).

The reintegration workers said the requirements of reapplication, including searching for other accommodation and providing evidence of lack of success, wore down ex-prisoners and frustrated their access to housing assistance, and to reintegrating generally.

They have to go to Housing, apply for TA, then go back every two to three days, and in the meantime apply for a certain amount of housing. And you're asking that of someone who may have spent two to three years in custody, and their anxiety levels, and their trauma-their trauma levels are added to the trauma they had prior to going into custody-all these things. The system is set up to send them back into custody again. (NSW R3)

Some additional problems were noted by Tasmanian interviewees. According to a corrective services interviewee, some accommodation providers were known to refuse temporary accommodation bookings 'because they don't want the clients' (Tas CS5). On the other hand, a reintegration service interviewee said most services in the state had spent their annual budget within six months (Tas R1).

\subsubsection{Transitional accommodation}

Transitional accommodation for ex-prisoners is accessed via referrals from corrections officers and can take a variety of forms, including: ordinary self-contained dwellings (such as the properties used by Tasmania's Prisoner Rapid Rehousing initiative); shared boarding-house-style accommodation; and repurposed former correctional facilities (such as the NSW COSPs). The level of engagement between provider and tenant, in terms of casework and other activities, and the degree of regimentation for people living in the accommodation, also varies.

Most of the ex-prisoners we interviewed were currently living in transitional accommodation: two in facilities with relatively high degrees of space-sharing and regulation. One described his experience of adjusting to life in the community, and the regimentation of the facility, like this:

The staff are good, the clients are good. I can sit and have coffees and chat to people. We just have chats about what we're doing - say, we're going to see a rental property, or what we're doing with the day, come back and have a coffee. The staff are good; if there's ever an issue we work it out-like, if I want to go to the shop and I haven't put it on my schedule, I've forgot to put it on, I just say to the staff, 'Sorry, I forgot to put it on my schedule, can I go at 9 o'clock today?' They'll put it on there for me and make an amendment. They're pretty flexible, the staff. Yeah, it's good. I fit in here. I've been out of jail a couple of weeks now and l've made a good adjustment. I don't have any paranoia, or think people are following me, or any delusions. I'm on my medication, so l'm mentally stable. I know my way around the neighbourhood: I can catch a bus down to [another suburb], and go up to [a shopping centre], have lunch there-I do that quite regularly - fish and chips, or KFC, or whatever. (NSW X3) 
4. Pathways after prison: what

do ex-prisoners and agency

representatives tell us?

The NSW reintegration service interviewees were generally positive about the state's transitional accommodation services, especially the FPl's Extended Reintegration Service, which 'comes with a worker and a house, and that's a totally different ballgame; it's only for people with severe mental health [conditions], but it should be for everyone (NSW R4)'. They also spoke highly of some shorter-term (12-week) transitional accommodation.

For men, it's like a boarding house, it's for three months, and there are case managers there, right next door, who follow up all the Housing Pathways [social housing register] applications and get the ball rolling. That's one of the best I've seen. They do all the paperwork, take them to get dosed if they've no methadone. (NSW R4)

Despite the praise, these interviewees also thought 12 weeks - which, as we saw in Chapter 3, is just less than the average wait time for priority social housing - was the bare minimum for an effective transition: 'I don't think three months is quite long enough. It could be twelve' (NSW R3). The NSW homelessness organisation interviewee also considered transitional accommodation to be valuable, but was concerned about the limits of these services in terms of duration and availability.

It's 12 weeks' support; it's not long-term supportive housing, it's short-term support ... The innercity homelessness services, that's the service system response, if we're honest. And TA. (NSW HL1)

For ex-prisoners, the rules they must follow when living in transitional accommodation can be a challenge. A NSW Corrective Services interviewee described the expectations and consequences at a COSP facility:

[Tenants] need to comply with the rules of the program, about violence and drugs and aggression. If they do those things, they'll get evicted, and then they're homeless as well. That's the reality of it. And then they're on Link2Home ... It can get pretty chaotic, and people get evicted quite regularly. (NSW CS1)

There is a significant difference between the COSP approach and that of other transitional housing programs. Corrective services interviewees explained that COSP facilities are strongly oriented to getting ex-prisoners into private rental rather than social housing, as social housing is a heavily restricted pathway for the program's main clientele: people convicted of sex offences. (We explore the issue of the blocked social housing pathway further below.) Regarding the way COSPs work with ex-prisoners, a corrective services interviewee described how 'in the first week, we're onto exit plans; that's our number one priority' (NSW CS1).

A lot of our case management is around accommodation. With intellectual disability, that makes it a real challenge-and they're child sex offenders, so that's even more of a challenge ... But we get them looking for accommodation, and going to viewings - even if they've been in custody for 20 years - just to get that process going: going to viewings and making applications. (NSW CS1)

The Victorian interviewees had mixed feelings about transitional accommodation in their state. Despite the Corrections Victoria Housing Program having been evaluated positively, interviewees regarded the CHP rooming houses used by the program as 'shocking places, that they struggle to fill'-places the social housing sector were trying to dispose of (Vic R1). Still, the dwellings were considered better than the privately operated rooming houses in which ex-prisoners often end up (discussed further below). An interviewee with experience of transitional accommodation in the Forensic Disability Program was more positive, noting the program's provision of 12-months' accommodation and continuing casework support after that.

For a lot of [ex-prisoners], once they get that support and someone to go on that journey with them, most go okay. They will have found a place they can call home, found work and linked in with other social groups and developed a different community. [They] just know when they've lost enough, [but] nobody knows when that will happen. (Vic CH1) 
4. Pathways after prison: what

do ex-prisoners and agency

representatives tell us?

Tasmania's Prisoner Rapid Rehousing initiative also offers 12 months' accommodation, but differs in that it uses ordinary dwellings. A reintegration worker reported that it had been difficult to convince private landlords and some community housing providers to put properties into the scheme (they have so far secured only 12 properties). Several Tasmanian interviewees observed a lack of transitional accommodation, particularly in the north of the state. To make up for the shortfall, a Tasmanian corrections interviewee told us, a Beyond the Wire caseworker 'roams across the north of the state and works out of her car, effectively, supporting people'.

I mean, she does an absolutely fantastic job and she goes above and beyond in supporting people. But aside from that we're back with Housing Connect and [a local CHP] and they don't really have any specific programs for people coming out of custody. (Tas CS2)

Despite the shortage of transitional properties, a reintegration worker highlighted two features of the Beyond the Wire initiative that have the potential to be developed into strengths. First is the integration of Beyond the Wire with other housing assistance services through their common participation in Housing Connect. Although, currently, Beyond the Wire workers do not always have up-to-date information regarding clients' other housing applications, there are lines of communication that could be activated to properly share information between services. The second is the potential for the initiative to offer a pathway into a long-term social housing tenancy.

I think, in doing it this way - with transitional [housing] — and putting somebody in and seeing how they go ... If that seems to work for them and it fills that need and it's the right location, why move them? Why say, 'Your 12 months is up and you have to go through all that stress of moving again'. Why not just move the support and gain another property? (Tas R1)

\subsubsection{Specialist Homelessness Services (SHS)}

As discussed in Chapter 2, it is common for ex-prisoners to seek assistance from SHS-around one in seven discharges in 2018-19 resulted in a request for assistance from a homelessness service (AlHW 2019a). For housing workers, SHS are the mainstay of assistance; these services are where they try to get clients accommodated after temporary housing and while waiting for social housing.

What's ideal is SHS, because there's another bucket of funding for that, and they can stay longer in those services. (NSW HA1)

A lot of people with complex needs, who need housing and support, simply don't have access.

A significant proportion of this group end up at homelessness entry points [such as SHS]. (Vic HA1)

However, as one Tasmanian Corrective Services officer observed, SHS have a fixed supply of accommodation and access is not assured: 'There's a lot of people who are just released to homelessness, and obviously shelters and ... crisis accommodation, things like that, are so limited' (Tas CS2). A NSW reintegration worker described it as a matter of 'being in the right place at the right time':

We had a woman released and two weeks later there was an opening to have 18 months [SHS) transitional accommodation. And that was gold. It's pretty rare as well. (NSW R4)

A Tasmanian reintegration worker described 'people ringing up every day' and feedback from SHS that they were turning away hundreds of cases (not just from backgrounds of incarceration) each month (Tas R1). 
4. Pathways after prison: what

do ex-prisoners and agency

representatives tell us?

It's important to note that all SHS are not alike. The large congregate homelessness services in the inner citywhich the NSW homelessness organisation representative characterised as the de facto primary response to post-release accommodation needs-were a difficult proposition for ex-prisoners. A reintegration worker observed:

Quite often there's a real reluctance for people to access homeless crisis accommodation-like the big crisis accommodation in the city, like [certain services] - people really don't want to access those. Because it's the type of environment, the amount of drug use going on, the amount of people with significant mental health issues. Most of the people we [alcohol and drug counsellors] work with would actively refuse to go to those places. (NSW R5)

This was, indeed, the experience of one ex-prisoner interviewee (NSW X3), who said he would not return to a crisis hostel. The NSW housing authority officer also acknowledged that, 'particularly for men, there's not a whole range of places for single men with complex issues - some, but not a huge range of options' (NSW HA1).

The reintegration workers said options for female ex-prisoners were limited too, with few services providing accommodation for an extended term.

There are some services in the city that will take women from custody for 3-6 months, including women with children and babies - especially if they've got DCJ watching them-but it's very hard to get into, very limited spaces, so that's a real issue. (NSW R3)

Shorter-term crisis accommodation options for women were also mentioned. Some of the premises were described as new and well appointed, but reintegration workers saw risks in the degree of sharing required of residents.

The only problem is, they have to share a unit with another person. Their bedrooms are separate and they get their own bathroom, but they have a combined living area and the bedrooms don't have locks on the doors ... I've had quite a few clients go in and there's been problems with drug use - and we're talking about people who, as part of their parole, can't be party to drug use. So, yes, [the facility's] brand new and looks really nice, but it's not really safe for the women we support, especially when they have complex trauma, or cognitive delay. (NSW R3, original emphasis)

Further gaps and deficiencies in SHS service provision were identified by other interviewees. In Victoria, several interviewees said options for single people were lacking, with men mostly affected: 'It's really hard to get traction to find housing for men that have come out of custody' (Vic CH1). However, others highlighted young women without children, and specifically young Indigenous women, as underserved groups, because their growing prevalence in the prisoner population had outpaced service responses. Tasmanian interviewees reported that the north of the state was underserved relative to the south: 'Hobart is okay sometimes, but the further north they go, and northwest-we don't have enough of those types of places [SHS]' (Tas CS2).

\subsubsection{Boarding houses}

Across all jurisdictions and all categories of interviewees, private boarding houses were acknowledged as an important accommodation option, but regarded with deep dissatisfaction.

A lot of the guys - and [l'm] talking about [men with] mental health and disability-rooming house accommodation is not really satisfactory for these guys. The reason is, most rooming houses are poorly run, and there's lots of people there with mental health issues, drug and alcohol issues, and it basically sets people up to fail. They are going back into a situation that's led them into prison in the first place. And there's definitely people I've spoken to who'll say, 'I'm not going into a rooming house, because it means l'll be straight back in [prison]. They're very aware of what will happen to them. (Vic $\mathrm{CH} 2)$

I've had guys saying, 'I've had to leave because there are so many guys doing drugs', or, 'I've had to leave because there is so much violence'. But the second they leave, they're in breach [of their parole] ... We're not enabling them to find a way out, we're enabling them to fail. (Vic R1) 
4. Pathways after prison: what

do ex-prisoners and agency

representatives tell us?

The Tasmanian reintegration workers saw boarding houses as placing ex-prisoners 'at risk'. Their NSW counterparts pointed to very bad conditions and practice in parts of the sector: 'The boarding houses we go into that are filthy -you wouldn't want to put anyone in there' (NSW R2). One NSW ex-prisoner (NSW X3) had lived in boarding houses before his time in prison and was determined not to go back.

Nonetheless, a Victorian reintegration worker said they tried to maintain relationships with boarding house proprietors, to keep the option open for clients. The NSW reintegration workers spoke highly of a partnership between the CRC and the Newtown Neighbourhood Centre, which provides information to ex-prisoner residents about vacancies in inner-city boarding houses and outreach services, and has worked patiently to build relations with property owners. These workers also noted, however, that some parts of the sector were becoming inaccessible to ex-prisoners, with facilities shifting their clientele to international students and workers.

\subsubsection{Engaging with housing and other service providers}

During the post-release phase-the journey from 'A to C', as the NSW Housing interviewee put it-how well do service providers maintain engagement with ex-prisoners and deliver the supports they need to live in the community?

Keeping ex-prisoners engaged with social housing providers during the often long wait for social housing is a challenge. The NSW housing authority interviewee said officers would push beyond the usual limits of assistance for clients who stayed engaged, 'as long as they are genuinely engaging — and to be honest it is rare to see that, because a lot disengage early on'.

They disengage. That's my experience of people who've been in custody. I've dealt with people who've been in [prison] a long time, and they find it difficult to readjust. And, reflecting on what clients have told me, those situations they're placed in - the hostels-resemble where they've just come from, which is negative. So, they decide it's easier to live on the streets. (NSW HA1)

A Tasmanian reintegration worker observed that ex-prisoners engaging with Housing Connect were similarly frustrated.

They all have to go through the Housing Connect model, and there's benefits in having just the one -stop shop, but it seems to me that inmates are frustrated that when they go down that pathway, they don't have much success. (Tas R6)

Something of the tedium and apparent futility of maintaining 'engagement' was suggested by a Victorian homelessness worker: '[We] put someone up again and again and again, and try to make something stick' (Vic $\mathrm{CH} 3$ ). Moreover, lack of stable accommodation affects engagement with other (non-housing) support services. Reintegration workers spoke about the difficulty of delivering services to clients in unstable housing.

It makes a massive impact ... If someone doesn't have halfway stable accommodation, they're not that interested in engaging with drug and alcohol counselling. It's not their first priority. And living in unstable housing makes it really difficult for people to make progress in their lives. (NSW R5)

One reintegration worker, a specialist AOD counsellor, considered that ‘having one support worker isn't enough, because there's so much going on'.

I feel the service I manage is more effective when people have more support workers working with them-like, when someone has a caseworker working on housing and other practical issues, quite often we find that client engages much better with AOD counselling. Otherwise, if we're the only service, quite often there's all these other things that people want to talk about and get assistance with, and you don't get to the AOD counselling because there's all of this other stuff [that needs ] to happen first. (NSW R5) 
4. Pathways after prison: what

do ex-prisoners and agency

representatives tell us?

The Victorian housing authority interviewee said, similarly: 'You need to have the right people in the right places in the different agencies and services' (Vic HA1).

The Victorian interviewees were generally positive-more so than those in other jurisdictions-about relations between services, and indicated that there are well-established networks and working relationships for determining roles and responsibilities, creating holistic support provision.

Engaging with the NDIS post-release is also difficult for ex-prisoners living in unstable or temporary accommodation. The NSW homelessness organisation interviewee described the barriers for homeless ex-prisoners.

In terms of homelessness services, they're generalists, and they'll refer people to mental health and disability services. But if you look at what's happening - surprise, surprise-people aren't really accessing the support plans when they're homeless. And that's because of the way it's structured. You need to have an address - the waiting lists are all localised, so if you move around, [it doesn't work]. There's a whole lot of things they haven't thought through, with the NDIS. (NSW HL1)

The intellectual disability organisation interviewee from NSW also noted the particular difficulties for ex-prisoners with cognitive disability in unstable accommodation.

Having an intellectual disability increases the need for stability of housing: if you don't have a stable home base where you feel safe, and where support workers can come, it's all the more challenging to readjust post-release. For people with intellectual disability, any change is challenging, and all the more so if the change is from the regimented, structured life of jail to the free-form [life] of the community. And a lot of people get in trouble going from that total structure to the total want of it. Homeless accommodation is often congregated, and people with intellectual disability are often vulnerable to negative role models around them. (NSW ID1)

From a community corrections perspective, the NDIS was 'an uphill battle, a mess; [but] it has improved' (NSW CS1). In the experience of the NSW Corrective Services interviewee, an ex-prisoner's 12 weeks of transitional accommodation is a difficult time to undertake NDIS assessments, and they had been advocating for more assessments to be done while participants are still in custody. They were starting to see some clients arrive at transitional accommodation already on an NDIS plan, with drop-in support.

You get all sorts of different agencies [providing drop-in support], and different levels in what they do. We [community corrections] have to push [back] quite hard: 'No, you're not to take them fishing!'- or whatever - 'They're supposed to be looking for accommodation! They're homelessness! Take them to property viewings!' (NSW CS1)

The two NSW ex-prisoner interviewees currently in transitional accommodation were generally positive about the way they were dealing with their relations with community corrections, accommodation providers, and the other supports they needed to access. A Tasmanian ex-prisoner interviewee spoke positively of the work of her Beyond the Wire case worker:

Okay, so [name] from Beyond the Wire; he does a lot of liaising with most of my supports-Red Cross, CatholicCare, Housing and Mission Australia-all of these places. They liaise with each other on my behalf and it usually works pretty well with all of them. He really advocates for me, but most of them ... do pretty well at communicating with each other and keeping each other in the loop. (Tas X2)

This interviewee, however, remained homeless (couch surfing), as she had been since her release. In this light, her comment suggests that, without long-term housing options available, there can be a proliferation of liaison and advocacy requirements, and increasingly complex interpersonal and inter-agency communications-and hence potential for miscommunication and disengagement. 


\subsection{Long-term housing}

What are the options for long-term housing (Point C, in the words of NSW HA1) for ex-prisoners with complex support needs?

This was a present issue for almost all our ex-prisoner interviewees, four of whom were currently in transitional accommodation, and one of whom (Tas X2) was homeless. NSW X2 and NSW X3, both single men with histories of homelessness, were in the process of applying for private rental properties but had also made applications for social housing. For each, the primary aim was to get a place of his own. For NSW X2, this meant a house and garage (for a ute and tools) in a North Coast town-'as far from [a South Coast town] as I can get'. NSW X3 was looking for a studio flat in an inner suburb of Sydney, and was eager 'to put some roots down and ... get some rental stability, and stay grounded'.

Tas X3 was in a Prisoner Rapid Rehousing property and said he would be happy to stay there: he liked the town and had joined a church group; he was also conscious that his status as a past sex offender could make securing alternative housing difficult. Tas X1 was seeking a larger property than his transitional one-bedroom flat, because he wanted his children (currently in out-of-home care) to live with him-the best prospect of this occurring, he felt, was in social housing. Similarly, Tas X2, who was homeless, wanted a social housing property with enough room to allow her to be reunited with her son.

In all our interviews, the most commonly discussed options for long-term accommodation were social housing and private rental housing, with some interviewees also discussing SDA.

\subsubsection{Private rental housing}

The common view held by interviewees was that entering the private rental market was hugely challenging for ex-prisoners with complex support needs-and for many, impossible.

This group, I find, is very hard to get into private rental, which shuts off a huge opportunity for them. (NSW HA1)

I don't meet a lot of people that live in private. They just don't get private rental. (NSW R1)

The main obstacle cited by interviewees was the unaffordability of private rental housing - more so than discrimination against ex-prisoners specifically, or restrictions imposed by parole and other post-release orders. In terms of the scarce properties that were let at affordably low rents, ex-prisoners generally did not compete well with other applicants, said the Tasmanian homelessness organisation interviewee.

That's a very competitive market, where people need to compete with other prospective tenants

... Prisoners would probably be one of the most disadvantaged [groups] because not only do they have different complex issues, on top of that they are not seen as easy to house. (Tas HL1)

Interviewees in all states highlighted that gaps in rental histories and lack of references caused problems when applying for properties through real estate agents. 'I just tell them I've been travelling', said one ex-prisoner (NSW X3). Another barrier cited by several Tasmanian interviewees was having a companion animal. This is an increasingly prominent issue in mainstream housing advocacy, but its relevance to ex-prisoners seems to have been overlooked. Indeed, it is especially pertinent to this cohort, as one corrective services interviewee explained.

A large percentage of our clients have a close affinity with their dogs, and it is almost universally a barrier to getting a housing property ... That pet has been a companion through some of their hardest times, and has probably slept on the streets with them and protected them, and stayed by their side when everybody else has abandoned them. And they're unwilling to separate themselves from the pet, even if it means finding other accommodation. (Tas CS5)

However, of necessity, agencies continue to assist clients to search for and try to access private rental housing. 
4. Pathways after prison: what

do ex-prisoners and agency

representatives tell us?

In NSW, a corrective services interviewee (NSW CS1) said private rental was the main pathway out of the COSPs, and described how COSP officers scoured online property portals on behalf of residents, searching for flats to let at \$200 per week or less (equivalent to $50 \%$ of JobSeeker Payment plus $100 \%$ of Commonwealth Rent Assistance). The interviewee said they tried not to refer ex-prisoners to boarding houses, but did so often, of necessity-and they had developed relationships with certain boarding house operators who could be contacted if a resident had no success elsewhere. The NSW officers did not, however, cultivate enduring relationships with real estate agents. The Victorian corrections interviewee, on the other hand, said they had spent 'a good deal of time fostering good working relationships' with a number of real estate agents, and had been able to refer ex-prisoners lacking rental histories to them, thus building the individual's tenancy record for further, longer-term, private rental options.

One of the NGO reintegration workers saw some limited prospects for clients renting privately in less costly outer suburbs.

In the city, it is really difficult to get someone into private rental-almost impossible, in the Sydney market. Out west [western Sydney], we've been able to get some women into private rental. However, the cost of that is very difficult. You need Housing to do the guarantee, and you need the right real estate agent. If they [the ex-prisoner] have got a support worker, they [the agent] might do it. (NSW R2)

This worker also noted that ex-prisoners are considered 'risks' in this part of the market, which can make them vulnerable.

If they don't have a support worker in the background, the only private rentals which will take them are ones that maybe aren't very reputable-like private landlords doing a bit of a dodge. Which puts them [ex-prisoners] into a vulnerable situation; like [the landlord might] say, 'You haven't paid rent, I'm going to do this', or they take their stuff. So, it's a vulnerable position. We've had women come to us after they've been in that position and tried to manage it themselves. (NSW R2)

Both corrections and NGO reintegration workers emphasised that successful private rental placements usually depended on both initial housing assistance (e.g. bond loans and tenancy guarantees) and ongoing support from a service. The NSW housing authority interviewee recounted how much work DCJ and other social housing providers currently do in assisting clients to access private rental, but expressed doubt as to broad efficacy of pursuing this type of housing for ex-prisoners as a group.

We've got private rental brokerage workers, and they work on the ground with local real estate agents and build rapport and help them understand the support we provide. They break down barriers, but it takes work. We've a suite of products, like bond loans, which can come with an advance rent component, which can help people get set up. Then there's a range of Rent Choice products, which is a subsidy with a taper over three years ... But my understanding is, there's broadly low uptake of these products. And they are of limited value to this cohort. If they had a support worker, and all the stars aligned, maybe you could get a good outcome, but at the moment, social housing is the way they are heading. It would be daunting, just coming out of custody and someone says 'private rental.' (NSW HA1)

The Victorian reintegration worker was similarly sceptical that circumstances, support and assistance would ever align to make private rental a viable option for more than a lucky few.

The idea that we access private rental more; how successful those programs are, I'm not sure. But it [seems] to me that [we're pursuing private rental instead of] giving someone public housing or a better start or an opportunity, [and private rental] will only work for some people ... [Maybe] it's better for families, because the income is higher, and there's more stability with families; [they might be] able to access houses out west ... There was this [belief] that PRAP [Private Rental Assistance Program] would sort it all out, and I guess it works for some but not enough. (Vic R1) 
4. Pathways after prison: what

do ex-prisoners and agency

representatives tell us?

\subsubsection{Social housing}

The main obstacle to social housing is, of course, the often long wait for an allocation - and the accompanying risk of an individual disengaging from the administrative requirements for keeping an application active.

Policy settings and requirements also present barriers. The most commonly encountered challenges relate to a person's past unsatisfactory tenancies and debts. In all three jurisdictions, social housing authorities may, depending on the circumstances, exclude or suspend unsatisfactory former tenants from eligibility; and require applicants to make satisfactory repayment of part of their debt before approving a new social housing tenancy. Several interviewees highlighted debt repayment requirements as a barrier to access - particularly in Tasmania, where the state housing authority requires repayment of 80 per cent of debt before they will grant a social housing tenancy. A Tasmanian corrections officer said:

They can chip away at it with the money that they get in here [jail] but, you know, it's often thousands of dollars ... That's a massive barrier. (Tas CS1)

One of the reintegration workers observed that debts were often accrued while the prospective tenant was in prison-for example, when their previous tenancy was terminated for arrears, and cleaning and repair costs were charged to the tenant. One ex-prisoner (Tas X2) said she was suspended from social housing eligibility as a result of a debt, which she was continuing to pay off.

In NSW, corrective services interviewees raised a problem specific to people with a record of sex offences, remarking that DCJ Housing often blocks such individuals from allocations of social housing, and even from other forms of assistance (e.g. bond loans). This particular issue is being investigated further by members of the present research team in another project.

In cases where ex-prisoners do make a successful application and receive a social housing tenancy, interviewees acknowledged a range of continuing challenges to desistance and reintegration. For example, the neighbourhood context of a social housing tenancy.

The places they get through Housing may be triggering, with active [drug] users and dealers in the block. But if they knock that back, they only get one more [chance before] they are cancelled off the list. So, sometimes they have to make a difficult decision: 'Do I take this property and risk breaching my parole, because I know there's a dealer in the flat above me or a user right next to me? And how do I stay abstinent during this time? How do I manage these people around me?' And then they get into vulnerable positions. (NSW R3)

I've definitely worked with people who got accommodation in, like, a tiny studio apartment, in a block where there's all kinds of stuff going on, and it's really hard. People can come out of prison with the best intentions [but], as an AOD worker, we might see someone for an hour a weekthere's a hell of a lot more time [for the client] to see all of these other things going on about the place. (NSW R5)

Nonetheless, the reintegration workers thought such challenges were better faced in the relative security of social housing than in unstable accommodation.

It's always a good thing for the people we're working with to get public housing. In a way, public housing can be in as unpleasant a place as you like-it still takes away that anxiety of not knowing where you're going to be. (NSW R5)

The social housing provider interviewees, on the other hand, observed other support services dropping away once a client was housed in social housing: 'This happens all the time' (NSW HA1). 
4. Pathways after prison: what

do ex-prisoners and agency

representatives tell us?

I can't tell you how many cases I've dealt with where they get a house and, within three months, every service is gone. Everything's gone. Because every service is geared to: 'This client, they've got a good housing outcome, they're well now, they're doing good.' The only reason they're doing good is because they had all this support around them. And when the long-term housing outcome is realised, all the support just moves on. So there's two parts of the puzzle: how do you get people to the long-term housing outcome, and how do you keep services engaged long term to ensure it is sustained? (NSW HA1)

A Victorian community housing provider also emphasised the need for ongoing support.

What's missing is the lack of support for people: 'We've got them a house, so let's hope everything works out' ... A range of different types of housing are needed but, more than anything-more than the housing itself-I would think the right support and the right amount of time to support people [is what's needed] (Vic CH3)

The reintegration workers agreed that a combination of stable housing and ongoing support was essential.

The feedback from the women we've supported, who have done a long time in custody, is that the difference between this time and other times is that this time they have stable accommodation. And that's huge. That's the feedback: it's stable accommodation that has enabled the turnaround this time-and the supports. The combination of the two. (NSW R3)

Reflecting on the practices of DHHS as a housing provider, the Victorian housing authority interviewee observed some deficiencies, particularly in relation to Indigenous people. They said DHHS adopted a general principle of 'sustaining tenancies', and were housing a high number of Indigenous ex-prisoners, but commented:

It's clear we are housing the right people, but where we're getting it wrong is that we're not sustaining them ... We expect tenants to be challenging, and understand they've never managed a tenancy before: we will link [them in] with support agencies so they have a better chance of succeeding. The only way to do this is to partner with support agencies that are good, but [these services] can be variable in what they offer and how responsive they are to challenges that arise. (Vic HA1).

Several Tasmanian interviewees spoke very highly of Indigenous organisations providing health, counselling and other casework services to ex-prisoners. However, the housing sector is seen to be lagging behind other sectors, particularly the health sector, in terms of Indigenous support organisations and Indigenous competency in mainstream organisations.

\subsubsection{Specialist Disability Accommodation (SDA)}

Aside from social housing and private rental, some interviewees looked to the NDIS and SDA for long-term housing options for ex-prisoners with very high levels of need.

The state disability representative, from NSW, highlighted how imprisonment further disables people with cognitive impairment, creating specific support needs post-release.

People with cognitive impairment or ID [intellectual disability] who been living in jail a long time, they need the support staff to help them navigate the community and their lives. You can drop down [the level of support], but you need to get that connection and activity and learning for that person. And that needs to be created around them, and then maintained. (NSW SD1) 
4. Pathways after prison: what

do ex-prisoners and agency

representatives tell us?

This interviewee recounted an experience where they negotiated with the NDIA to help an ex-prisoner living in transitional accommodation. They described the client as 'a very complex person, in contact with criminal justice since his teens, in his fifties but like an eighty-year old'. Working with the NDIA, the disability worker made a plan for the client that included access to SDA: 'So he got out [of transitional accommodation] and got support, his own bedroom, some valued activities' (NSW SD1).

The same interviewee reported that they had seen good outcomes for ex-prisoners in group homes under the former CJP, as did the intellectual disability organisation representative. However, both interviewees also pointed to the failings of this type of accommodation. The state disability worker acknowledged incompatibility between residents was often a problem and could lead to vacancies in group homes. NSW ID1 noted that their organisation had endorsed peak organisation statements against congregate accommodation for people with disability (see PWDA 2011).

Other interviewees mused, somewhat imprecisely, about possible specialist forms of congregate accommodation for ex-prisoners with disability that would facilitate close support and supervision.

For people with disability, [what we need is] some sort of independent living but with support available ... Sometimes, if someone could step in or intervene and resolve the issue on the spot, it wouldn't blow out. If you had someone there providing that support, that could prevent a lot of situations being exacerbated. (Vic $\mathrm{CH} 1)$.

The NDIA interviewee, however, was apprehensive about agencies' intentions in pushing for SDA and other forms of congregate accommodation for ex-prisoners. They pointed to the risks of segregated accommodation, including the perpetuation of institutionalisation and punishment.

One of the principles of the [NDIS] is community engagement: getting you to be more individual in your approach to support and your housing, increasing your independence-it ain't about building a jail outside of a jail. And we're getting a bit of push on that at the moment. I get it, being in jail is terrible, but is it any better being outside if you're still in a jail that looks a bit more modern? (NDIA1)

\subsubsection{The road home}

From all our interviews, it felt like good news stories were in short supply. We finish this chapter with two examples of successful 'roads home'.

Only one of the ex-prisoners interviewed, NSW X1, was in long-term housing: an NRAS affordable housing unit. This individual's post-release pathway was unusual: after more than a decade in prison, on release he lived with a supportive family friend, before finding an NRAS unit through a public advertisement on Domain.com.au. He did not stay in temporary accommodation, nor go through the social housing application process.

I've been homeless before, and I know how difficult that is. And throw in the added dimension of parole and everything else-I can't imagine doing all of this homeless. It would be mind-blowingly complicated. That's the only way of putting it. I've done homelessness plenty of times, I know how hard it is. I didn't want to go there. (NSW X1)

This interviewee had continued to see a psychologist to whom he had been referred pending release, and a drug and alcohol counsellor at a post-release support service. He had also found a job, and attended to a long-term medical problem. He marvelled at 'the fact that I have solid, stable housing'.

It's absolutely awesome-my own little flat. It's great, really great ... It is so nice that I have somewhere to go back to at the end of the day, and I'm not freaking out and I'm not anxious about what's going on, who's going to be there, anything like that. (NSW X1) 
There was one other 'good pathway' story among the interviewees. Prior to her current career, one of the reintegration workers (NSW R4) had been, as she described it, an 'institutionalised' repeat offender. During what would be her last term in prison, she qualified for a pilot transitional program.

How crucial is a safe pathway? I'm an example. I joined up to one program, and doors opened. (NSW R4)

\subsection{Summary}

All the interviewees emphasised the crucial role of housing in desistance, reintegration and the delivery of support for complex needs; they all also saw a dearth of housing options for ex-prisoners.

Pre-release planning is constrained by heavy workloads, and referrals to transitional accommodation and support are tightly prioritised and rationed. The lack of accommodation options means that referrals and housing arrangements are often left until very shortly before release. Reintegration and homelessness service workers, in particular, thought that more could be made of the pre-release period in terms of information provision and relationship-building with post-release support providers. The NDIA interviewee noted that the agency is trying to improve pre-release access to prisoners, acknowledging that it is currently 'hit and miss'.

With very few people released directly to a new tenancy, ex-prisoners face a fraught pathway through various forms of temporary accommodation - motels, caravan parks, SHS facilities and boarding houses - with a few also accessing, via referrals from corrections, transitional accommodation specifically for ex-prisoners. Workers indicated that temporary accommodation could be a useful tool to change a client's course and link them with other services, but having to rely on it was highly stressful for clients. There is considerable variation in the accommodation offered by SHS, with interviewees identifying large congregate services and shared spaces, in particular, as posing risks to residents. There is a high level of dissatisfaction with private boarding houses but, out of necessity, use is still made of them.

In regard to long-term housing, most interviewees saw social housing, rather than private rental, as the better option for ex-prisoners. Of necessity, they still worked at accessing private rental, but the challenges are formidable: for example, the scarcity of affordable properties, ex-prisoners' gaps in rental histories, and discrimination. For ex-prisoners with high support needs, some interviewees referred to the NDIS and the possibilities of SDA, but others worried about the risk of perpetuating congregate, institutional forms of accommodation. The social housing pathway was acknowledged to have challenges of its own, with a tendency for support services to drop away after a tenancy commences. However, our interviewees viewed social housing as optimal in terms of providing affordability, security (safety and permanence), and space for personal fulfilment and engagement with support. 


\section{Pathways after prison: what does the linked administrative data tell us?}

- CITS analysis of linked administrative data shows that receiving public housing significantly reduces ex-prisoners' interactions with the criminal justice system.

- After ex-prisoners commence a public housing tenancy, there are significant downward trends across a range of measures.

- Police incidents: down 8.9 per cent per year.

- Court appearances: down 7.6 per cent per year.

- Proven offences: down 7.6 per cent per year.

- Time in custody: down 11.2 per cent per year.

- Time on supervised orders: following an initial increase, down 7.8 per cent per year.

- Justice costs per person: following an initial decrease of $\$ 4,996$, down a further $\$ 2,040$ per year per person.

- Women, Indigenous people and people with multiple diagnoses demonstrate, for most measures, similar improvements to people outside those subgroups. Age is associated with a small additional improvement for most measures.

- In dollar terms, a public housing tenancy for an ex-prisoner generates a net benefit of between $\$ 5,200$ and $\$ 35,000$ after five years.

- Were public housing provided sooner following exit from prison, the benefits to the individual and society would also be expected to occur sooner, with even greater cumulative cost savings over time. 
This chapter uses linked administrative data for a cohort of people who have been in prison in NSW to investigate how interactions (contacts) with the criminal justice system, and the associated costs, differ for people who receive public housing after exiting prison, compared with similar people who do not receive public housing.

The first section describes our source of data - the MHDCD Databank — and how we derived the sample for analysis. The second section describes the two groups in the sample. In the third section, we present the results of our CITS analysis, showing the effects of a public housing tenancy on a range of criminal justice outcomes -noting also variations by sex, Indigenous status and complexity (based on diagnoses). We use those results in the fourth section, as the basis of a cost-benefit analysis of public housing assistance, relative to other forms of assistance.

\subsection{Linked administrative data: the MHDCD Databank}

The MHDCD Databank (the Databank) contains linked administrative data for a cohort of 2,731 people who have been imprisoned in NSW. The cohort was drawn from the Inmate Health Survey 2001, the Survey of Reception Prisoners 2001 and the Corrective Services State-wide Disability Service Database (up to 2008). Most of the cohort have a diagnosed mental health disorder or cognitive disability. Many have had numerous contacts, before and after their imprisonment, with other state government agencies, and state-funded non-government agencies, including housing assistance providers.

The date ranges of available data vary between the different agencies providing the data. In this research, we draw on data provided to the Databank by the BOCSAR, NSW Police, NSW Corrective Services, and DCJ and its predecessor, the Department of Family and Community Services (FACS). The DCJ/FACS Databank includes data about public housing and other housing assistance. The key datasets and respective date ranges are summarised in Table 4, below.

Table 4: MHDCD datasets and date ranges

\begin{tabular}{|c|c|c|c|}
\hline Dataset & Variable & First date & Last date \\
\hline Finalised court appearances (BOCSAR) & Offence date & January 1994 & December 2016 \\
\hline Police events (NSW Police) & Incident start date & January 1988 & December 2008 \\
\hline Custody episode (NSW Corrective Services) & Custody start date & January 1988 & December 2018 \\
\hline Community orders (NSW Corrective Services) & Community order start date & January 1994 & December 2018 \\
\hline Public housing tenancy (DCJ/FACS) & Public housing start date & March 1988 & March 2008 \\
\hline
\end{tabular}

Source: The authors, drawing on MHDCD data (2020).

A search of the Databank found 1,499 people in the cohort (55\%) received a form of housing assistance. The two main forms of assistance were: public housing, received by 761 people (28\%); and 'rent assistance'-e.g. state grants or loans to pay bonds and rents in the private rental sector ${ }^{5}$ - which was the sole form of assistance received by 640 people (23\%). Small numbers of people received other forms of assistance: specifically CJP (155 people [4\%], including 42 who also received public housing); and transitional accommodation in a COSP or NGO facility (25 people [1\%]). We were not able to identify whether a person received community housing, so it may be that a small number of people in the 'rental assistance only' group were in fact assisted with a community housing tenancy.

5 This does not include Commonwealth Rent Assistance, receipt of which is not recorded in the MHDCD Dataset. 
The analysis presented in this chapter compares the group who received public housing with the group who received rental assistance only ('the comparison group'). The groups are comparable because both satisfy the social housing eligibility criteria. However, people in the public housing group may have additional factors in order to be allocated a public housing tenancy (e.g. to satisfy priority housing criteria). The analysis shows that there are, in fact, some differences between the groups regarding criminal justice outcomes prior to the public housing intervention, but these are not significant enough to make the cohorts incomparable. The descriptive statistics, below, also support comparability of the groups.

To allow at least 12 months to observe any effects of a public housing tenancy following exit from prison, the analysis is restricted to people whose first prison exit was before March 2007. For the purposes of the comparison, we removed from the public housing group the small number of individuals recorded as receiving CJP, and those who had received public housing prior to their imprisonment only. From both groups we removed people with serious data anomalies (e.g. observations after death). The final sample for analysis comprises 623 people who received public housing after exiting prison and 612 people who received rental assistance only.

\subsection{Descriptive statistics}

This section describes some characteristics of the two groups in the sample.

The MHDCD Databank, compiled from various administrative datasets, includes individuals with the following known diagnoses.

- Alcohol or other drug problems (AOD)

- Borderline intellectual disability (BID)

- Intellectual disability (ID)

- Mental health disorders (MH)

From this diagnostic data, the following complexity groups were derived.

- No diagnosis (0)

- Single diagnosis (1)

- Dual diagnoses (2)

- Multiple (three or more) diagnoses (3)

The proportions of people with each level of complexity are shown in Table 5, along with other characteristics of the public housing and comparison groups. 
Table 5: Characteristics of the public housing and comparison groups

\begin{tabular}{lll}
\hline Characteristic & $\begin{array}{l}\text { Public housing group } \\
(n=623)\end{array}$ & $\begin{array}{l}\text { Comparison group } \\
(n=612)\end{array}$ \\
\hline Male/Female & $80 \% / 20 \%$ & $88 \% / 12 \%$ \\
\hline Aboriginal or Torres Strait Islander & $26 \%$ & $23 \%$ \\
\hline In out-of-home care as a child & $11 \%$ & $11 \%$ \\
\hline No diagnosis & $4 \%$ & $3 \%$ \\
\hline Single diagnosis & $22 \%$ & $23 \%$ \\
\hline Dual diagnoses & $51 \%$ & $47 \%$ \\
\hline Multiple diagnoses & $23 \%$ & $27 \%$ \\
\hline Age at first custody end date & $\begin{array}{l}\text { Median 23, mean 26 } \\
(\text { sd 7.9) }\end{array}$ & Median 22, mean 25 \\
(sd 7.8)
\end{tabular}

Note: $s d=$ standard deviation. Index tenancy year = the year that post-prison public housing first commenced. Source: The authors, drawing on MHDCD data (2020).

Individuals in the public housing group are more likely to be female (20\% cf. $12 \%$ ) and slightly more likely to be Aboriginal or Torres Strait Islander (26\% cf. 23\%) than those in the comparison group. In both groups, 11 per cent were in out-of-home care in childhood. The average age at first custody end date is similar (26 cf. 25 years). In both groups, 74 per cent have two or more diagnoses, with the public housing group slightly more likely to have dual diagnoses and slightly less likely to have multiple diagnoses than the comparison group. The characteristics that differ between the public housing and comparison groups are controlled for in the regression modelling.

For the group who received public housing after exiting prison, the median year of commencement of post-prison public housing is 2003. On average, this group received public housing five years after their first prison exit.

\subsection{Comparative interrupted time series (CITS) analysis}

Statistical models are used to estimate the impact of receiving public housing after prison on criminal justice outcomes. The methodology used is CITS analysis, which is an extension of 'difference-in-difference' analysis. Typical difference-in-difference analysis compares differences between an intervention group and comparison group before and after an intervention, assuming a common underlying time trend. CITS analysis is a more rigorous approach, which includes multiple time points to control for differences in underlying trends between the intervention and comparison groups (e.g. Lopez Bernal, Cummins et al. 2018; Jacob, Somers et al. 2016).

In the present analysis, the intervention point is the date at which public housing first commenced, at any time after the first exit from prison. The inclusion of a comparison group ('rental assistance only') helps to control for any changes over time that would still have occurred in the absence of public housing.

For each person in the cohort, the data was shaped into a panel representing 31 annual time periods from January 1988 to December 2018. For those who received public housing, an intervention date was flagged, being the first observed 'public housing start date' following exit from prison. The year of the intervention was split into two periods: the time before and the time after the intervention. For each period, the models adjust for the number of days 'available', if the year is not fully observed (e.g. due to the person turning 18 or dying during a year, which has been divided into days pre-and post-intervention). For non-custody outcomes, the models also adjust for days in custody, as this reduces the time available to offend. 
Models were run for various criminal justice outcomes, including: police incidents, time in custody, time on a supervised order, court appearances, and proven offences. Each analysis was restricted to the duration of the dataset, which varies as shown in Table 4. Random effects models were used, which take into consideration the panel nature of the data (i.e. repeated observations for the same individuals over time). The models control for age (centred at the average age at first prison exit), sex, Indigenous status, and complexity (based on diagnoses). As well as simply controlling for these characteristics, models with interactions were also run to evaluate whether the impact of public housing differs for subpopulations.

Finally, unit costs were allocated per event and used to estimate an overall costs model, estimating the savings to the justice system as a result of providing public housing to ex-prisoners. The predicted cost savings take into account the cost of providing public housing, relative to the alternative cost of providing rental assistance and/or homelessness services, to provide the estimated net benefit of public housing for ex-prisoners.

Each model and the results are discussed under the subheadings below.

\subsubsection{Police incidents}

Police incidents data is available in the MHDCD Databank from 1988 to 2008. Regression modelling compares the number of police incidents per annum over time, before and after public housing, relative to the comparison group. Because the data comprises counts of incidents, a negative binomial random effects regression model was used, which is appropriate for overdisbursed count data. ${ }^{6}$ The model includes an adjustment for exposure, which is the time available each year. ${ }^{7}$ The results of the model are presented in Table 6, below, as incidence rate ratios (IRRs).

Table 6: Police incidents regression output

\begin{tabular}{lcccccc}
\hline Police incidents & IRR & Std err. & z-score & p>z & {$[95 \%$ Conf. interval] } \\
\hline $\begin{array}{l}\text { Public housing group intercept } \\
\text { (cf. comparison group) }\end{array}$ & 0.863 & 0.040 & -3.160 & 0.002 & 0.787 & 0.945 \\
\hline Comparison group time trend & 1.055 & 0.002 & 25.850 & 0.000 & 1.050 & 1.059 \\
\hline $\begin{array}{l}\text { Public housing group time trend } \\
\text { (cf. comparison group) }\end{array}$ & 1.037 & 0.004 & 10.440 & 0.000 & 1.030 & 1.044 \\
\hline Post-public housing shift & 0.994 & 0.035 & -0.160 & 0.870 & 0.927 & 1.066 \\
\hline Post-public housing trend change & 0.911 & 0.006 & -14.710 & 0.000 & 0.900 & 0.922 \\
\hline
\end{tabular}

Note: Adjusted for age, sex, Indigenous status and complexity, and exposure time. Sample size = 19,659 observations for 1,235 individuals. The average number of observations per person is 16 (ranging from 2 to 22).

Source: The authors, drawing on MHDCD data (2020).

The IRRs show the rate of police incidents compared to (cf.) the reference case. A p-value of $<0.05$ indicates statistical significance. At the start of the observation period, the group who will receive public housing have 0.863 times as many police incidents (or 13.7\% fewer) per annum than the comparison group. Over time, the rate of incidents increases by 5.5 per cent per annum for the comparison group and by an additional 3.7 per cent for the group who will receive public housing. The 'post-public housing shift' is not statistically significant, in that there is no immediate change in incidents following the intervention, but there is a decrease in the trend over time of 8.9 per cent $(1$ - 0.911). This means public housing decreases the number of police incidents over time by 8.9 per cent every year after the intervention.

6 Overdispersion is where the conditional variance exceeds the conditional mean.

7 For example, people who turn 18 or die in a particular year, or who are in custody for part of the year, are not 'available' for the entire year. 
Figures 13 and 14, below, illustrate the average predicted number of police incidents over time for the comparison group and public housing group, respectively. Because the commencement of public housing occurs in different years, the predictions for the public housing group are graphed over the number of years before and after housing, where 0 represents the year that post-prison public housing first commenced. Time periods where there are fewer than 10 observations are excluded from the graphs. The graphs show that police incidents initially increase over time for both groups, with a slightly higher rate of increase for the group who will receive public housing. The higher 'pre-public housing' incident rate for the public housing group indicates that public housing allocations tend to go to people more at risk of offending. Following public housing, there is a marked ongoing decrease in police incidents per annum - that is, public housing 'flattens the curve'.

Figure 13: Average predicted number of police incidents per annum, for people with rental assistance only following exit from prison

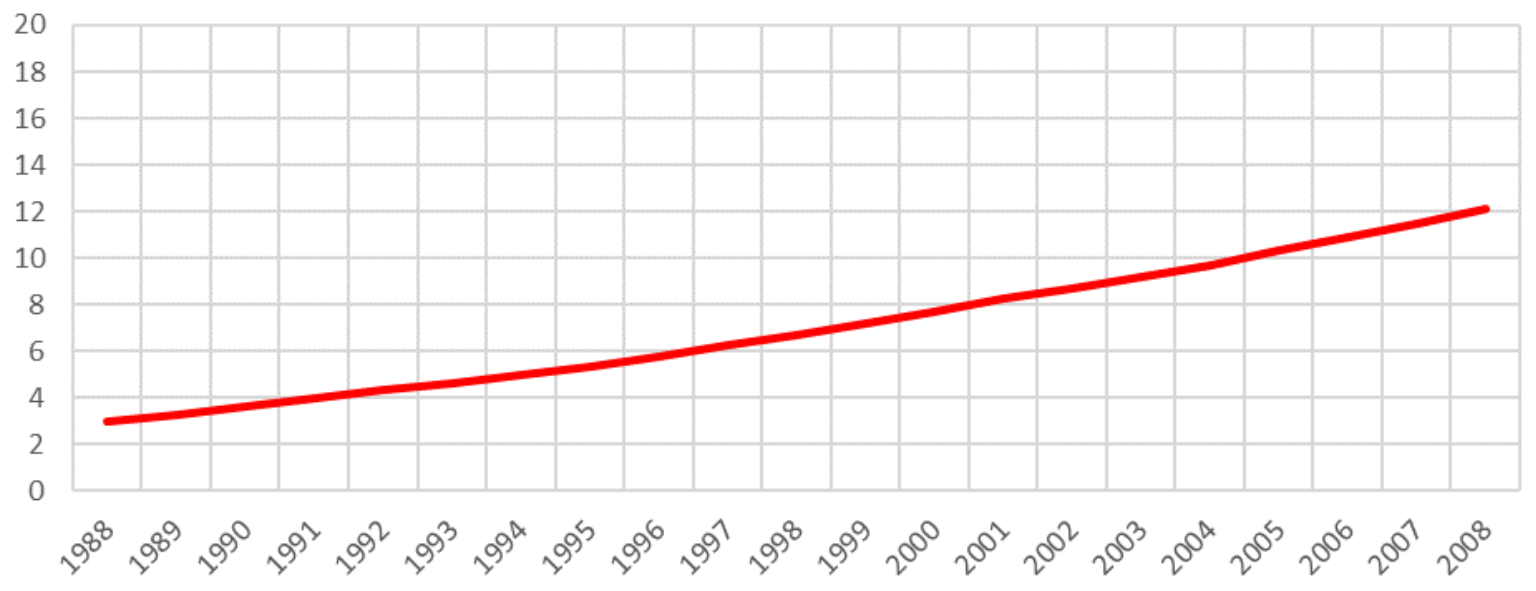

Source: The authors, drawing on MHDCD data (2020).

Figure 14: Average predicted number of police incidents per annum, before and after first receiving public housing following exit from prison

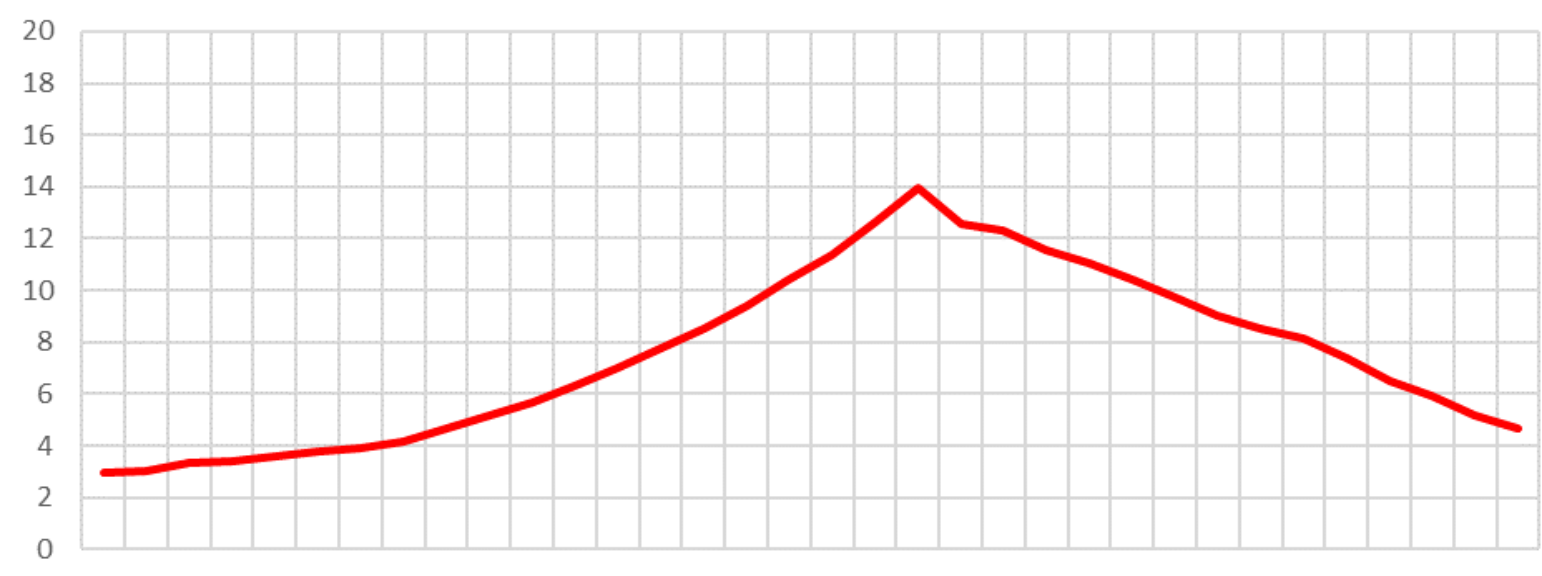

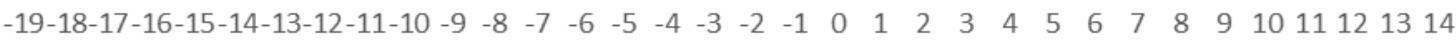

Note: Public housing received at year 0 .

Source: The authors, drawing on MHDCD data (2020).

\section{Subgroup analyses}

The model was repeated with interactions (one characteristic at a time) to investigate whether the impact of receiving public housing differs for different subgroups. 
For female ex-prisoners, the decrease in police incidents over time is not as great as for men. For men, the decrease is 9.8 per cent per year, while for women it is 6.8 per cent.

- For Indigenous ex-prisoners, who start with a higher number of incidents, the decrease in police incidents over time is not as great as for non-Indigenous people. For non-Indigenous people, the decrease is 10.0 per cent per year, while for Indigenous people it is 6.7 per cent.

- There is a very small downward shift in incidents (0.1\%) after receiving public housing for each additional year of age (based on age at first prison exit).

- No difference was found in the rate of decrease in incidents over time based on the level of complexity (i.e. diagnosis group 0, 1, 2 or 3).

\subsubsection{Court appearances}

Data on finalised court appearances, from BOCSAR, are available in the MHDCD Databank from 1994 to 2017. Because the offence date precedes the finalised court date, the time used for this analysis is based on the date of offence. The data are restricted to offence dates from 1994 to 2016, as offences in 2017 are not fully observed, given the lag between offending and finalised appearance. To ensure that everyone in the intervention group has both pre- and post-public housing observations, people who received post-prison public housing before 1994 are excluded from the analysis.

Three models were run comparing court appearances per annum over time for offences before and after post-prison public housing, relative to the comparison group. The first model is the number of finalised court appearances per annum; the second model is the number of proven appearances (where at least one offence was proven guilty); and the third model is the number of proven offences (as opposed to appearances). Because the data are counts, negative binomial random effects regression models were used, including an adjustment for exposure time (time available to offend).

Finalised court appearances

The results of the model of finalised court appearances over time are presented in Table 7, below, as IRRs.

Table 7: Finalised court appearances regression output

\begin{tabular}{|c|c|c|c|c|c|c|}
\hline Finalised appearances & IRR & Std err. & z-score & $p>z$ & \multicolumn{2}{|c|}{ [95\% Conf. interval] } \\
\hline $\begin{array}{l}\text { Public housing group intercept } \\
\text { (cf. comparison group) }\end{array}$ & 0.511 & 0.040 & -8.690 & 0.000 & 0.439 & 0.594 \\
\hline Comparison group time trend & 0.942 & 0.002 & -28.790 & 0.000 & 0.939 & 0.946 \\
\hline $\begin{array}{l}\text { Public housing group time trend } \\
\text { (cf. comparison group) }\end{array}$ & 1.063 & 0.006 & 10.970 & 0.000 & 1.051 & 1.074 \\
\hline Post-public housing shift & 0.950 & 0.039 & -1.240 & 0.214 & 0.875 & 1.030 \\
\hline Post-public housing trend change & 0.924 & 0.006 & -12.570 & 0.000 & 0.913 & 0.936 \\
\hline
\end{tabular}

Note: Adjusted for age, sex, Indigenous status and complexity, and exposure time. Sample size $=24,867$ observations for 1,230 individuals The average number of observations per person is 20 (ranging from 3 to 24).

Source: The authors, drawing on MHDCD data (2020). 
The IRRs in Table 7 show the rate of finalised court appearances compared to (cf.) the reference case. A p-value of $<0.05$ indicates statistical significance. At the start of the observation period, ${ }^{8}$ the public housing group have 0.737 times as many court appearances (or $24.3 \%$ fewer) per annum than the comparison group. Over time, the rate of incidents decreases by $5.8 \%$ per annum for the comparison group (1 - 0.942) but increases very slightly for the group who received public housing $(0.942 \times 1.063=1.001$, an increase of $0.1 \%)$. The 'post-public housing shift' is not statistically significant, indicating no immediate change in court appearances following the intervention. However, there is a decrease in the trend over time of 7.6\% (1 - 0.924), meaning that receiving public housing decreases the number of court appearances over time by $7.6 \%$ every year after the intervention.

Figure 15 and Figure 16, below, illustrate the average predicted number of finalised court appearances over time for the comparison group and public housing group, respectively. As previously, the predictions for the public housing group are graphed over the number of years before and after housing, where 0 represents the year that post-prison public housing first commenced. The graphs illustrate finalised court appearances steadily decreasing over time for the comparison group, and initially increasing slightly for the group who will receive public housing. Following receipt of public housing, there is a decrease in finalised court appearances per annum.

Figure 15: Average predicted number of finalised court appearances per annum, for people with rental assistance only following exit from prison

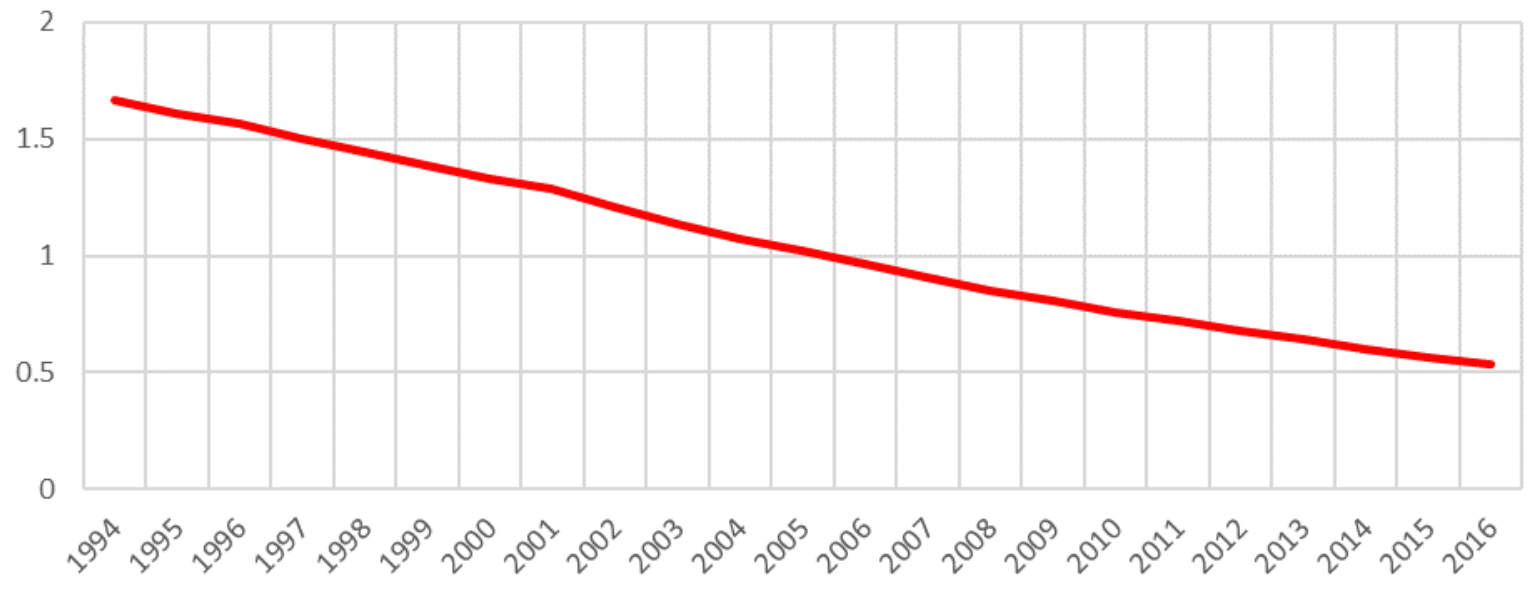

Source: The authors, drawing on MHDCD data (2020).

8 Time = 1 in 1988 and we begin to observe court appearances in 1994. IRR of predicted court appearances for the public housing group, relative to the comparison group, at the start of 1994 would be $0.511 \times 1.0636=0.737$. 
Figure 16: Average predicted number of finalised court appearances per annum, before and after receiving public housing following exit from prison

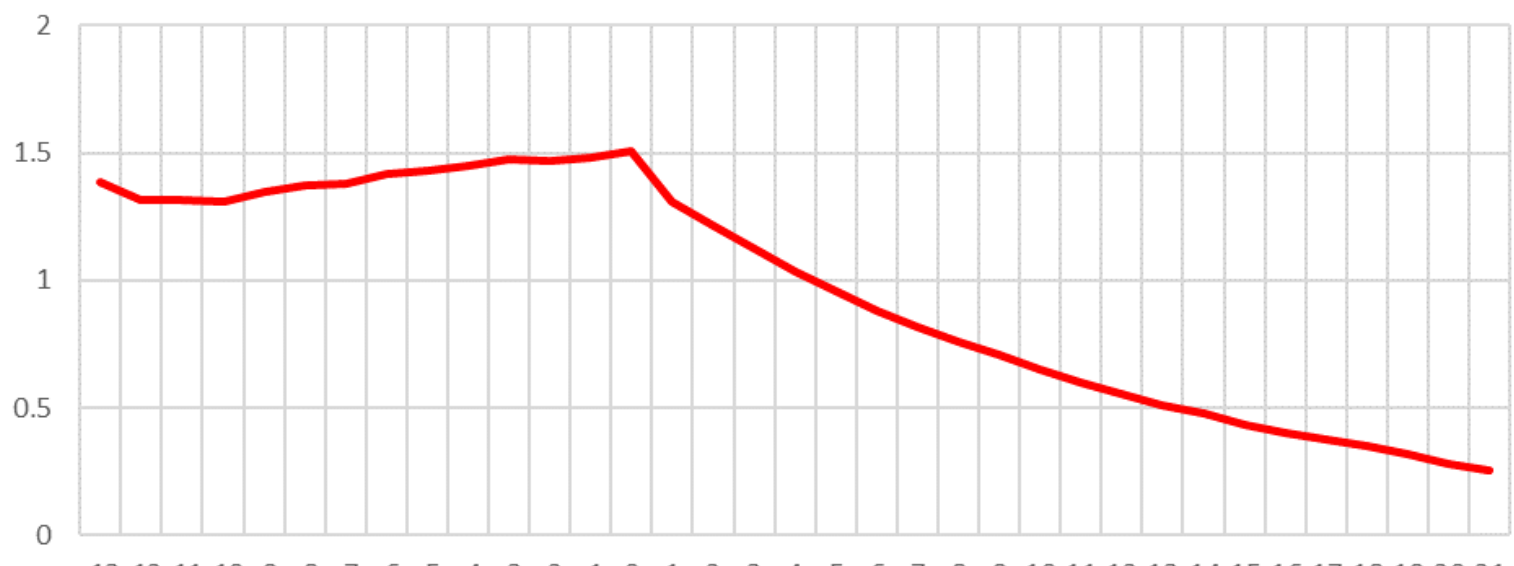

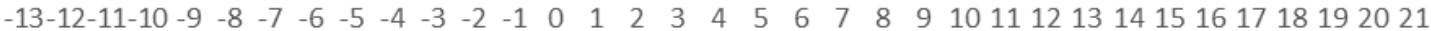

Note: Public housing received at year 0 .

Source: The authors, drawing on MHDCD data (2020).

\section{Proven court appearances}

The results of the model of proven court appearances over time are presented in Table 8, below, as IRRs.

Table 8: Proven court appearances regression output

\begin{tabular}{|c|c|c|c|c|c|c|}
\hline Proven court appearances & IRR & Std err. & z-score & $p>z$ & \multicolumn{2}{|c|}{ [95\% Conf. interval] } \\
\hline $\begin{array}{l}\text { Public housing group intercept } \\
\text { (cf. comparison group) }\end{array}$ & 0.509 & 0.041 & -8.430 & 0.000 & 0.435 & 0.595 \\
\hline Comparison group time trend & 0.942 & 0.002 & -28.150 & 0.000 & 0.938 & 0.946 \\
\hline $\begin{array}{l}\text { Public housing group time trend } \\
\text { (cf. comparison group) }\end{array}$ & 1.062 & 0.006 & 10.510 & 0.000 & 1.050 & 1.074 \\
\hline Post-public housing shift & 0.917 & 0.040 & -1.980 & 0.047 & 0.843 & 0.999 \\
\hline Post-public housing trend change & 0.926 & 0.006 & -11.770 & 0.000 & 0.914 & 0.938 \\
\hline
\end{tabular}

Note: Adjusted for age, sex, Indigenous status and complexity, and exposure time. Sample size $=24,867$ observations for 1,230 individuals. The average number of observations per person is 20 (ranging from 3 to 24).

Source: The authors, drawing on MHDCD data (2020).

The regression results for proven court appearances are similar to, but slightly stronger than, the results for finalised court appearances. Again, the group who will receive public housing start with fewer proven appearances than the comparison group. However, the comparison group's proven appearances decrease over time by 5.8 per cent per annum, while for the group who will receive public housing proven appearances are fairly stable $(0.942 \times 1.062=1.0004)$. Following receipt of public housing, there is an initial decrease in proven appearances of 8.3 per cent (1 - 0.917) and a decrease in the trend over time of 7.4 per cent per annum (1 - 0.926).

Figure 17 and Figure 18, below, illustrate the average predicted number of proven court appearances over time for people in the comparison group and public housing group, respectively. The graphs illustrate that predicted proven court appearances steadily decrease over time for the comparison group and initially increase slightly for the group who will receive public housing. Following public housing, there is an immediate decrease and a downward trend in predicted proven court appearances per annum. 
Figure 17: Average predicted number of proven court appearances per annum, for people with rental assistance only following exit from prison

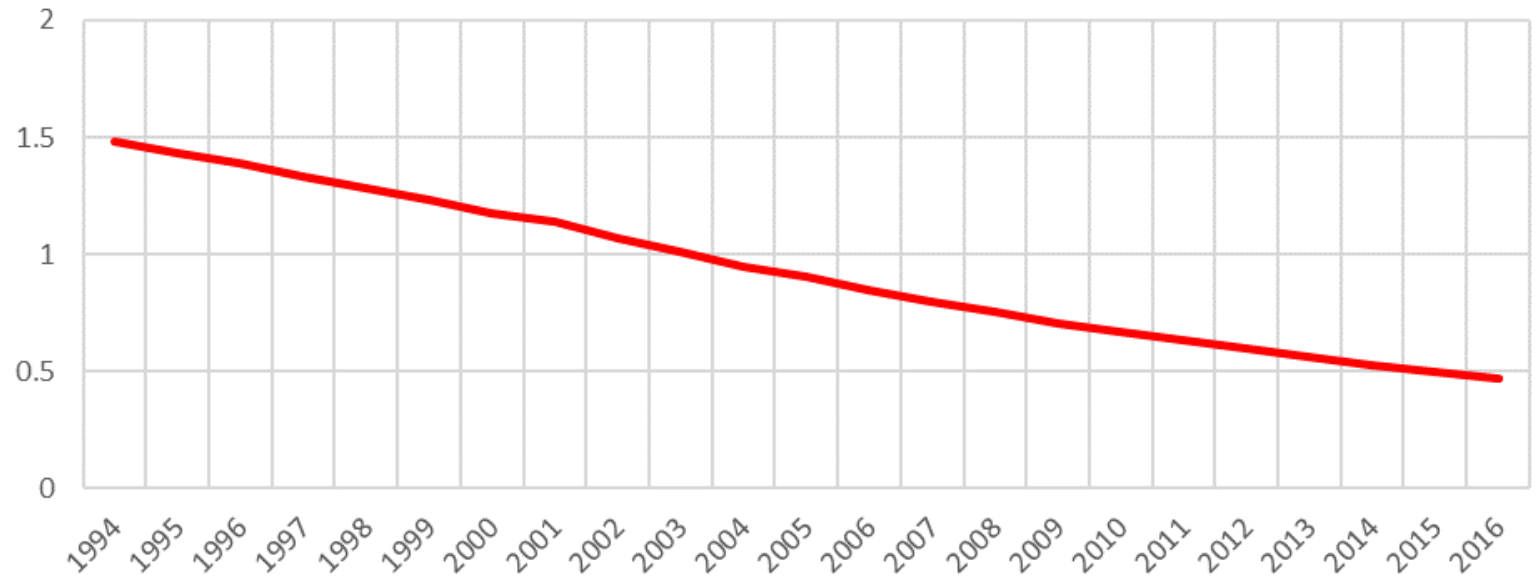

Source: The authors, drawing on MHDCD data (2020).

Figure 18: Average predicted number of proven court appearances per annum, before and after receiving public housing following exit from prison

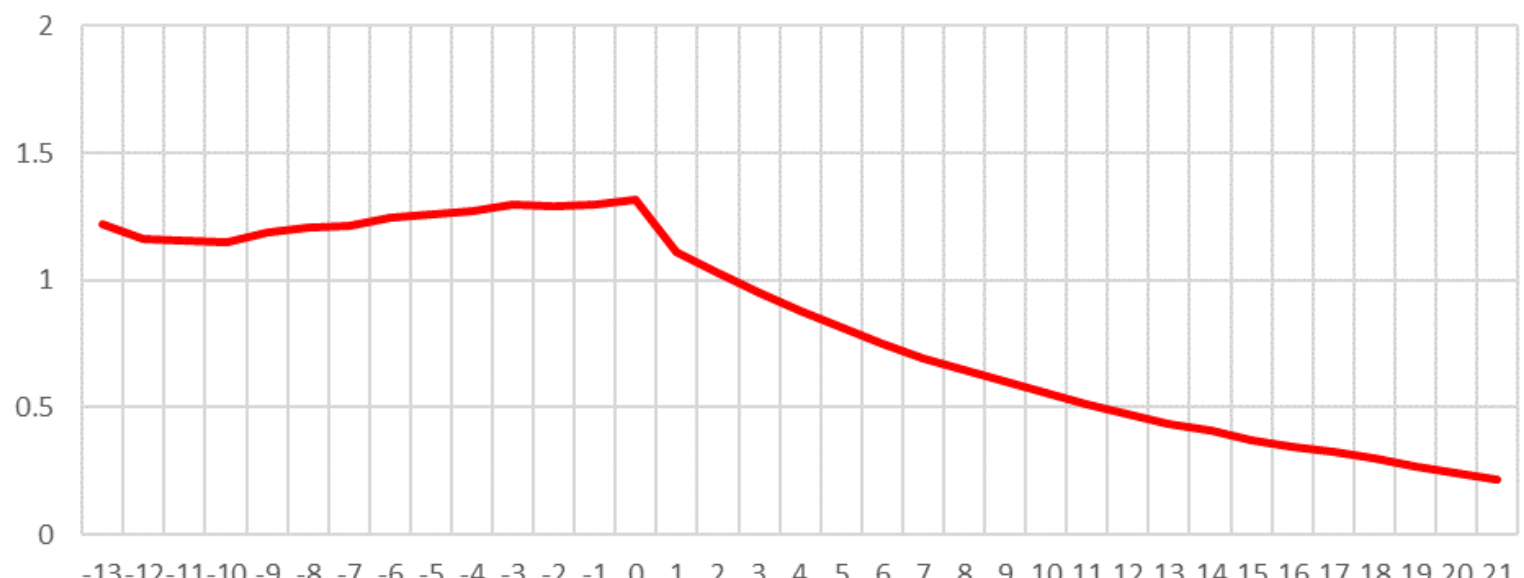

Note: Public housing received at year 0 .

Source: The authors, drawing on MHDCD data (2020).

\section{Proven offences}

The results of the model of the number of proven offences over time are presented in Table 9, below, as IRRs. The number of proven offences is, on average, greater than the number of proven court appearances because multiple offences can be heard in one court case. 
Table 9: Proven offences regression output

\begin{tabular}{lccccccc}
\hline Proven offences & IRR & Std err. & z-score & p>z & & [95\% Conf. interval] \\
\hline $\begin{array}{l}\text { Public housing group intercept } \\
\text { (cf. comparison group) }\end{array}$ & 0.532 & 0.039 & -8.610 & 0.000 & 0.460 & 0.614 \\
\hline Comparison group time trend & 0.941 & 0.002 & -28.770 & 0.000 & 0.938 & 0.945 \\
\hline $\begin{array}{l}\text { Public housing group time trend } \\
\text { (cf. comparison group) }\end{array}$ & 1.059 & 0.006 & 10.630 & 0.000 & 1.048 & 1.070 \\
\hline $\begin{array}{l}\text { Post-public housing shift } \\
\text { Post-public housing trend change }\end{array}$ & 0.959 & 0.042 & -0.970 & 0.334 & 0.880 & 1.044 \\
\hline
\end{tabular}

Note: Adjusted for age, sex, Indigenous status and complexity, and exposure time. Sample size =24,867 observations for 1,230 individuals. The average number of observations per person is 20 (ranging from 3 to 24).

Source: The authors, drawing on MHDCD data (2020).

Similar to the models for court appearances, the regression model for proven offences shows that the group who will receive public housing starts with fewer offences than the comparison group. However, for the comparison group, offences decrease over time by 5.9 per cent per annum (1 - 0.941), while the group who will receive public housing initially has relatively stable number of offences per annum $(0.941 \times 1.059=0.997$, a decrease of less than 1\%). The 'post-public housing shift' is not statistically significant, with no immediate change in proven offences following the intervention. However, there is a decrease in the trend over time of 7.6 per cent (1 - 0.924), indicating that public housing decreases offending over time by 7.6 per cent every year after the intervention.

Figure 19 and Figure 20 below illustrate the average predicted number of proven offences over time for people in the comparison group and public housing group, respectively. The graphs illustrate a steady decrease in number of offences per annum for the comparison group, and an average of around 3.3 proven offences per year initially for the group who will receive public housing. Following public housing, there is a downward trend in the number of proven offences per annum.

Figure 19: Average predicted number of proven offences per annum, for people with rental assistance only following exit from prison

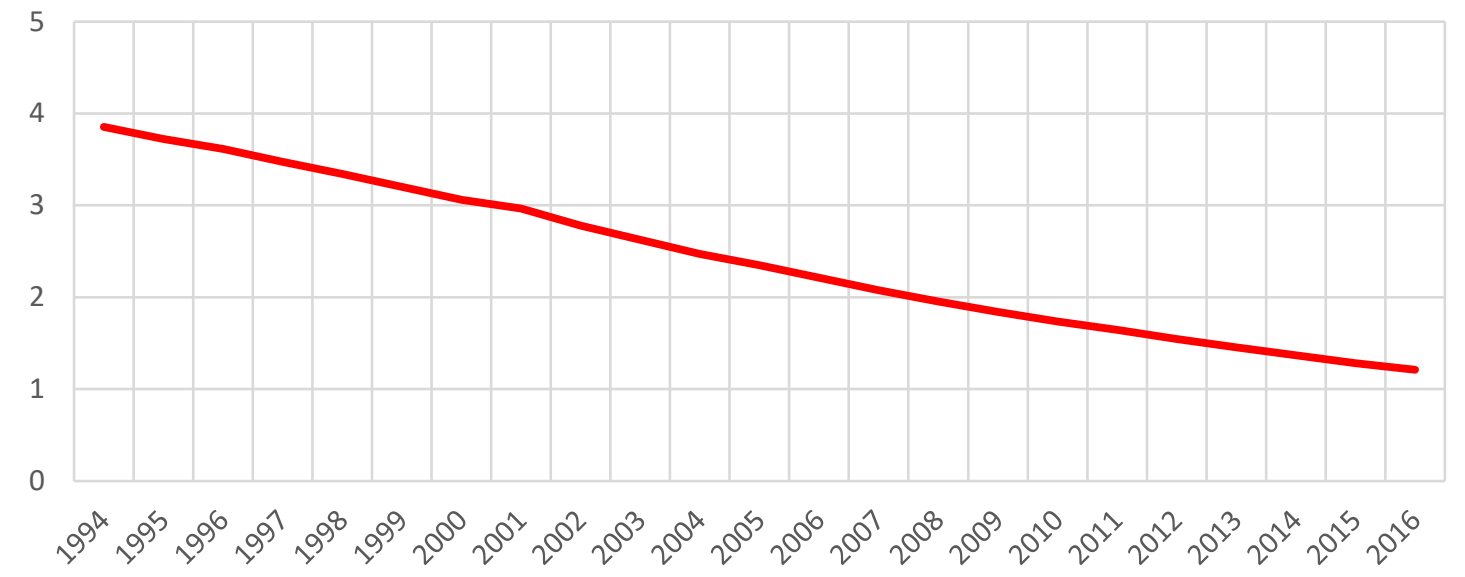

Source: The authors, drawing on MHDCD data (2020). 
Figure 20: Average predicted number of proven offences per annum, before and after receiving public housing following exit from prison

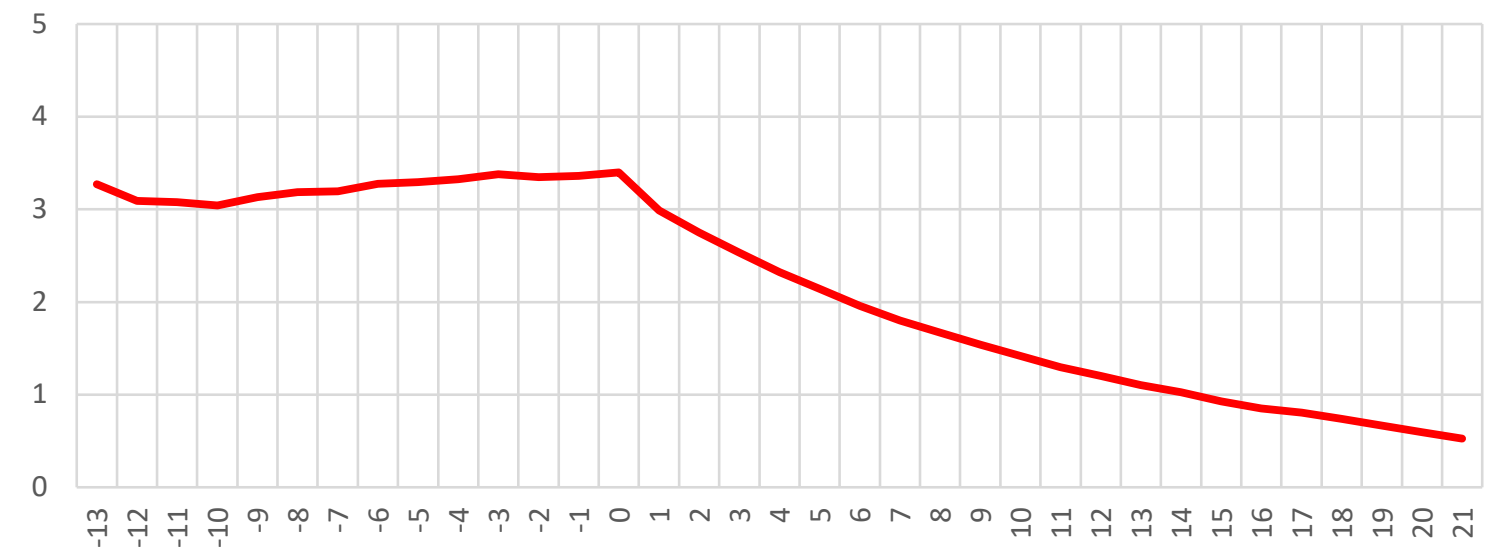

Note: Public housing received at year 0 .

Source: The authors, drawing on MHDCD data (2020).

\section{Subgroup analyses}

The three court models—-finalised court appearances, proven court appearances and proven offences-were repeated with interactions (one characteristic at a time) to investigate whether the impact of receiving public housing after exiting prison differs for different subgroups.

- For female ex-prisoners, there are initial downward shifts in finalised court appearances and proven appearances of 21 and 22 per cent, respectively, after public housing. For men, there is no immediately significant shift, but the trends over time in each of the court outcomes decrease at a greater rate (a 4-5\% additional decrease per annum) for men than women.

- No significant differences were found in the rate of decrease in post-public housing court outcomes between Indigenous and non-Indigenous ex-prisoners.

- There is a very small, but statistically significant, additional decrease in trend after public housing of less than 0.5 per cent per additional year of age at first prison exit.

- The impact of public housing on court outcomes is smaller for people with multiple diagnoses than for those with no known mental health, cognitive or AOD diagnosis. The post-public housing trend in finalised court appearances over time decreases by around 16 per cent per year for people with none of these diagnoses, and by around 7 per cent for people with one or more diagnoses. For proven court appearances and proven offences, the decrease in post-public housing trends does not differ significantly by level of complexity. However, for people with multiple diagnoses (group 3), the number of proven court appearances and proven offences initially doubles after receiving public housing, before decreasing over time.

\subsubsection{Time in custody}

The MHDCD Databank contains custody data from 1988 to 2018. Because custody episodes can span more than one year, the number of days in custody each calendar year were calculated. A negative binomial random effects regression model was run of the number of days in custody per annum, before and after receiving public housing, relative to the comparison group. The model includes an adjustment for exposure, which is the time available each year. ${ }^{9}$ The results of the model are presented in Table 10, below, as IRRs.

9 For example, people who die in a particular year are not 'available' to be in custody the entire year. 
Table 10: Table 10: Days in custody regression output

\begin{tabular}{|c|c|c|c|c|c|c|}
\hline Days in custody & IRR & Std err. & z-score & $p>z$ & \multicolumn{2}{|c|}{ [95\% Conf. interval] } \\
\hline $\begin{array}{l}\text { Public housing group intercept } \\
\text { (cf. comparison group) }\end{array}$ & 0.598 & 0.030 & -10.410 & 0.000 & 0.543 & 0.659 \\
\hline Comparison group time trend & 0.965 & 0.002 & -22.050 & 0.000 & 0.962 & 0.968 \\
\hline $\begin{array}{l}\text { Public housing group time trend } \\
\text { (cf. comparison group) }\end{array}$ & 1.063 & 0.004 & 16.500 & 0.000 & 1.056 & 1.071 \\
\hline Post-public housing shift & 0.986 & 0.043 & -0.310 & 0.754 & 0.906 & 1.074 \\
\hline Post-public housing trend change & 0.888 & 0.004 & -23.570 & 0.000 & 0.880 & 0.897 \\
\hline
\end{tabular}

Note: Adjusted for age, sex, Indigenous status and complexity, and exposure time. Sample size = 32,205 observations for 1,235 individuals. The average number of observations per person is 26 (ranging from 6 to 32).

Source: The authors, drawing on MHDCD data (2020).

At the start of the observation period, the group who will receive public housing has 0.598 times as many days in custody (or $40.2 \%$ fewer) per annum than the comparison group. Over time, the number of days in custody decreases by 3.5 per cent ( 1 - 0.965) per annum for the comparison group, while increasing by 2.6 per cent (0.965 $x 1.063)$ for the group who will receive public housing. The 'post-public housing shift' is not statistically significant, indicating no immediate change in time spent in custody following the intervention. However, there is a decrease in the trend over time of 11.2 per cent $(1-0.888)$, meaning that public housing decreases the number of days in custody over time by 11.2 per cent every year after the intervention.

Figure 21 and Figure 22, below, illustrate the average predicted number of days in custody over time for people in the comparison group and public housing group, respectively. The graphs show that time in custody decreases over time for the comparison group, and initially increases for the group who will receive public housing. Following public housing, there is a downward trend in the number of days in custody per annum.

Figure 21: Average predicted number of days in custody per annum, for people with rental assistance only following exit from prison

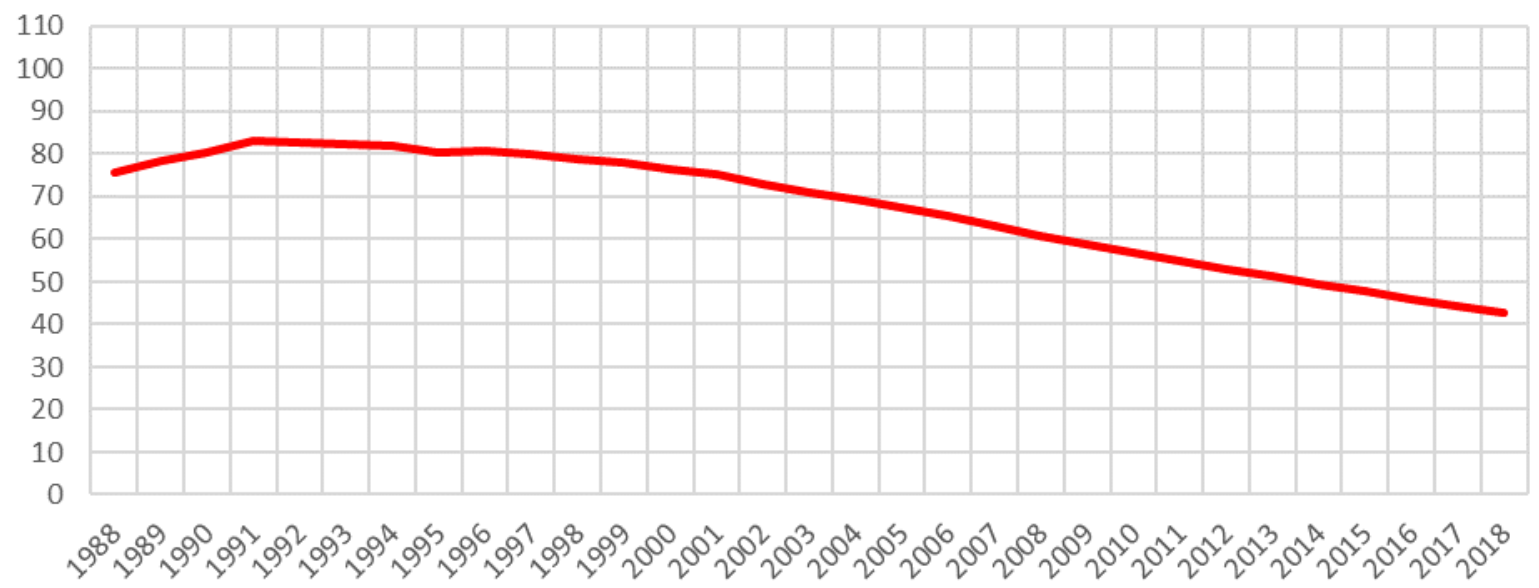

Source: The authors, drawing on MHDCD data (2020). 
Figure 22: Average predicted number of days in custody per annum, before and after receiving public housing following exit from prison

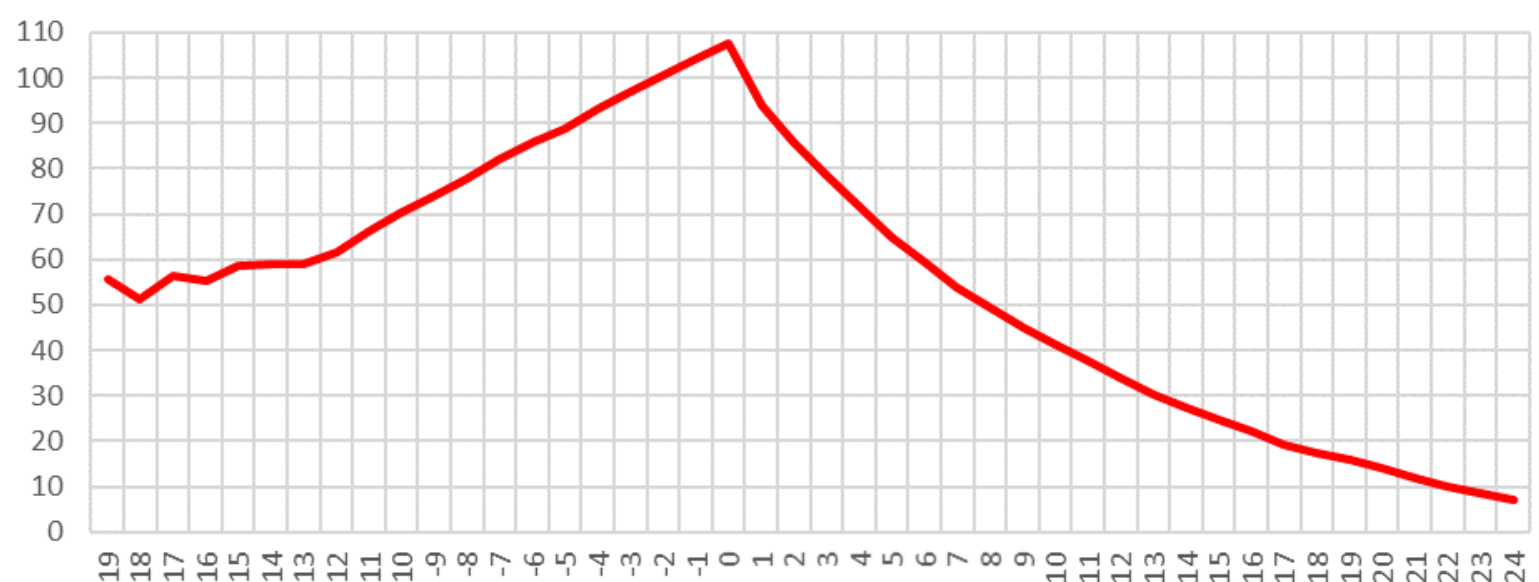

Note: Public housing received at year 0 .

Source: The authors, drawing on MHDCD data (2020).

\section{Subgroup analyses}

The model was repeated with interactions (one characteristic at a time) to investigate whether the impact of receiving public housing after exiting prison differs for different subgroups. The results below are based on these models.

- Females spend less time in custody than males, but there is no significant difference between men and women in the rate of decrease over time following receipt of public housing.

- Aboriginal and Torres Strait Islander people spend more time in custody than non-Indigenous people (24\% more days at the start of the observation period). The decreasing trend in custody days post-public housing does not differ significantly by Indigenous status. However, for Aboriginal and Torres Strait Islander ex-prisoners, the decrease in custody days is not evident until the second year after receiving public housing because of an upward shift immediately post-public housing, which cancels out the decreasing trend in the first year.

- Days in custody per annum are lower for older people- decreasing by 11 per cent for each additional year of age (based on age at first prison exit). There is a very small, but statistically significant, upward shift, followed by an additional decrease in trend, after receiving public housing of less than 1 per cent per additional year of age at first prison exit.

- At the start of the observation period, people with multiple diagnoses in the public housing group have more than double the number of days in custody than those with no known mental health, cognitive or AOD diagnosis, but they show a larger decreasing trend over time. This difference is not found in the comparison group, for whom complexity is not associated with differences in custody days. After receiving public housing, the trend in custody days over time decreases by nearly 20 per cent for people with no diagnosis (group 0), 11 per cent for those with one or two diagnoses (groups 1 and 2), and 10 per cent for those with multiple diagnoses (group 3). 


\subsubsection{Time on supervised community orders}

The MHDCD Databank contains supervised community orders data (including parole) from 1994 to 2018. As with custody episodes, community orders can span more than one year, so the number of days of community supervision each calendar year was calculated. A negative binomial pooled regression model was run of the number of days of community supervision per annum, before and after receiving public housing, relative to the comparison group..$^{10}$ The model includes an adjustment for exposure, which is the time available each year..$^{11}$ The results of the model are presented in Table 11, below, as IRRs.

Table 11: Days of community supervision regression output

\begin{tabular}{|c|c|c|c|c|c|c|}
\hline Days of community supervision & IRR & Std err. & z-score & $\mathrm{p}>\mathrm{z}$ & \multicolumn{2}{|c|}{ [95\% Conf. interval] } \\
\hline $\begin{array}{l}\text { Public housing group intercept } \\
\text { (cf. comparison group) }\end{array}$ & 0.547 & 0.092 & -3.600 & 0.000 & 0.394 & 0.760 \\
\hline Comparison group time trend & 0.967 & 0.004 & -7.730 & 0.000 & 0.959 & 0.975 \\
\hline $\begin{array}{l}\text { Public housing group time trend } \\
\text { (cf. comparison group) }\end{array}$ & 1.050 & 0.012 & 4.350 & 0.000 & 1.027 & 1.073 \\
\hline Post-public housing shift & 1.239 & 0.085 & 3.140 & 0.002 & 1.084 & 1.416 \\
\hline Post-public housing trend change & 0.922 & 0.012 & -6.320 & 0.000 & 0.899 & 0.945 \\
\hline
\end{tabular}

Note: Adjusted for age, sex, Indigenous status and complexity, and exposure time. Sample size =27,051 observations for 1,230 individuals. The average number of observations per person is 22 (ranging from 5 to 26).

Source: The authors, drawing on MHDCD data (2020).

At the start of the observation period, the group who will receive public housing has 0.733 times as many days of community supervision (or $26.7 \%$ fewer) per annum than the comparison group. ${ }^{12}$ Over time, the number of days of community supervision decreases by 3.3 per cent (1 - 0.967) per annum for the comparison group, while increasing by 1.5 per cent $(0.967 \times 1.050)$ for the group who will receive public housing. Following receipt of public housing, there is an initial increase in days of community supervision, of 23.9 per cent. However, there is a decrease in the trend over time of 7.8 per cent (1 - 0.922), indicating that public housing eventually decreases the number of days in community supervision over time by 7.8 per cent every year.

Figure 23 and Figure 24, below, illustrate the average predicted number of days of community supervision over time for people in the comparison group and public housing group, respectively. For the group who will receive public housing, supervision days are initially lower, and increase over time, while for the comparison group, supervision days start higher but decrease over time. Following receipt of public housing, there is an initial increase, followed by a downward trend, in days of community supervision per annum.

10 A random effects model was run initially but had convergence problems. Switching between Newton-Raphson (NR) and DavidonFletcher-Powell (DFP) algorithms achieved convergence. However, the likelihood ratio (LR) test found no significant difference compared with the pooled model $(p=0.471)$. Therefore, the final model is a pooled negative binomial regression with clustered variances.

11 For example, people who die in a particular year or who are in custody for part of the year are not 'available' to be on a community order for the entire year.

12 Time = 1 in 1988 and we begin to observe community orders in 1994. IRR of predicted days of community supervision for the public housing group, relative to the comparison group, at the start of 1994 would be $0.547 \times 1.0506=0.733$. 
Figure 23: Average predicted days on supervised community order per annum, for people with rental assistance only following exit from prison

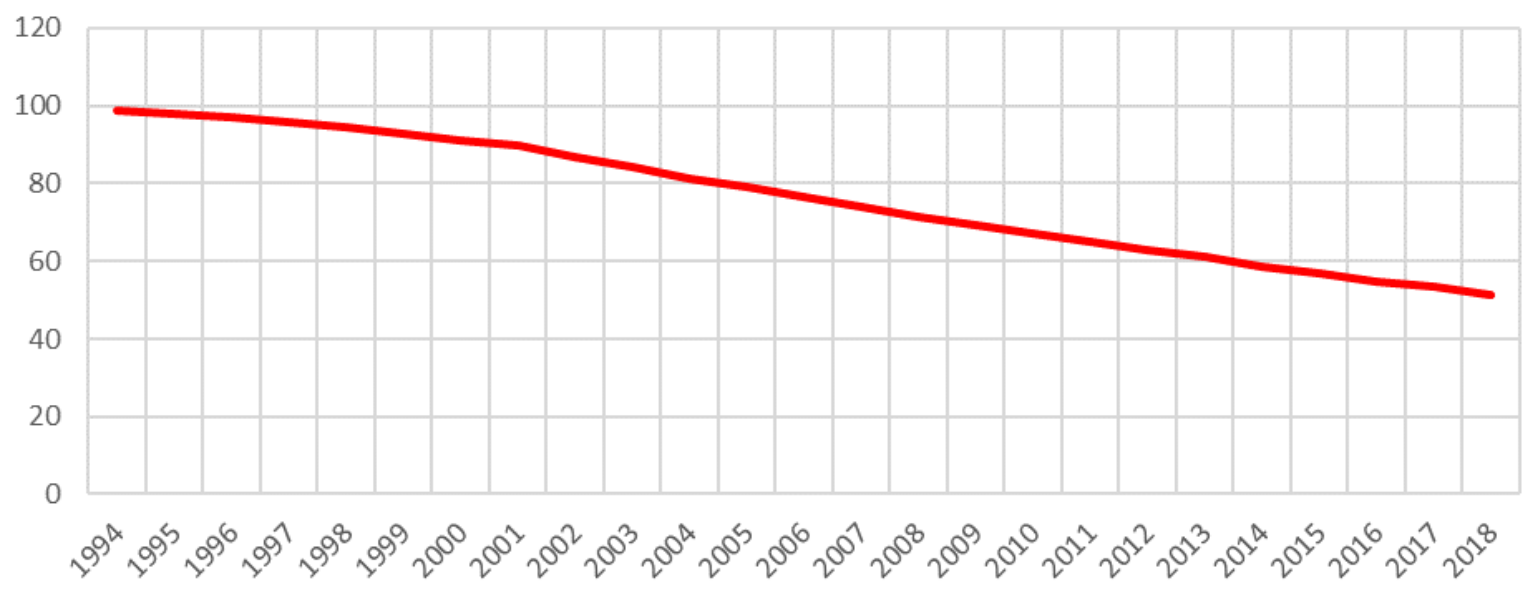

Source: The authors, drawing on MHDCD data (2020).

Figure 24: Average predicted days on supervised community order per annum, before and after receiving public housing following exit from prison

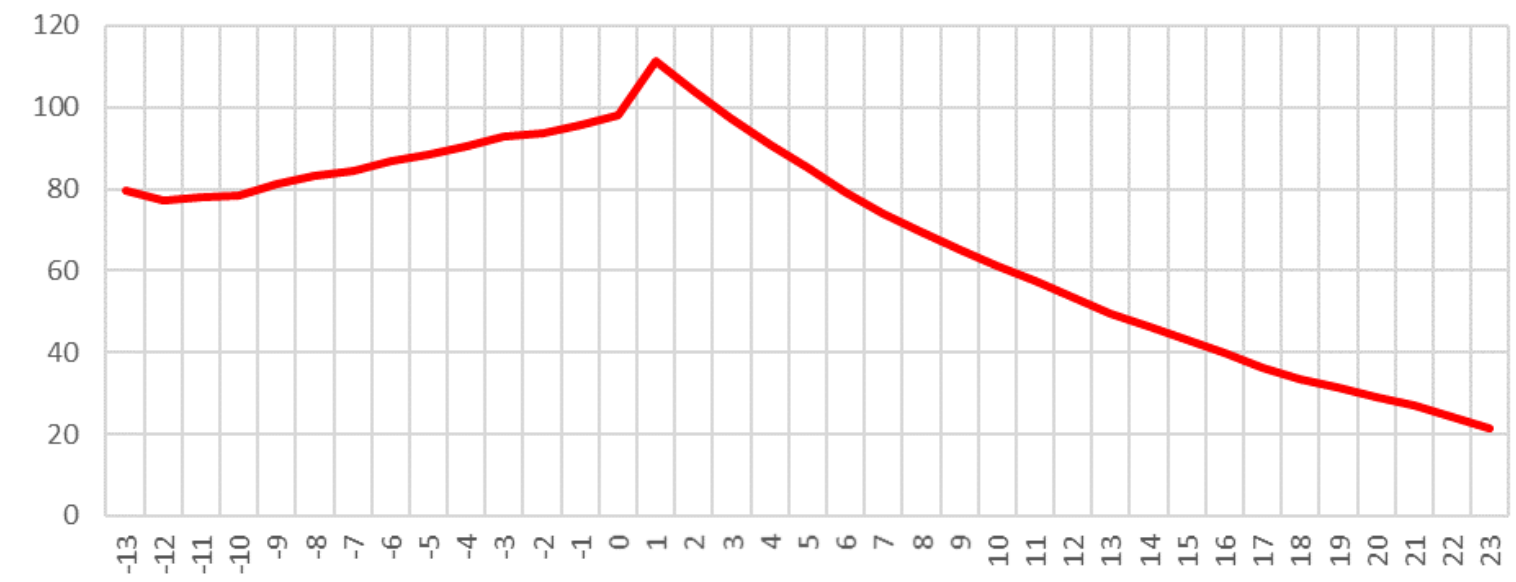

Note: Public housing received at year 0 .

Source: The authors, drawing on MHDCD data (2020). 


\section{Subgroup analyses}

The above model was repeated with interactions (one characteristic at a time) to investigate whether the impact of receiving public housing after exiting prison differs for different subgroups.

- No significant differences were found between men and women.

- For Aboriginal and Torres Strait Islander people, initially the number of days of community supervision per year is fewer than for non-Indigenous people, but falls at a lower rate over time. There is no significant difference between Aboriginal and Torres Strait Islander and non-Indigenous people in either the spike or rate of decrease over time following receipt of public housing.

- No significant differences were found in relation to age at first prison exit.

- People with one or two diagnoses (compared to none or multiple diagnoses) have a significantly smaller spike in days of supervision after receiving public housing, but no difference in the rate of decrease over time.

\subsubsection{Justice costs}

Unit costs in 2019 dollars were allocated to each outcome. The costs were then summed for the years where all outcome data was available (1994 to 2008), to give the total criminal justice cost per person per annum. The source and calculations for these costs are explained below.

Police incidents

The cost of police incidents was calculated as the cost of police work relating to crime, divided by the number of recorded criminal incidents, including driving offences. Data on incidents including driving offences is not publicly available, but was previously provided to the research team by BOCSAR for the 2014-15 financial year-this was combined with 2015-16 police expenditure data from RoGS (SCRGSP 2017) to calculate the cost per incident, as follows.

NSW Police expenditure for 2015-16 was $\$ 3,763,368,400,{ }^{13}$ from which 20 per cent was deducted to account for police work that does not relate directly to crime (see Smith, Jorna et al. 2014). The remaining budget $(\$ 3,010,694,720)$ was then divided by the number of recorded criminal incidents in NSW for July 2015 to June 2016 (1,425,996 incidents) to come up with a cost per incident of $\$ 2,111.29$. This was then inflated to 2018-19 dollars using the Consumer Price Index $(\mathrm{CPI})^{14}$ to give a cost per incident of \$2,225.30 in 2018-19 AUD.

\section{Court appearances}

Average costs per case (including payroll tax) by court type in NSW in 2018-19 were obtained from the RoGS 2020 (SCRGSP 2020)..$^{15}$

- Children's court:16 $\$ 893$

- Local (magistrates) court: \$577

- District court: $\$ 8,007$

- Supreme court: $\$ 43,752$

Drug court costs were obtained from Goodall, Norman et al. (2008). The mean drug court cost in 2008 was $\$ 22,000$. This was inflated using CPI to \$27,953 in 2018-19 AUD.

13 RoGS 2017 Table 6A.1: Net recurrent expenditure + payroll tax + user cost of capital + capital expenditure

14 Australian Bureau of Statistics (2020: Catalogue 6401.0 Consumer Price Index, Australia): 2018-19 CPI = 114.1; 2015-16 CPI = 108.3: $114.1 / 108.3=1.054$.

15 RoGS 2020 Table 7A.31: 'Real net recurrent expenditure per finalisation, criminal, 2018-19 dollars'.

16 The analysis is restricted to adulthood. However, it is possible to have a children's court appearance at ages 18 to 21 , inclusive. 
Time in custody

The RoGS 2020 (SCRGSP 2020) was used to identify recurrent expenditure per NSW prisoner per day, as follows.

Net operating expenditure and capital costs per prisoner in 2018-19 was \$263.09 (RoGS 2020 Table 8A.18), and payroll tax was $\$ 8.48$ per prisoner. ${ }^{17}$ These were summed to calculate the cost per day per prisoner: $\$ 271.57$.

Time on supervised community order

The RoGS 2020 (SCRGSP 2020) was used to identify recurrent expenditure per 'offender' per day \$26.52 (RoGS Table 8A.18) plus payroll tax $\$ 1.22 .{ }^{18}$ These were summed to calculate the cost per day per person on a supervised community order in NSW in 2018-19: \$27.74.

\section{Social costs of crime}

For each proven offence we calculated an average social cost per crime, derived from Smith, Jorna et al. (2014) and data supplied by BOCSAR on the number of criminal incidents, including driving offences, in 2015-16. A conservative weighted average social cost of all crimes (which uses a cost of $\$ 0$ if the cost per incident is unknown), based on the distribution of criminal incidents for 2015-16, was calculated as \$1,334.23 in 2011 AUD. ${ }^{19}$ This was CPI inflated from the 2011 calendar year to 2018-19 financial year: \$1,533.09.

Random effects regression modelling was run on annualised costs from 1994 to 2008-the period for which all outcomes are observed. The results are shown in Table 12, below. Because this is a linear regression model, the coefficients are interpreted as marginal effects.

Table 12: Justice costs regression output

\begin{tabular}{|c|c|c|c|c|c|c|}
\hline Costs & Coefficient & Std err. & z-score & $p>z$ & \multicolumn{2}{|c|}{ [95\% Conf. interval] } \\
\hline $\begin{array}{l}\text { Public housing group intercept } \\
\text { (cf. comparison group) }\end{array}$ & $-10,823.120$ & $3,560.916$ & -3.040 & 0.002 & $-17,802.390$ & $-3,843.854$ \\
\hline Comparison group time trend & 838.191 & 150.221 & 5.580 & 0.000 & 543.765 & $1,132.618$ \\
\hline $\begin{array}{l}\text { Public housing group time trend } \\
\text { (cf. comparison group) }\end{array}$ & $1,052.504$ & 263.959 & 3.990 & 0.000 & 535.154 & $1,569.853$ \\
\hline Post-public housing shift & $-4,995.841$ & $1,684.537$ & -2.970 & 0.003 & $-8,297.474$ & $-1,694.209$ \\
\hline Post-public housing trend change & $-2,039.994$ & 377.540 & -5.400 & 0.000 & $-2,779.959$ & $-1,300.029$ \\
\hline
\end{tabular}

Note: Adjusted for age, sex, Indigenous status and complexity, and exposure time. Sample size = 16,925 observations for 1,230 individuals. The average number of observations per person is 14 (ranging from 3 to 16).

Source:' The authors, drawing on data from SCRGSP (2017; 2020); BOCSAR; Goodall, Norman et al. (2008).

In 1994, at the start of the observation period, ${ }^{20}$ the average criminal justice costs for the group who will receive public housing are $\$ 4,508.10$ lower per annum per person than the comparison group. Over time, the costs increase by $\$ 838.19$ per annum per person for the comparison group, and by an additional $\$ 1,052.50$ per person for the group who will receive public housing. Following receipt of public housing, there is an initial decrease in costs of $\$ 4,995.84$ per person, and a decrease in the trend over time of $\$ 2,039.99$ per person per year.

17 Total payroll tax for prisons $\$ 41,812,000$ (see RoGS Table 8A.1) divided by 365.25 days per year, divided by the average daily number of prisoners 13,495 (see RoGS Table 8A.4).

18 Total payroll tax for community corrections $\$ 10,880,000$ (see RoGS Table 8A.1) divided by 365.25 days per year, divided by the daily average community corrections offender population 24,426 (see RoGS Table 8A.8).

19 Further details of this calculation are in the working paper: Reeve, R. and McCausland, R. (forthcoming).

20 Time=1 in 1988 and we begin to observe all costs in 1994. Costs for the public housing group relative to the comparison group at the start of 1994 would be $-10,823.120+(6 \times 1052.504)=-4508.096$. 
Figure 25 and Figure 26, below, illustrate the average predicted criminal justice costs over time for people in the public housing group and comparison group, respectively. The graphs show that costs are initially lower, but increase at a greater rate, for the group who will receive public housing. For the comparison group, costs start higher and rise steadily over time. Following receipt of public housing, there is a downward shift in costs and a downward trend over time.

Figure 25: Average criminal justice costs, for people with rental assistance only following exit from prison

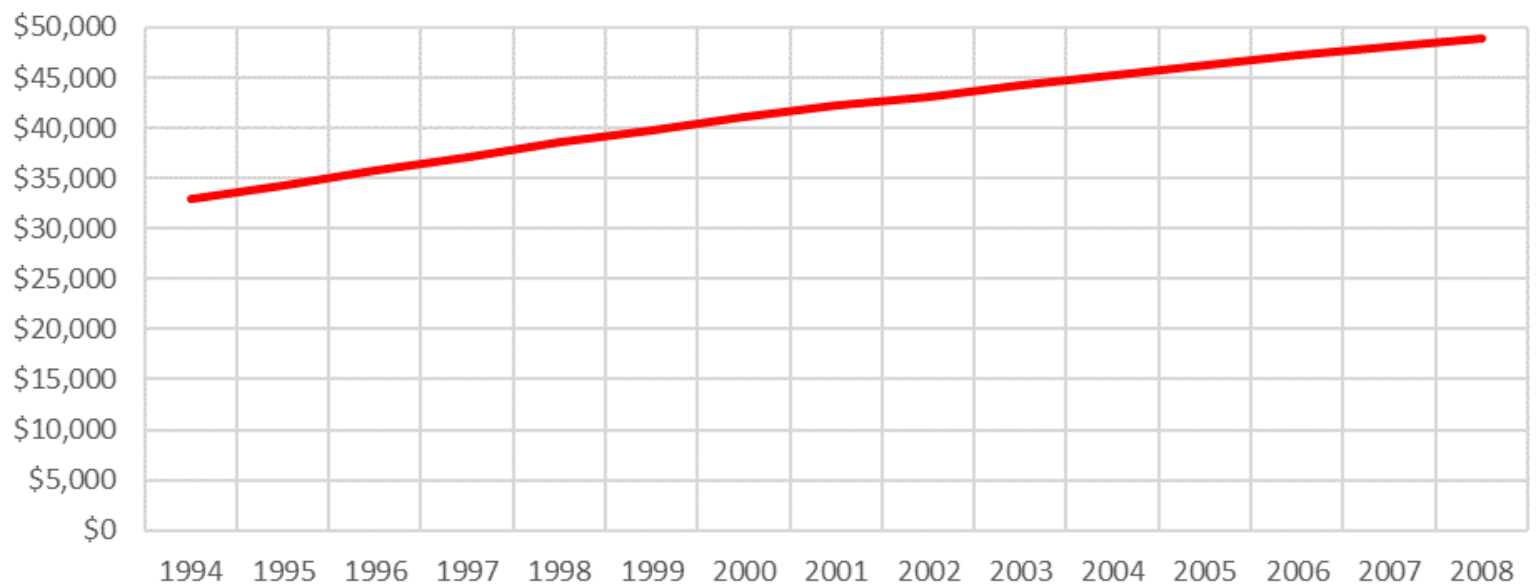

Source: The authors, drawing on data from SCRGSP (2017; 2020); BOCSAR; Goodall, Norman et al. (2008).

Figure 26: Average criminal justice costs, before and after receiving public housing following exit from prison

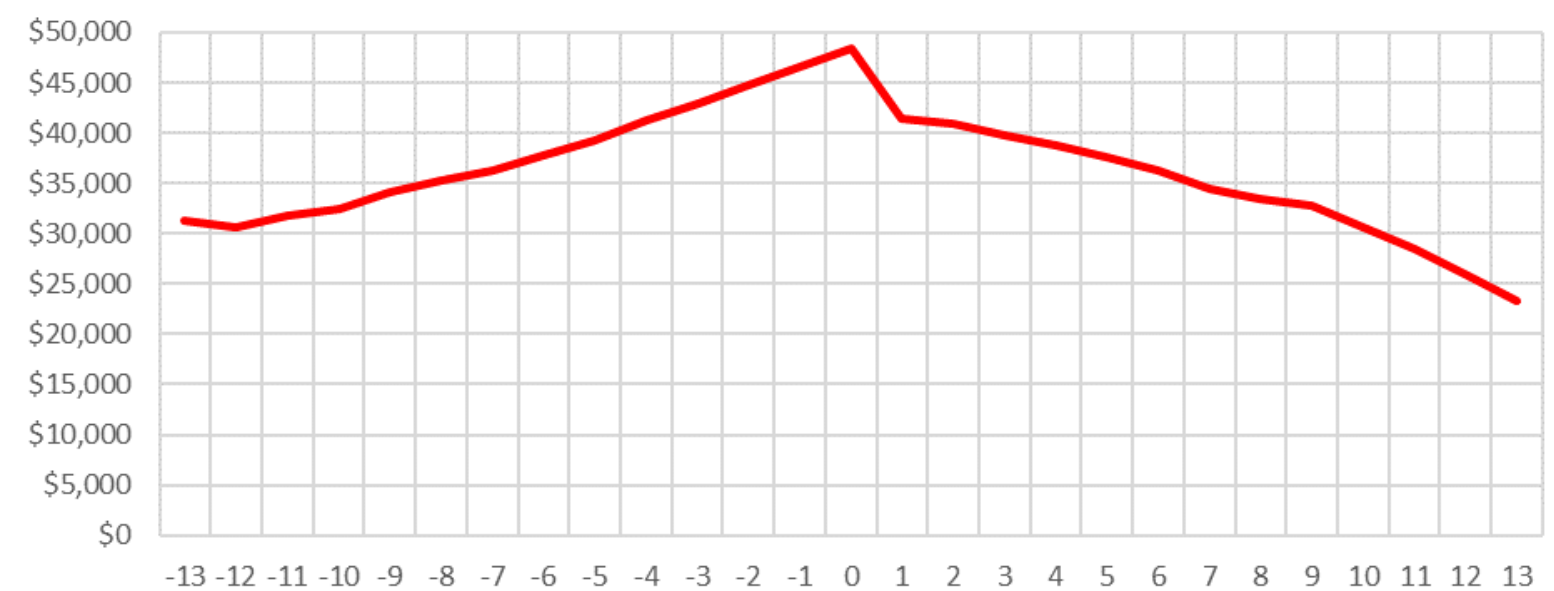

Note: Public housing received at year 0.

Source: The authors, drawing on data from SCRGSP (2017; 2020); BOCSAR; Goodall, Norman et al. (2008). 


\section{Subgroup analyses}

The above model was repeated with interactions (one characteristic at a time) to investigate whether the impact of receiving public housing after exiting prison differs for different subgroups.

- There was no statistically significant difference in justice costs by sex or Indigenous status.

- Costs per annum are lower for people who were older at their first prison exit. Following receipt of public housing, costs initially shift down by a further $\$ 383.25$ per person for each additional year of age. The decrease in costs over time is also larger for older people, with an additional decrease in costs of $\$ 1,868.27$ per person per year for each additional year of age at first prison exit.

- People with greater levels of complexity (based on diagnosis group) have higher justice costs. There is no difference in the size of decrease after receipt of public housing by complexity level.

\subsection{Cost-benefit analysis}

The regression model can be used to compare the predicted difference in costs over time for ex-prisoners who receive public housing compared to those who do not, controlling for other differences and underlying trends. The 'post-public housing shift' and trend change represent the 'difference-in-difference' in costs between the public housing group and the comparison group after public housing commences. The predicted criminal justice cost savings for each year after public housing is received are shown in Table 13, below. Because, on average, ${ }^{21}$ post-prison public housing commenced in 2003 and the public housing allocations data goes to 2008, predictions are made for five years. The predicted cost savings can be compared to the estimated cost of providing public housing relative to the alternative cost of providing rental assistance and/or homelessness services.

Table 13: Criminal justice cost savings per person from providing public housing for ex-prisoners

\begin{tabular}{lrr}
\hline Years after public housing & Calculation & Cost savings (\$) \\
\hline Year 1 & $4,995.84+(1 \times 2,039.99)$ & $7,035.83$ \\
\hline Year 2 & $4,995.84+(2 \times 2,039.99)$ & $9,075.82$ \\
\hline Year 3 & $4,995.84+(3 \times 2,039.99)$ & $11,115.81$ \\
\hline Year 4 & $4,995.84+(4 \times 2,039.99)$ & $13,155.80$ \\
\hline Year 5 & $4,995.84+(5 \times 2,039.99)$ & $15,195.79$ \\
\hline
\end{tabular}

Note: Calculation is post-public housing shift + (no. of years after public housing x post-public housing trend change). Post-public housing shift $=\$ 4,995.84$ and post-public housing trend change $=\$ 2,039.99$, as calculated in the justice costs regression output (Section 5.3.5: Table 12).

Source: The authors, drawing on data from SCRGSP (2017; 2020); BOCSAR; Goodall, Norman et al. (2008).

\subsubsection{Cost of providing public housing}

Public housing costs are derived from the Productivity Commission's 2020 RoGS (SCRGSP 2020: Section G) and the 2018-19 FACS annual report (FACS 2019). Net recurrent expenditure on public housing in NSW in 2018-19, including the cost of capital and payroll tax, was \$45,016 per dwelling (RoGS 2020 Table 18A.43). Revenue from rent and other charges totalled $\$ 852.4$ million (FACS 2019). Dividing this by the number of public housing dwellings -107,241 (RoGS 2020 Table 18A.43) — comes to $\$ 7,948$ revenue per dwelling. Deducting this income from the cost per dwelling $(\$ 45,016$ - $\$ 7,948)$ gives the cost of public housing per dwelling of $\$ 37,068$.

21 Median 2003, mean 2002.498. 
If not in public housing, the intervention group would be eligible for rental assistance and/or homelessness services. The average cost of Commonwealth Rent Assistance per household is \$3,484 per annum (RoGS 2020 Table GA.7). The cost of SHS is $\$ 33.63$ per support day (RoGS 2020 Table 19A.16).

From the public housing data in the MHDCD Databank, the average number of people per household in the public housing group is 1.9. From the commencement of their first post-custody public housing tenancy, people in the public housing group are in public housing for an average of 57 per cent of the time for which we observe them in the data. On this basis, the average cost of the intervention per person per year is $\$ 11,120.40$. If the alternative is CRA, then the cost would be $\$ 1,045.20$. If the alternative is SHS, the cost would be $\$ 6,996.72$.

- The net cost of public housing cf. rental assistance is: $\$ 11,120.40-\$ 1,045.20=\$ 10,075.20$

- The net cost of public housing cf. homelessness is:

$$
\$ 11,120.40-\$ 6,996.72=\$ 4,123.68
$$

It is uncertain what proportion of time ex-prisoners who do not receive public housing would be homeless.

Therefore, Tables 14-16, below, present three alternative scenarios, comparing the criminal justice cost savings per person to the cost of: 1) public housing cf. rental assistance; 2) public housing cf. homelessness support; and 3) public housing cf. being homeless for 50 per cent of the time and receiving rental assistance the other 50 per cent of the time.

Table 14: Cost-benefit scenario 1: Public housing compared with private rental

\begin{tabular}{lrrr}
\hline Years after public housing & $\begin{array}{r}\text { Benefit of public housing } \\
\text { (justice cost savings) } \\
\text { p.p. }(\$)\end{array}$ & $\begin{array}{r}\text { Cost of public housing } \\
\text { cf. rental assistance p.p. } \\
(\$)\end{array}$ & $\begin{array}{r}\text { Net benefit (benefit } \\
\text { minus cost) } \\
\text { p.p. (\$) }\end{array}$ \\
\hline Year1 & $7,035.83$ & $10,075.20$ & $-3,039.37$ \\
\hline Year 2 & $9,075.82$ & $10,075.20$ & -999.38 \\
\hline Year 3 & $11,115.81$ & $10,075.20$ & $1,040.61$ \\
\hline Year 4 & $13,155.80$ & $10,075.20$ & $3,080.60$ \\
\hline Year 5 & $15,195.79$ & $10,075.20$ & $5,120.59$ \\
\hline Total after 5 years & $\$ 55,579.05$ & $\$ 50,376.00$ & $\$ 5,203.05$ \\
\hline
\end{tabular}

Note: Costs and benefits per person (p.p.).

Source: The authors, drawing on data from SCRGSP (2017; 2020); BOCSAR; Goodall, Norman et al. (2008); FACS 2019.

Table 15: Cost-benefit scenario 2: Public housing compared with homelessness

\begin{tabular}{lrrr}
\hline Years after public housing & $\begin{array}{r}\text { Benefit of public housing } \\
\text { (justice cost savings) } \\
\text { p.p. }(\$)\end{array}$ & $\begin{array}{r}\text { Cost of public housing } \\
\text { cf. homelessness support } \\
\text { p.p. (\$) }\end{array}$ & $\begin{array}{r}\text { Net benefit (benefit } \\
\text { minus cost) p.p. (\$) }\end{array}$ \\
\hline Year1 & $7,035.83$ & $4,123.68$ & $2,912.15$ \\
\hline Year 2 & $9,075.82$ & $4,123.68$ & $4,952.14$ \\
\hline Year 3 & $11,115.81$ & $4,123.68$ & $6,992.13$ \\
\hline Year 4 & $13,155.80$ & $4,123.68$ & $9,032.12$ \\
\hline Year 5 & $15,195.79$ & $4,123.68$ & $11,072.11$ \\
\hline Total after 5 years & $\$ 55,579.05$ & $\$ 20,618.40$ & $\$ 34,960.65$ \\
\hline
\end{tabular}

Note: Costs and benefits per person (p.p.).

Source: The authors, drawing on data from SCRGSP (2017; 2020); BOCSAR; Goodall, Norman et al. (2008); FACS 2019. 
Table 16: Cost-benefit scenario 3: Public housing compared with private rental and homelessness (50:50 weighting)

\begin{tabular}{lrrr}
\hline & $\begin{array}{r}\text { Benefit of public housing } \\
\text { (justice cost savings) } \\
\text { Years after public housing }\end{array}$ & $\begin{array}{r}\text { Cost of public housing } \\
\text { cf. rental assistance and } \\
\text { homelessness support } \\
(\$)\end{array}$ & $\begin{array}{r}\text { Net benefit (benefit } \\
\text { minus cost) } \\
(\$)\end{array}$ \\
\hline Year1 & $7,035.83$ & $7,099.44$ & -63.61 \\
\hline Year 2 & $9,075.82$ & $7,099.44$ & $1,976.38$ \\
\hline Year 3 & $11,115.81$ & $7,099.44$ & $4,016.37$ \\
\hline Year 4 & $13,155.80$ & $7,099.44$ & $6,056.36$ \\
\hline Year 5 & $15,195.79$ & $7,099.44$ & $8,096.35$ \\
\hline Total after 5 years & $\$ 55,579.05$ & $\$ 35,497.20$ & $\$ 20,081.85$ \\
\hline
\end{tabular}

Note: Costs and benefits per person (p.p.)

Source: The authors, drawing on data from SCRGSP (2017; 2020); BOCSAR; Goodall, Norman et al. (2008); FACS 2019.

The benefits, per person, of public housing from reduced criminal justice costs increase over time. The net benefit, including the cost of public housing, depends on the alternative. If the alternative to public housing is private rental assistance, positive benefits are not felt until the third year after public housing commences (see Table 14). If the alternative is homelessness, positive net benefits are reaped immediately (see Table 15). If the alternative is a combination of homelessness and private rental, there is a small net cost in the first year, with benefits every year thereafter (see Table 16). In each of these scenarios there are positive net benefits from public housing for ex-prisoners, over time. After five years, the expected net benefit ranges from about $\$ 5,200$ to $\$ 35,000$ per person.

\subsection{Summary}

The analysis shows there are clear benefits from providing public housing to ex-prisoners.

As a preliminary matter, it also shows that public housing is targeted at people with worse criminal justice outcomes - this is evident from the observed differences in the measures of outcomes between the comparison group and the public housing group in the years leading up to the latter's receipt of public housing.

For the public housing group, there are remarkable improvements, over time, across the range of criminal justice outcomes. Average reductions in predicted criminal justice contacts for ex-prisoners in the period following tenancy commencement are as follows.

- Police incidents: down 8.9 per cent per year.

- Court appearances: down 7.6 per cent per year.

- Proven offences: down 7.6 per cent per year.

- Time in custody: down 11.2 per cent per year.

- Time on supervised orders: following an initial increase, down 7.8 per cent per year.

- Justice costs: an initial decrease of $\$ 4,996$, followed by a further $\$ 2,040$ per year.

Looking at the effect of public housing by subgroups provides further insights.

- There is a small additional benefit associated with age (i.e. each additional year of age at time of first prison exit); this additional benefit is seen across all measures, except 'time on supervised orders' (where there is no difference from the rest of the group). 
- For women, Indigenous people, and people with multiple diagnoses, the downward trends in criminal justice contacts are mostly no different from that of people outside the respective subgroups. The exceptions are as follows.

- Women experience a lesser rate of reduction in police incidents (down 6.8\% p.a., cf. 9.8\% for men). Also, after a greater initial reduction in court appearances, women have a lesser rate of reduction over the long term than men.

- Indigenous people experience a lesser rate of reduction in police incidents (down 6.7\% p.a., cf. 10\% for non-Indigenous people).

- People with multiple diagnoses experience a lesser rate of reduction in court appearances (down 7\% p.a., cf. $16 \%$ for those with no diagnoses), and a lesser rate of reduction in time in custody (10-11\% p.a., cf. $20 \%$ for those with no diagnoses).

Fewer criminal justice contacts means cost savings to the justice system. When housing costs are taken into consideration, there is an estimated net benefit of $\$ 5,200$ to $\$ 35,000$ per person over five years, compared with the cost of providing assistance to an ex-prisoner in private rental and/or via homelessness services.

The cohort's median time from first prison exit to public housing is five years (mean 5.9). Were public housing received sooner following exit from prison, the benefits to the individual and society would be expected to occur sooner and therefore be even greater. 


\section{Two case studies of the costs and benefits of housing assistance after prison}

- Two case studies drawn from the MHDCD Databank-'Jason' and 'Debra' -illustrate the role that social housing can play in the trajectories of people who have complex support needs and are in contact with the criminal justice system.

- Costing Jason and Debra's institutional contacts (i.e. interactions with the criminal justice system and other agencies) highlights the economic, as well as social, benefits of providing social housing for people released from custody.

- Jason's housing tenancies are associated with a dramatic reduction in his costly interactions with the criminal justice system, some of which related to violent offences against women.

- Debra had stable periods of up to 18 months with no contact with the criminal justice system after each housing tenancy she received.

- The criminal justice system cost savings observed for Jason and Debra associated with accessing social housing would likely have been increased by more timely availability of housing upon release from custody, along with specialist disability support to maintain housing. 
As well as cohort analyses, the linked administrative data in the MHDCD Databank can be used to generate deidentified individual case studies.

The Databank contains linked administrative data about each individual in the cohort from as far back as the contributing agencies' electronic records allow. Once linked and merged, individual identifying details are removed from the data. Subject to privacy protection protocols, the de-identified data may be extracted to map individual trajectories, from a young age, between and within service systems, complemented by qualitative data such as police and corrections health case notes, which provide information about a person's background, treatment and perspective (see Baldry, Dowse et al. et al. 2012, 2013; Baldry, McCausland et al. 2015).

Using this method, two case studies were developed for this study: one male ('Jason') and one female ('Debra'). ${ }^{22}$ Neither is Indigenous. ${ }^{23}$ Each had received public housing after a custodial episode, and their backgrounds and trajectories reflect experiences and pathways of interest.

\subsection{Jason}

\section{Background}

Jason was born in the late 1970s and has lived all his life in Sydney. At 18, he was assessed as having a moderate intellectual disability (total IQ in the 50s). There is no record that he was assessed as a child, and he appears to never have received any support from disability services. Until his early twenties, Jason lived with his parents; he also had a brother who was sometimes in prison.

\section{Criminal justice contact as a young person}

Jason's first recorded contact with police was at the age of 15, when he broke into a local public school on a weekend. Charged with illegal entry with intent, resisting arrest and assaulting a police officer, he was found guilty and given a 12-month bond with supervision. A year later, aged 16, Jason was convicted of indecently assaulting a woman, and given a two-year probation order with supervision. Jason's Juvenile Justice assessment report recommended counselling in a sex offender program, but there is no record of this happening. Jason had no further contact with police until after he turned 18.

\section{Criminal justice contact as an adult}

Between the ages of 18 and 20, Jason was convicted of three further attacks against women. At 18, he punched a woman and stole her handbag, and was given a bond with supervision and a fine. Soon after, Jason was for the first time diagnosed as having an intellectual disability.

At 19, Jason indecently assaulted a woman in a park and stole a handbag. After three weeks in custody on remand, Jason was bailed, but arrested again for repeatedly calling 000 and not giving his name. Jason was then given a two-month custodial sentence.

The next attack was a year later, when Jason followed a woman home and indecently assaulted and robbed her. He spent nine months in custody before being released on parole, and returned to live with his parents.

22 These and other names in the case studies were assigned by the research team, and do not reflect real names. Other minor details have been changed to protect the subjects' anonymity.

23 See Chapter 1 for an explanation of our approach to Indigenous-specific experience. 


\section{First public housing tenancy}

Two months after his release from custody, Jason applied for public housing and was placed on the wait-turn list. A year later, Jason was convicted of a fifth attack, after he followed and robbed a pregnant woman. Convicted of aggravated robbery and breaching his parole conditions, Jason spent 15 months in custody, then was released on parole. His corrective services case plan noted: 'Lives with parents. Brother gets out of jail in Sept. Could be a problem.'

Six months later, aged 23, and after two years on the waiting list, Jason received his first public housing tenancy. Jason then had relatively little contact with police for four years, and mostly as a witness. One year into his tenancy, Jason reported to police that a brick had been thrown through his window, likely by his ex-partner Cara. Three months later, police were again called, after an argument between Jason and Cara; no charges were laid. Six weeks later, Jason reported that someone had broken into his apartment and stolen some belongings.

When Jason was 25, Tanya moved in with him and they married a year later. Tanya also has an intellectual disability.

Jason's next contact with police was just before he turned 28, when he reported that someone had thrown eggs at his apartment. A week later, a passer-by reported that Jason and Tanya had shouted abuse at him when he walked past their apartment. No apprehended violence order (AVO) or charges ensued. The only contact Jason had with police over the next two years was when he twice reported his wife was missing-both times she returned home the next day.

\section{Housing transfer}

The following year, Jason (now 29) reported to police that he had received a threatening note from an unknown person. A month later, Jason submitted a transfer application; two months later, he and Tanya were offered and moved to another public housing dwelling.

Jason's only other recorded contact with the criminal justice system was at age 30, when he was fined for urinating near a bus stop (Jason told police, 'I was busting'). It was his first court appearance in more than eight years.

\section{Analysis}

Jason's consecutive public housing tenancies are associated with a dramatic change in his interactions with the criminal justice system. An emerging pattern of serious violent offences against women (five in five years) and custodial episodes (four) has ceased, and he has desisted from virtually all offending. He has also navigated a volatile relationship break-up, and formed a new and lasting relationship with Tanya. He has accessed and maintained income in the form of the Disability Support Pension (DSP).

From the perspective of tenancy management, Jason has presented a number of challenges, but the public housing landlord has responded in ways that have sustained his tenancy. In particular, what appears to have been an emerging problem with some neighbours was headed off with a timely transfer. 


\subsection{Debra}

\section{Background}

Debra was born in the early 1960s and has lived all her life in Sydney. At school, Debra attended a special class, indicating recognition of a learning disability, but she was not assessed as having an intellectual disability until her forties. At the age of 10, Debra was sexually abused, but this was not recorded at the time-Debra disclosed the event later in life. Debra left school at Year 10. At age 27, Debra gave birth to a son who was then raised by Debra's mother, with Debra in weekly contact.

Debra had no recorded contact with police, or other criminal justice or human services agencies, until she was 35. For the next ten years, Debra was frequently in contact with police and increasingly spent time in custody. It was not until she was in custody for the sixth time, at age 43, that Debra was assessed as having a mild intellectual disability (with a total IQ in the 60s), a personality disorder, schizophrenia, and problematic drug and alcohol use. She then came under the responsibility of the Public Guardian.

\section{First police contact}

At age 35, Debra's relationship with her partner of five years, Steven, broke down and he took out an AVO against her. Debra was subsequently charged with breaching the AVO and was remanded in custody for one week before charges were dropped. The following year, Debra gave birth to her and Steven's daughter, who joined Debra's son in the care of Debra's mother.

\section{First public housing tenancy}

At 37, Debra started a public housing tenancy on her own, and the children continued in the care of her mother. Debra had no contact with police for the next 18 months. She was then charged in relation to a threatening letter sent to Steven, but the charges were dropped. Two months later, Debra was charged and convicted of malicious damage and further AVO breaches, and sentenced to four months in prison. While in prison, her public housing tenancy was terminated.

\section{Second public housing tenancy}

Upon her release from custody, Debra (now 39) applied for tenancy reinstatement, and two months later commenced her second public housing tenancy. She had no contact with police over the following year. Police notes then record allegations of more threats against Steven, and a threat against a police officer. Debra was admitted to hospital under the Mental Health Act, then sentenced to two months in prison. On release, she returned to her tenancy, but eight months later was again charged with contravening an AVO protecting Steven. She was remanded in custody for three months, during which time her tenancy was terminated.

Released on a bond without supervision, Debra applied again for housing assistance and received private rental assistance. Soon after, Debra's mother alleged to police that Steven was sexually assaulting his and Debra's daughter during weekend access visits; the same day, Debra was charged again with making threats against Steven. She subsequently received a suspended sentence.

\section{Third public housing tenancy}

A month later, and six months after her most recent application for housing assistance, Debra (now 42) commenced her third public housing tenancy. Debra had no contact with police for nine months, but then was again charged with making threats against Steven and lighting fires. Sentenced to 12 months in prison, Debra's tenancy was terminated.

It was during this period in custody — her sixth — that Debra (now 43) was first diagnosed with an intellectual disability. 


\section{Fourth public housing tenancy}

Three days after being paroled, Debra (now 44) began her fourth and final recorded public housing tenancy. She also received the DSP for the first time. Notes by her community corrections officer during this time record that Debra:

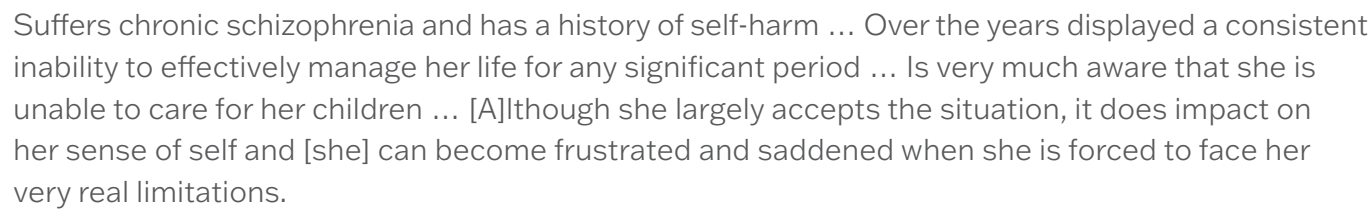

After 12 months of no contact with police, Debra once again had a period of intense institutional contact involving incidents of self-harm, admission to hospital under the Mental Health Act, and charges of malicious damage. Debra was sentenced to 18 months' imprisonment. Her tenancy was terminated three months into her sentence.

\section{Temporary accommodation post-release}

Released on parole, Debra (now 47) applied again for housing assistance, and was recorded as paying \$200 per week for temporary accommodation. Seven months later, Debra, armed with kitchen knife, attempted to rob a store, and was sentenced to five months in prison. The final record in the MHDCD Databank shows she was released on parole, without permanent housing.

\section{Analysis}

Since childhood, Debra has had impairments, difficulties and traumatic experiences with which she was largely unsupported, except by her mother. However, her contact with the criminal justice system began relatively late, in her mid-adulthood, during a conflictual relationship break-down: she expressed frustration and distress through impulsive behaviour and lacked the capacity to comply with AVO conditions. Over the next seven years, she would be in frequent contact with police, and in custody six times, before her intellectual disability was identified and her mental health conditions diagnosed.

Debra's contact with the social housing system also began in her late thirties, shortly after the start of this period of frequent offending and mental health crises, and she received four public housing tenancies during that time. In social housing practice and in criminal justice practice there is a tendency to talk of a person getting so many 'chances'; using this way of thinking, the public housing landlord has given Debra numerous chances. However, we might also think of the many chances missed by state agencies in the course of Debra's life to identify and address her support needs.

After starting each new tenancy, Debra had stable periods of up to 18 months with no contact with the criminal justice system, which would amount to significant savings in criminal justice costs. However, there is no record of her receiving disability support services in the community during any of her tenancies. Her worsening mental health precipitated increasingly intensive hospital admissions under the Mental Health Act, and more serious offending and custodial episodes. Debra's tenancies were repeatedly terminated while she was in custody and, with one exception, it took a number of months before she was housed after each release. 


\subsection{Case study costings}

Previous costings studies drawing on the MHDCD Databank (Baldry, Dowse et al. 2012; McCausland, Baldry et al. 2013; Reeve, McCausland et al. 2017; McCausland, Reeve et al. 2019; Reeve and McCausland forthcoming) have developed a methodology for calculating all tangible costs allowed for by the data, including: direct costs (those that can be directly attributed to a service or intervention); indirect costs (those not directly attributable but necessary to the delivery of the service or intervention-i.e. management and administration costs); and capital costs, where possible. This involves calculating unit costs for each interaction and service associated with each agency in the Databank, and applying those to available data for each case study.

That methodology was applied to this study, using updated costs where required (see Chapter 4 and footnote below for more detail) to estimate the costs of providing housing assistance compared to the benefits (cost savings) realised in the criminal justice system. ${ }^{24}$

\subsubsection{Jason}

Table 17: Jason's institutional contacts, by age and agency

\begin{tabular}{|c|c|c|c|}
\hline & Under 18 years & $18-24$ years & $25-30$ years \\
\hline Police & 5 incidents & 16 incidents & 10 incidents \\
\hline Legal Aid & - & 10 duty lawyer & - \\
\hline Courts & $\begin{array}{l}2 \text { finalised appearances, } \\
4 \text { matters }\end{array}$ & $\begin{array}{l}5 \text { finalised appearances, } \\
9 \text { matters }\end{array}$ & $\begin{array}{l}1 \text { finalised appearance, } \\
1 \text { matter }\end{array}$ \\
\hline Juvenile Justice & 741 days supervision & - & - \\
\hline \multirow[t]{2}{*}{ Corrections } & & 808 days in custody & - \\
\hline & & 1,347 days on community orders & \\
\hline Justice Health & 2 assessment reports & - & - \\
\hline Hospitalisations & - & - & 2 nights \\
\hline Disability services & - & - & - \\
\hline Centrelink & - & 1,361 days & 2,192 days \\
\hline Housing & - & 498 days & 2,192 days \\
\hline
\end{tabular}

Source: The authors, drawing on MHDCD data (2020).

24 Unit cost calculations and data sources are discussed in Chapter 5 for police incidents, court appearances, days in custody and community orders, and public housing. Current legal aid costs were obtained from legal aid fee scales https://www.legalaid.nsw. gov.au/for-lawyers/fee-scales/state-matters/criminal-matters-solicitors and applied using methodology as described in Reeve, McCausland et al. 2017. Juvenile Justice costs were obtained from RoGS 2020 and inflated to 2018-19 AUD. Justice Health appointments were proxied by the NSW hospital outpatient costs from the National Hospital Cost Data Collection Report, Public Sector, Round 22 (Financial year 2017-18), \$262, and inflated to 2018-19 AUD, \$266 per appointment. Inpatient hospitalisations were obtained from the same source and also inflated to give the following unit costs per day in 2018-19 AUD: acute \$1,872; subacute $\$ 1,087$; general mental health $\$ 1,144$; forensic mental health $\$ 1,087$. Centrelink payments were obtained from https://guides. dss.gov.au/guide-social-security-law/5/2/2/40. 
6. Two case studies of the costs and benefits of housing assistance after prison

Table 18: Jason's institutional costs, by age and agency

\begin{tabular}{|c|c|c|c|c|}
\hline & Unit cost & Under 18 years & $18-24$ years & $25-30$ years \\
\hline Police & $\$ 2,225.30$ per incident & $\$ 11,126.50$ & $\$ 35,604.80$ & $\$ 22,253.00$ \\
\hline Legal Aid & Varies by service provided & - & $\$ 4,720.00$ & - \\
\hline Courts & Varies by court type & $\$ 1,786.00$ & $\$ 10,315.00$ & $\$ 577.00$ \\
\hline Juvenile Justice & \$135.51 per supervision day & $\$ 100,412.91$ & - & - \\
\hline \multirow[t]{2}{*}{ Corrections } & $\$ 271.57$ per custody day & & $\$ 219,428.56$ & \\
\hline & $\$ 27.74$ per supervision day & & $\$ 37,365.78$ & \\
\hline Justice costs & & $\$ 113,325.41$ & $\$ 307,434.14$ & $\$ 22,830.00$ \\
\hline Justice Health & $\$ 266.00$ per appointment & $\$ 532.00$ & - & - \\
\hline Hospitalisations & $\$ 1,872.00$ per night & - & - & $\$ 3,744.00$ \\
\hline Health costs & & $\$ 532.00$ & $\$ 0.00$ & $\$ 3,744.00$ \\
\hline Disability services & $\mathrm{N} / \mathrm{A}$ & - & - & - \\
\hline Centrelink & $\begin{array}{l}\$ 32.51 \text { per day DSP (partnered, } \\
<21 \text { years) } \\
\$ 45.42 \text { per day DSP (partnered, } \\
21+\text { years) }\end{array}$ & - & $\$ 55,477.81$ & $\$ 99,560.64$ \\
\hline Housing & $\begin{array}{l}\$ 101.56 \text { per day (per dwelling) } \\
\text { Divided by } 2 \text { people from age } 25\end{array}$ & - & $\$ 50,576.88$ & $\$ 111,309.76$ \\
\hline Support services cc & & $\$ 0.00$ & $\$ 106,054.69$ & $\$ 210,870.40$ \\
\hline
\end{tabular}

Source: The authors, drawing on MHDCD data (2020).

Figure 27: Jason's institutional costs, by age and agency
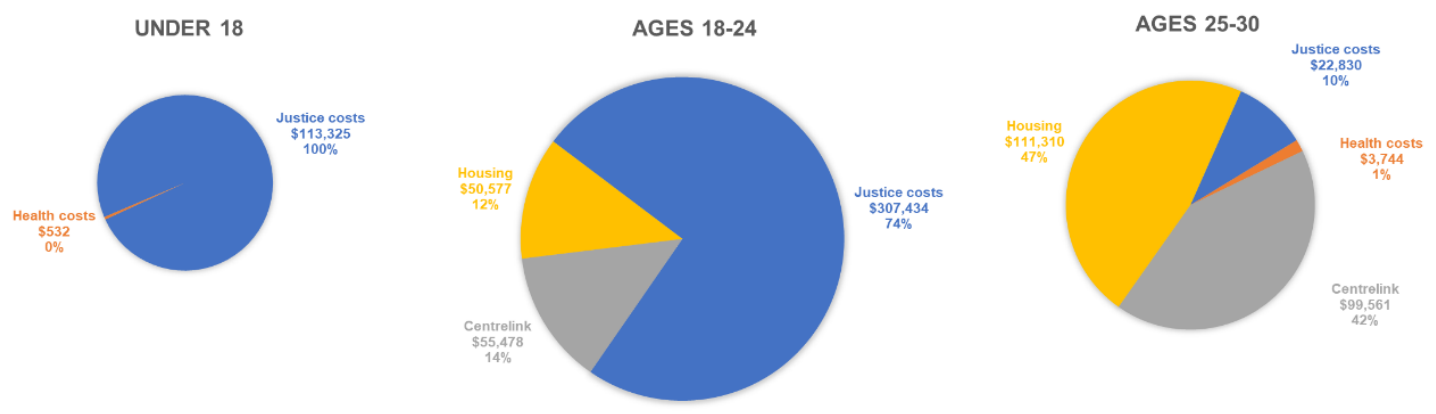

Note: Pie charts are scaled to reflect total costs. Jason received public housing from age 23.

Source: The authors, drawing on MHDCD data (2020).

Jason's early offending involved increasingly violent sexual offences, with indications that he was not receiving the support he needed from his family, or disability or other support services. Table 17 and Figure 27 highlight that after receiving social housing (at age 23), Jason's institutional contacts shifted from being almost entirely criminal justice-focussed to social support-related. Social housing vastly improved his quality of life and also provided cost savings to the state (see Table 18). Jason's early and costly criminal justice contact reduced significantly when he moved into social housing. The stable base provided by social housing enabled Jason to access the DSP and live with his partner. 
6. Two case studies of the costs and benefits of housing assistance after prison

\subsubsection{Debra}

Table 19: Debra's institutional contacts, by age and agency

\begin{tabular}{|c|c|c|c|}
\hline & $35-39$ years & 40-44 years & $45-47$ years \\
\hline Police & 44 police incidents & 24 police incidents & 18 police incidents \\
\hline \multirow[t]{2}{*}{ Legal Aid } & 10 duty lawyer & 11 duty lawyer & 1 duty lawyer \\
\hline & 6 legal advice & 2 legal advice & 2 legal advice \\
\hline Courts & 2 finalised appearances & 5 finalised appearances & 2 finalised appearances \\
\hline \multirow[t]{2}{*}{ Corrections } & 134 days in custody & 581 days in custody & 711 days in custody \\
\hline & 436 days on community orders & 835 days on community orders & 349 days on community orders \\
\hline Justice Health & - & - & 140 appointments \\
\hline Hospitalisations & 1 day & 94 days & 7 days \\
\hline Disability services & & & - \\
\hline Centrelink & & 365 days & 385 days \\
\hline \multirow[t]{2}{*}{ Housing } & 740 days in public housing & 1,285 days in public housing & 147 days in public housing \\
\hline & 1 period of Rentstart assistance & 1 period of Rentstart assistance & \\
\hline
\end{tabular}

Source: The authors, drawing on MHDCD data (2020).

Table 20: Debra's institutional costs, by age and agency

\begin{tabular}{|c|c|c|c|c|}
\hline & Unit cost & 35-39 years & 40-44 years & $45-47$ years \\
\hline Police & $\$ 2,225.30$ per incident & $\$ 97,913.20$ & $\$ 53,407.20$ & $\$ 40,055.40$ \\
\hline Legal Aid & Varies by service provided & $\$ 7,253.00$ & $\$ 5,053.00$ & $\$ 640.00$ \\
\hline Courts & $\$ 577.00$ per local court case & $\$ 1,154.00$ & $\$ 2,885.00$ & $\$ 1,154.00$ \\
\hline \multirow[t]{2}{*}{ Corrections } & $\$ 271.57$ per custody day & $\$ 36,390.38$ & $\$ 157,782.17$ & $\$ 193,086.27$ \\
\hline & $\$ 27.74$ per supervision day & $\$ 12,094.64$ & $\$ 23,162.90$ & $\$ 9,681.26$ \\
\hline Justice costs & & $\$ 154,805.22$ & $\$ 242,290.27$ & $\$ 244,616.93$ \\
\hline Justice Health & $\$ 266.00$ per appointment & & - & $\$ 37,240.00$ \\
\hline Hospitalisations & Varies by type of admission & $\$ 1,872.00$ & $\$ 125,995.00$ & $\$ 8,679.00$ \\
\hline Health costs & & $\$ 1,872.00$ & $\$ 125,995.00$ & $\$ 45,919.00$ \\
\hline Disability services & $\mathrm{N} / \mathrm{A}$ & - & - & - \\
\hline Centrelink & $\begin{array}{l}\$ 60.26 \text { per day } \\
\text { (DSP single) }\end{array}$ & - & $\$ 21,994.90$ & $\$ 23,200.10$ \\
\hline Housing & $\begin{array}{l}\text { \$101.56 per day } \\
\text { (plus Rentstart) }\end{array}$ & $\$ 75,334.40$ & $\$ 131,684.60$ & $\$ 14,929.32$ \\
\hline \multicolumn{2}{|c|}{ Support services costs } & $\$ 75,334.40$ & $\$ 153,679.50$ & $\$ 38,129.42$ \\
\hline
\end{tabular}

Source: The authors, drawing on MHDCD data (2020). 
Figure 28: Debra's institutional costs, by age and agency
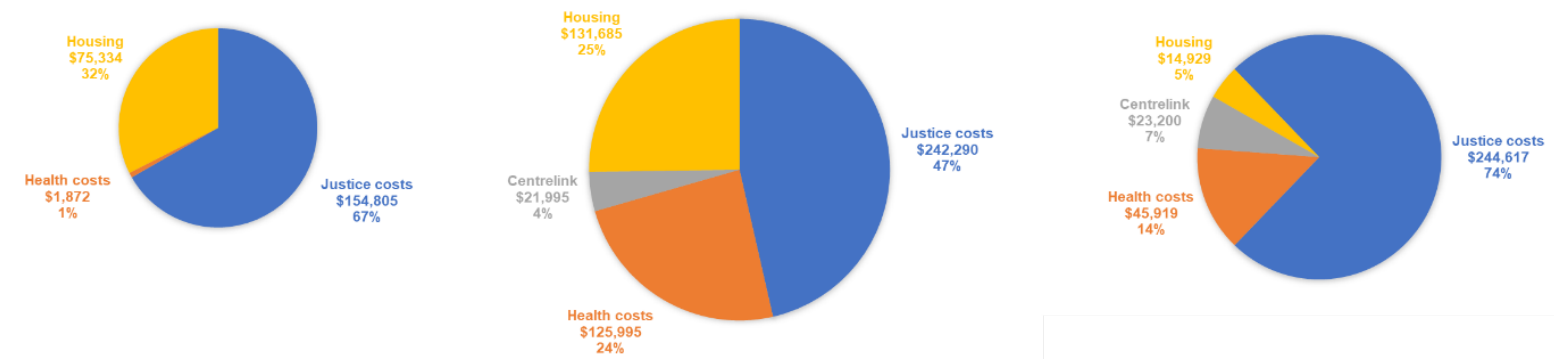

Note: Pie charts are scaled to reflect total costs. Debra received public housing, intermittently, from age 37 to 45.

Source: The authors, drawing on MHDCD data (2020).

Debra has a history of unsupported disability, abuse and mental health needs. Table 20 and Figure 28 highlight the cost impact of the crisis she experienced in her mid-thirties after no previous institutional contact. The response to Debra's increasingly complex needs and repeated breaches of apprehended violence orders was predominantly via the criminal justice system, which was costly and disruptive to Debra's tenancies. The funding expended on Debra's criminal justice costs was more than twice as much as the amount spent on providing housing for her-and many times more than the amount expended on her health. After receiving each of her public housing tenancies, Debra had a period of up to 18 months without police contact. However, each of those tenancies was terminated while she was in custody on remand or a short sentence. It was not until Debra's final public housing tenancy that she received the DSP for the first time-there is no record of her receiving any other disability or specialist support. When the data expires, Debra (aged 47) was again waiting for social housing. The periods of stability Debra experienced after receiving public housing indicate that further investment in support to assist Debra to manage crisis situations and maintain social housing tenancies could offset hundreds of thousands of dollars in police, emergency hospital admissions and custody costs.

\subsection{Summary}

These two case studies, drawn from the MHDCD Databank, illustrate the role that social housing can play in the trajectories and experiences of people with cognitive disability and complex needs who are in contact with the criminal justice system. Costing their institutional contacts highlights the economic, as well as social, benefits of providing housing for people released from custody, both in the short and longer term.

Jason's consecutive public housing tenancies are associated with a dramatic reduction in his costly interactions with the criminal justice system, some of which related to violent offences against women.

- Debra had stable periods of up to 18 months, with no contact with the criminal justice system, after each housing tenancy she received upon release from custody, providing significant cost savings. The provision of more support around Debra's mental health and complex needs may have avoided her repeated crisis-related contact with police and emergency hospital admissions, and assisted her to maintain her tenancies-at less cost to Debra and the state.

- Both Jason and Debra waited to receive public housing after release from custody, during which time they frequently reoffended.

- The criminal justice system cost savings observed for Jason and Debra associated with accessing social housing would likely have been increased by more timely availability of post-release housing options, along with specialist disability support where required. 


\section{Policy development options}

Over a decade ago, Australian governments acknowledged the special vulnerability of people exiting prison into homelessness. Since then, imprisonment rates have generally increased and ex-prisoners' housing needs have grown, but housing assistance capacity has decreased. Homelessness and social housing have again slipped down the national policy agenda, and the social housing sector, in particular, has suffered a real reduction in expenditure.

The evidence presented in this research strongly supports the need for much greater provision of social housing to people exiting prison, particularly for those with complex support needs. Relatively secure, affordable public housing is a steady 'hook for change' that a person exiting prison can hold onto as they make changes in their circumstances, and in themselves, to desist from offending. It is also a stable base from which to receive and engage with support services.

After ex-prisoners commence a public housing tenancy, there are downward trends in a range of measures regarding contact with the criminal justice system. Subgroups of ex-prisoners-women, Indigenous people, and people with multiple diagnoses-experience similar downward trends on most measures. In dollar terms, a public housing tenancy results in net cost savings of between $\$ 5,200$ and $\$ 35,000$ per person over five years, relative to assisting an ex-prisoner in private rental housing and/or through homelessness services.

Our linked data analysis looked specifically at public housing, because we could not identify in the data assistance from community housing providers and Indigenous NGOs. We see no reason why the beneficial effects of public housing for ex-prisoners would not also be realised in community housing or Indigenous housing, provided they offer secure, affordable tenancies and associated conditions (e.g. access to transfers), like public housing. By the same token, the findings also argue against policy strategies that aim to reduce the security associated with social housing - such as time-limited tenancies and reviews of continuing eligibility.

We suggest the findings support increased provision by Indigenous housing organisations. Indigenous people are massively over-represented in prisons and equally over-represented among ex-prisoners. If, as this research shows, provision of social housing is a mechanism for desistance and reintegration, more resources and capacity to increase the supply of housing for this cohort should be in the hands of Indigenous organisations.

It may be possible to increase access to social housing for ex-prisoners through prioritisation; that is, by changing eligibility policies so that a person exiting prison has the highest priority. However, to be effective, this approach would require a tightening of priority as regards other classes of applicants. Thus, we do not recommend this approach. Rather, there should be increased provision of social housing generally, to which ex-prisoners, as well as others in need, have greater access. Furthermore, policy reforms should be made to reduce barriers to housing access for ex-prisoners, such as current requirements around repayment of debts. 
It is important to acknowledge that social housing is not a panacea. The availability of supports from other agencies is vital, and more generous provision should be made to bolster these services. The evidence from our interviews, and from the wider body of research, shows that the importance of inter-agency work is generally accepted across criminal justice, disability, housing and homelessness sectors; but currently, agency interaction is often limited to one resource-constrained agency handing off to another, rather than a genuine collaboration and linking of different specialist strengths.

This lack of inter-agency cooperation is especially evident in the period when a prisoner is approaching their expected release date and thoughts are turning to their housing options and other needs post-release. More can be made of this period: firstly, by improving access to prisoners for reintegration, disability and housing and homelessness workers, who bring with them specialist skills and knowledge; second, by assigning a single case manager to each person exiting prison, to help them navigate the many services and obligations they will face upon release. However, there are limits to the impacts these strategies can make: pre-release planning is hard and emotionally draining, both for workers and people exiting prison; and the current lack of housing options means there is often nothing to plan with. 


\section{References}

ABA - see Australian Bureau of Statistics

Aboriginal Housing Victoria (2019) 'Discussion Paper 9: Justice-What housing options would improve outcomes for people in contact with the justice system?', The Victorian Aboriginal Housing and Homelessness Summit, 5 April, accessed 20 June 2021, https://ahvic.org.au/cms_uploads/docs/16.-pm-session-c_discussion-paper-9.pdf.

AlHW-see Australian Institute of Health and Welfare

Anderson, S. and McNeill, F. (2019) ‘Desistance and cognitive transformations', in D. Farrington, L. Kazemian and A. Piquero (eds) The Oxford Handbook of Developmental and Life-Course Criminology, Oxford University Press, Oxford: 600-623.

Australian Bureau of Statistics (ABS) (2020a) Prisoners in Australia: 2020, cat. no. 4517.0, ABS, Canberra.

Australian Bureau of Statistics (ABS) (2020b) Corrective Services, Australia: September quarter 2020, cat no. 4512.0, ABS, Canberra.

Australian Government (2020) National Agreement on Closing the Gap, accessed 23 May 2021, https://www.closingthegap. gov.au/sites/default/files/files/national-agreement-ctg.pdf.

Australian Institute of Health and Welfare (AIHW) (2019a) The health of Australia's prisoners: 2018, cat. no. PHE 246, AlHW.

Australian Institute of Health and Welfare (AIHW) (2019b) Specialist homelessness services annual report 2017-18, cat. no. HOU 299, AlHW, www.aihw.gov.au/reports/homelessness-services/specialist-homelessness-services-2017-18/.

Baldry, E. (2014) 'Disability at the margins: limits of the law', Griffith Law Review, vol. 23, no. 3: 370-388.

Baldry, E., Dowse, L., McCausland, R. and Clarence, M. (2012) Lifecourse institutional costs of homelessness for vulnerable groups, Report to the Department of Families, Housing, Community Services and Indigenous Affairs, Australian Government, Canberra.

Baldry, E., Dowse, L. and Xu, H. (2013) People with mental and cognitive disabilities: pathways into prison, background paper, University of NSW.

Baldry, E., McCausland, R., Dowse, L. and McEntyre, E. (2015) A predictable and preventable path: Aboriginal people with mental and cognitive disabilities in the criminal justice system, University of NSW, accessed 20 June 2021, http:// unsworks.unsw.edu.au/fapi/datastream/unsworks:37093/binb10f2bda-8816-4112-aeeb-6cd6d8efe6f7? view=true.

Baldry, E., McDonnell, D., Maplestone, P. and Peeters, M. (2003) Ex-prisoners and accommodation: what bearing do different forms of housing have on social reintegration?, AHURI Final Report No. 46, Australian Housing and Urban Research Institute Limited, Melbourne, https://www.ahuri.edu.au/research/final-reports/46.

Bevitt, A., Chigavazira, A., Herault, N., Johnson, G., Moschion, J., Scutella, R., Tseng, Y-P., Wooden, M. and Kalb, G. (2015) Journeys Home research report no. 6: complete findings from waves 1 to 6, University of Melbourne, accessed 21 May 2021, https://melbourneinstitute.unimelb.edu.au/_data/assets/pdf_file/0007/2202865/Scutella_et_al_ Journeys_Home_Research_Report_W6.pdf.

BOCSAR- see Bureau of Crime Statistics and Research

Bullen \& Eileen Baldry (2019) 'I waited 12 months': how does a lack of access to housing undermine Housing First?', International Journal of Housing Policy, vol. 19 no.1: 120-130. 
Bureau of Crime Statistics and Research (2020) 'New South Wales Custody Statistics Quarterly Report March 2020', Government of NSW, accessed 1 July 2021, https://www.bocsar.nsw.gov.au/Pages/bocsar_custody_stats/bocsar custody_stats_archived.aspx.

Clancey, G., Fisher, D. and Yeung, N. (2016) 'A recent history of Australian crime prevention', Crime Prevention and Community Safety, vol. 18, no. 4: 309-328.

COAG_-see Council of Australian Governments

Corrections Victoria (2014) Correctional management standards for prisons, accessed 22 May 2021, https://www. corrections.vic.gov.au/standards-for-prisoners-and-offenders.

Corrections Victoria (2020) 'Monthly Time Series Prisoner and Offender Data', Government of Victoria, accessed 1 July 2021, https://www.corrections.vic.gov.au/monthly-time-series-prisoner-and-offender-data

Corrective Services Administrators' Council (CSAC) (2018) Guiding principles for Corrections in Australia, Government of Victoria, accessed 25 May 2021, https://www.corrections.vic.gov.au/guiding-principles-for-corrections-in-australia.

Council of Australian Governments (COAG) (2015) Applied Principles and Tables of Support, COAG, accessed 2 May 2021, https://www.coag.gov.au/sites/default/files/communique/NDIS-Principles-to-Determine-ResponsibilitiesNDIS-and-Other-Service.pdf.

CSAC-see Corrective Services Administrators' Council

Culhane, D (2008) 'The cost of homelessness: a perspective from the United States', European Journal of Homelessness, vol. 2, no. 1: 97-114.

Department of Communities and Justice (DCJ) (2019) Quarterly statistical report on social housing delivery: April-June 2019, Government of NSW, accessed 18 June 2021, https://public.tableau.com/profile/facs.statistics\#!/vizhome/ FACSquarterlystatisticalreportonhousingdelivery/Socialhousingdeliveryreport.

Department of Communities and Justice (DCJ) (2020) No Exits from Government Services into Homelessness: a framework for multi-agency action 2020, Government of NSW, accessed 20 June 2021, https://www.facs.nsw.gov. au/download?file=326055.

Department of Communities Tasmania (2018) Prisoner Rapid Rehousing: information for service providers, V4.A November, accessed 21 June 2021, https://www.communities.tas.gov.au/housing/tasmanian_affordable_housing strategy/key-projects/rapid-rehousing/fact-sheet-prisoner-rapid-rehousing.

Department of Community and Family Services (FACS) (2019) Annual Report 2018-19, FACS, Government of NSW, accessed 15 June 2021, https://www.facs.nsw.gov.au/resources/publications/annual-reports.

Department of Families, Housing, Community Services and Indigenous Affairs (FaHCSIA) (2008) The Road Home: a national approach to reducing homelessness, FaHCSIA, Canberra.

Department of Health and Human Services Tasmania (DHHS Tas.) (2015) Tasmania's affordable housing strategy 2015-2025, accessed 21 May 2021, https://www.communities.tas.gov.au/_data/assets/pdf_file/0014/30254/AHS_Strategy_ Final.pdf.

Department of Health and Human Services Victoria (DHHS Vic.) (2018) Victoria's Homelessness and Rough Sleeping Action Plan, accessed 23 May 2021, www.dhhs.vic.gov.au/sites/default/files/documents/201802/Rough\%20 Sleeping\%20Action\%20Plan_20180207.pdf.

Department of Justice Tasmania (2011) Breaking the cycle: a strategic plan for Tasmanian Corrections 2011-2020, accessed 23 May 2021, https://www.justice.tas.gov.au/correctiveservices/breaking-the-cycle/breaking-the-cycle/ corrections-strategic-plan.

DHHS Tas. - see Department of Health and Human Services Tasmania

DHHS Vic.-see Department of Health and Human Services Victoria

Disability Reform Council (2019) Meeting of the COAG Disability Reform Council: Sydney-9 October 2019 communique, Department of Social Services, accessed 21 May 2021, https://www.dss.gov.au/sites/default/files/documents/ 10_2019/communique-drc-9-october_2019.pdf.

Duff, C., Hill, N., Blunden, H. valentine, k., Randall, S., Scutella, R., and G. Johnson. (2021) Enhancing the Coordination of Housing Supports for People Leaving Mental Health and/or Substance Use Treatment. AHURI Final Report, Australian Housing and Urban Research Institute Limited, Melbourne. 
Easthope (2014) 'Making a Rental Property Home', Housing Studies, vol. 29, no. 5: 579-596.

FACS—see Department of Family and Community Services

FaHCSIA — see Department of Families, Housing, Community Services and Indigenous Affairs

Flanagan, K., Levin, I., Tually, S., Varadharajan, M., Verdouw, J., Faulkner, D., Meltzer, A. and Vreugdenhil, A. (2020) Understanding the experience of social housing pathways, AHURI Final Report No. 324, Australian Housing and Urban Research Institute Limited, Melbourne, https://www.ahuri.edu.au/research/final-reports/324, doi: 10.18408/ ahuri-4118301.

Flanagan, K., Martin, C., Jacobs, K. and Lawson, J. (2019) A conceptual analysis of social housing as infrastructure, AHURI Final Report No. 309, Australian Housing and Urban Research Institute Limited, Melbourne, https://www.ahuri.edu. au/research/final-reports/309.

Giordano, P., Cernkovich, S. and Rudolph, J. (2002) 'Gender, crime and desistance: toward a theory of cognitive transformation', American Journal of Sociology, vol. 107, no. 4: 990-1064.

Goodall, S., Norman, R. and Haas, M. (2008) 'The costs of NSW drug court', Crime and Justice Bulletin No. 122, NSW Bureau of Crime Statistics and Research.

Graham, H. and White, R. (2015) Innovative Justice, Routledge, London.

Gregoire, P. (2020) 'Strip searching women is routine in Australia', Sydney Criminal Lawyers, 4 November, accessed 21 June 2021, https://www.sydneycriminallawyers.com.au/blog/strip-searching-women-is-routine-in-australia/.

Herault, N. and Johnson, G. (2016) 'Homelessness in Australia: service reform and research in the 21st century', European Journal of Homelessness, vol. 10, no. 3:127-144.

Irwin, J. and Owen, B. (2005) 'Harm and the contemporary prison', in A. Liebling and S. Maruna (eds) The Effects of Imprisonment, Routledge, Abingdon: 94-117.

Herrlander Birgerson, E. (2018) 'A Real Gap': consequences of defunding Tasmania's Reintegration for Ex-Offenders' program, Masters Thesis, University of Tasmania.

Hulse, K., Milligan, V. and Easthope, H. (2011) Secure occupancy in rental housing: conceptual foundations and comparative perspectives, AHURI Final Report No. 170, Australian Housing and Urban Research Institute Limited, Melbourne, https://www.ahuri.edu.au/research/final-reports/170.

Hulse, K., Reynolds, M., Nygaard, C., Parkinson, S. and Yates, J. (2019) The supply of affordable private rental housing in Australian cities: short-term and longer-term changes, AHURI Final Report No. 323, Australian Housing and Urban Research Institute Limited, Melbourne, https://www.ahuri.edu.au/research/final-reports/323.

Jacob R., Somers, M.-A., Zhu, P. and Bloom, H. (2016) 'The validity of the comparative interrupted time series design for evaluating the effect of school-level interventions' Evaluation Review, vol. 40, no. 3: 167-198.

Justice Reform Initiative (2020) 'Jailing is failing', Justice Reform Initiative, accessed 21 May 2021, https://www. justicereforminitiative.org.au/jailingisfailing.

Laub, J. and Sampson, R. (2001) 'Understanding desistance from crime', Crime and Justice, vol. 28: 1-69.

Lawson, J., Pawson, H., Troy, L., van den Nouwelant, R. and Hamilton, C. (2018) Social housing as infrastructure: an investment pathway, AHURI Final Report No. 306, Australian Housing and Urban Research Institute Limited, Melbourne, https://www.ahuri.edu.au/research/final-reports/306.

LeBel, T.P. (2017) 'Housing as the tip of the iceberg in successfully navigating prisoner reentry', Criminology and Public Policy, vol. 16, no. 3: 891-908.

Lopez Bernal, J., Cummins, S. and Gasparrini, A. (2018) 'The use of controls in interrupted time series studies of public health interventions', International Journal of Epidemiology, vol. 47: 2082-2093.

Martin, C., Hulse, K. and Pawson, H. with Hayden, A., Kofner, S., Schwartz, A. and Stephens, M. (2018) The changing institutions of private rental housing: an international review, AHURI Final Report No. 292, Australian Housing and Urban Research Institute Limited, Melbourne, https://www.ahuri.edu.au/research/final-reports/292, doi:10.18408/ ahuri-7112201.

Martin, R., Cordier, C., Jau, J., Randall, S., Thoresen, S., Ferrante, A., Chavulak, J., Morris, S., Mendes, P., Liddiard, M., Johnson, G., and Chung, D. (forthcoming) Accommodating transition: improving housing outcomes for young people leaving $\mathrm{OHC}$, AHURI Final Report, Australian Housing and Urban Research Institute Limited, Melbourne. 
Maruna, S. (2001) Making Good: How Ex-Convicts Reform and Rebuild Their Lives, American Psychological Association, Washington DC.

Maruna, S. and Toch, H. (2005) 'The impact of imprisonment on the desistance process', in J. Travis C. and Visher (eds) Prisoner Reentry and Crime in America, Cambridge University Press, Cambridge: 139-178.

McCausland, R., Baldry, E., Johnson, S. and Cohen, A. (2013) People with mental health disorders and cognitive disability in the criminal justice system: cost-benefit analysis of early support and diversion, Report for the Australian Human Rights Commission.

McCausland, R., Reeve, R. and Gooding, P. (2019) 'The economic case for improving legal outcomes for accused persons with cognitive disability: an Australian study', International Journal of Law in Context, vol. 15, 367-389.

McNeill, F. (2006) 'A desistance paradigm for offender management', Criminology and Criminal Justice, vol. 6, no. 1: 39-62.

Metraux, S. and Culhane, D.P. (2004) ‘Homeless shelter use and reincarceration following prison release', Criminology and Public Policy, vol. 3, no, 2:139-160.

Milligan, V., Martin, C., Phillips, R., Liu, E., Pawson, H. and Spinney, A. (2016) Profiling Australia's affordable housing industry, AHURI Final Report No. 268, Australian Housing and Urban Research Institute, Melbourne, https://www. ahuri.edu.au/research/final-reports/268.

Milligan, V., Pawson, H., Phillips, R. and Martin, C. with Elton Consulting (2017) Developing the scale and capacity of Australia's affordable housing industry, AHURI Final Report No. 278, Australian Housing and Urban Research Institute Limited, Melbourne, https://www.ahuri.edu.au/research/final-reports/278.

Morony, S. (2018) 'The Initial Transitional Support Service (ITS) 2014-2017', presentation to the Reintegration Puzzle conference, 20-22 June 2018, Hobart, Tasmania.

Morrison, B. and Bowman, J. (2017) 'What happens beyond the gate? Findings from the post-release employment study', Practice: The New Zealand Corrections Journal, vol. 5 no. 1.

National Disability Insurance Scheme (NDIS) (2018) Improving the NDIS participant and provider experience, NDIS, accessed 2 May 2021, https://www.ndis.gov.au/media/1068/download.

Needham, K. (2013) 'Sex criminals halfway house to shut', Sydney Morning Herald, 13 October 2013, accessed 1 July 2022, https://www.smh.com.au/national/nsw/sex-criminals-halfway-house-to-shut-20131012-2vf3w.html.

NSW Corrective Services (2013) 'New community support to reduce re-offending', media release, 9 August 2013.

NSW Government (2018) NSW homelessness strategy 2018-2023, accessed 23 May 2021, https://www.facs.nsw.gov.au/ download?file=590515.

NSW Government (2020) 'Premier's Priorities: reducing recidivism in the prison population', NSW Government, accessed 20 June 2021, https://www.nsw.gov.au/premiers-priorities/reducing-recidivism-prison-population.

NSW Inspector of Custodial Services (2020a) Inspection standards: for adult custodial services in New South Wales, accessed 22 May 2021, https://www.inspectorcustodial.nsw.gov.au/documents/inspection-standards-for-adultcustodial-services-in-new-south-wales.pdf.

NSW Inspector of Custodial Services (2020b) Residential Facilities and the compulsory drug treatment correctional centre, accessed 22 May 2021, https://www.inspectorcustodial.nsw.gov.au/inspector-of-custodial-services/reportsand-publications/inspection-reports/adult-reports/residential-facilities-and-the-compulsory-drug-treatmentcorrectional-centre.html

NSW Inspector of Custodial Services (2020c) Kariong and Kirkconnell Correctional Centres and the Integration Support Centre, accessed 22 May 2021, https://www.inspectorcustodial.nsw.gov.au/inspector-of-custodial-services/ reports-and-publications/inspection-reports/adult-reports/kariong-and-kirkconnell-correctional-centres-and-theintegration.html

NSW Treasury (2015) Evaluation of the Community Justice Program: final report, Centre for Program Evaluation, NSW Treasury for the Department of Family and Community Services NSW, Sydney.

Office of the Custodial Inspector Tasmania (2018) Inspection standards: for adult custodial centres in Tasmania, accessed 25 May 2021, https://www.custodialinspector.tas.gov.au/_data/assets/pdf_file/0005/546278/FINALInspection-Standards-for-Adult-Custodial-Centres-in-Tasmania-July-2019.pdf. 
Parsell, C., Petersen, M. and Culhane, D. (2017) 'Cost offsets for supportive housing: evidence for social work', British Journal of Social Work, vol. 47: 1534-1553.

Pawson, H., Martin, C., Flanagan, K. and Phillips, R. (2016) Recent housing transfer experience in Australia: implications for affordable housing industry development, AHURI Final Report No. 273, Australian Housing and Urban Research Institute Limited, Melbourne, https://www.ahuri.edu.au/research/final-reports/273, doi:10.18408/ahuri-7108101.

Pawson, H., Milligan, V. and Yates, J. (2020) Housing Policy in Australia: A Case for System Reform, Palgrave Macmillan, Singapore.

Pawson, H., Parsell, C., Liu, E., Hartley, C. and Thompson, S. (2020) Australian Homelessness Monitor 2020, Launch Housing, Melbourne.

Pawson, H., Parsell, C., Saunders, P., Hill, T. and Liu, E. (2018) Australian Homelessness Monitor 2018, Launch Housing, Melbourne.

People With Disability Australia (PWDA) (2011) Shut In: campaign to close institutions: position statement, PWDA for the Shut In Campaign Committee, Sydney.

Petersilia, J. (2009) When Prisoners Come Home: Parole and Prisoner Reentry, Oxford University Press, Oxford.

Phibbs, P. and Young, P. (2005) Housing assistance and non-shelter outcomes, AHURI Final Report No. 74, Australian Housing and Urban Research Institute Limited, Melbourne, https://www.ahuri.edu.au/research/final-reports/74.

Phillips R. and Parsell C. (2012) The role of assertive outreach in ending 'rough sleeping', AHURI Final Report No.179, Australian Housing and Urban Research Institute, Melbourne, https://www.ahuri.edu.au/research/final-reports/179.

PWDA—see People With Disability Australia

Reeve, R. and McCausland, R. (forthcoming) Calculating the criminal justice, health and human services costs for the MHDCD Databank: updated method, University of New South Wales, Sydney.

Reeve, R., McCausland, R., Dowse, L. and Trofimovs, J. (2017) Economic evaluation of criminal justice support network: Intellectual Disability Behaviour Support Program, University of New South Wales, Sydney.

Ross, S., Diallo Roost, F., Azpitarte Raposeiras, F. and Hanley, N. (2013), Evaluation of the Corrections Victoria Housing Program: final report, University of Melbourne, Melbourne.

Smith, R., Jorna, P., Sweeney, J. and Fuller, G. (2014) Counting the costs of crime in Australia: a 2011 estimate, AIC Research and Public Policy Series No. 129 (revised with corrections to Tables 10, 11 and 20), Australian Institute of Criminology, viewed April 2017, https://www.aic.gov.au/publications/rpp/rpp129.

Steering Committee for the Review of Government Service Provision (SCRGSP) (2017) Report on government services 2017, Productivity Commission, accessed 12 June 2021, https://www.pc.gov.au/research/ongoing/report-ongovernment-services/2017/.

Steering Committee for the Review of Government Service Provision (SCRGSP) (2020) Report on government services 2020, Productivity Commission, accessed 7 June 2021, https://www.pc.gov.au/research/ongoing/report-ongovernment-services/2020/.

Tasmanian Government (2020) Tasmanian Government Submission: Inquiry into Homelessness in Australia, July 2020.

Thomas, E., Spittal, M., Taxman, F. and Kinner, S. (2015) 'Health-related factors predict return to custody in a large cohort of ex-prisoners: new approaches to predicting re-incarceration', Health and Justice, vol. 3, no. 10: 1-13.

United Nations Office on Drugs and Crime (UNOCD) (2015) United Nations Standard Minimum Rules for the Treatment of Prisoners: The Nelson Mandela Rules, UNOCD, accessed 25 May 2021, https://www.unodc.org/documents/ justice-and-prison-reform/Nelson_Mandela_Rules-E-ebook.pdf.

Victorian Aboriginal Justice Advisory Committee (VAJAC) (2020) Victorian Aboriginal Justice Agreement: Phase 4, accessed 23 May 2021, https://www.aboriginaljustice.vic.gov.au/aboriginal-justice-agreement-phase-4-0.

Victorian Government (2020) Budget 2020-21: Budget Paper No. 2, Victorian Government, Melbourne.

Victorian Ombudsman (2015) Investigation into the rehabilitation and reintegration of prisoners in Victoria, Victorian Ombudsman, Melbourne.

Western, B. (2018) Homeward: Life in the Year After Prison, Russel Sage Foundation, New York. 
Western, B., Braga, A., Davis, J. and Sirois, C. (2015) 'Stress and hardship after prison', American Journal of Sociology, vol. 120, no. 5: 1512-1547.

Willis, M. (2018) Supported housing for prisoners returning to the community: a review of the literature, AIC Research Report 07, Australian Institute of Criminology, Canberra.

Zaretzky, K. and Flatau, P. (2013) The cost of homelessness and the net benefit of homelessness programs: a national study, AHURI Final Report No. 218, Australian Housing and Urban Research Institute, Melbourne, https://www. ahuri.edu.au/research/final-reports/218. 


\title{
Appendix 1. Interview topic guide-agency representatives
}

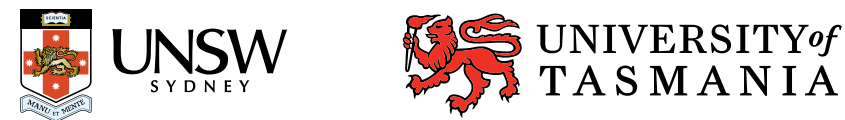

$\triangle \mathrm{RMIT}$

UNIVERSITY

\section{Exiting prison with complex support needs: the role of housing assistance - agency perspectives}

\author{
Interview topic guide \\ Thank you for taking the time to meet with us today. \\ This interview is part of a research project about the housing pathways of persons exiting prison, particularly \\ persons with complex support needs relating to mental health disorders and/or cognitive disorders.
}

We are interested in how persons exiting prison are housed, the housing assistance they might receive, and how housing affects other outcomes, such as contact with health services and criminal justice agencies and returns to prison.

We want to hear your views and experience, as someone who works with persons exiting prison. We are interested in your views as a representative of your agency, and as an individual professional person. You may be critical of your agency, other agencies or law and policy. We will never publish information from interviews that may identify an individual person, or an agency (except the state Corrections and Housing departments, because there is only one of these in each jurisdiction - but we will never identify individual persons in these agencies). If quoted in the research report, you will be 'X, community sector, Vic', or 'Y, Corrective Services, NSW', or similar.

Please note that this is not Indigenous-led research, so the research will not focus experiences specific to Indigenous persons. Where Indigenous participants tell us their experience is different we will use the information to say that specific Indigenous-led research needs to be done.

1. Please introduce yourself, your agency and your role in working with persons exiting prison.

2. Please outline what you see as typical housing pathways for persons exiting prison. Please reflect specifically on persons with complex support needs (i.e. persons with mental and/or cognitive disability or other disability, multiple diagnoses and other disadvantages)

3. What expectations are there (formally and informally) on the following actors to assist with housing:
a. The individual person exiting prison
b. The person's family or friends
c. State Corrections agencies
d. State housing agencies
e. Community organisations
f. Private market actors (e.g. landlords, real estate agents, boarding house proprietors, caravan park operators) 
4. Please reflect on the availability and utility of the following forms of housing assistance:
a. pre-release planning
b. Corrections-related accommodation
c. crisis accommodation
d. transitional housing
e. social housing
f. Commonwealth Rent Assistance
g. bond loans/grants
h. brokerage services
i. case work
j. legal information and advice

5. What role or influence do non-housing agencies and services (e.g. re-integration services, rehabilitation programs) have regarding housing for persons exiting prison?

6. What impact do parole conditions, orders and other post-release legal conditions have on housing pathways and housing assistance?

7. Can you please give your reflection on inter-agency service co-ordination regarding housing after prison-in particular:
a. initiating plans for post-release housing
b. planning processes
c. referrals
d. information sharing
e. following up

8. What are some of the challenges or barriers you face in working with persons exiting prison regarding their housing? Are there work-arounds to overcome these? Please reflect specifically on persons with complex support needs

9. What do you observe to be the major barriers facing persons leaving prison in securing suitable housing? Please reflect specifically on persons with complex support needs

10. What have you found works when working with persons exiting prison especially in relation to housing? Please reflect specifically on persons with complex support needs

11. Do you have information about the relative costs of different forms of assistance?

12. Are there some key messages you would like policy makers to hear about your experience of working with persons exiting prison? 


\title{
Appendix 2. Interview topic guide-ex-prisoners
}

\section{UNSW

\section{Exiting prison with complex support needs: the role of housing assistance - ex-prisoner perspectives}

\author{
Interview topic guide \\ Thank you for taking the time to meet with us today. \\ This interview is part of a research project about the housing pathways of persons exiting prison, particularly \\ persons with complex support needs relating to mental health disorders and/or cognitive disorders.
}

We are interested in how persons exiting prison are housed, the housing assistance they might receive, and how housing affects other outcomes, such as contact with health services and criminal justice agencies, and returns to prison.

We want to hear your views and experience, as someone who has left prison.

The questions are not intended to upset you, or bring up painful memories. If this happens, let me know. We can skip the question. We can also stop the interview and take a break, or finish up and return to the interview another day. You can also decide to withdraw from the research. There will be no hard feelings or disadvantage to you if to decide to withdraw.

The research is not about detecting illegal activities. There is a question about drug use, and a question about contact with police, but your answers will be kept confidential. Please do not reveal any new offence or offence not known to police.

We will never publish any identifying information about you (if we quote you, you'll be called 'Mr X or 'Ms Y or just 'Z, NSW', or similar).

Please note that this is not Indigenous-led research, so the research will not focus experiences specific to Indigenous persons. Where Indigenous participants tell us their experience is different we will use the information to say that specific Indigenous-led research needs to be done.

1. Let's start with a bit about yourself: [age, gender, ATSI status, NESB status, diagnosis/disability, single or partnered, children, employed or studying, income level].

2. Where do you live now? [location; with whom; tenure type] Is this accommodation:

a. secure [do you feel you can stay for a reasonable period of time?],

b. appropriate [is it fairly comfortable, private, accessible?] and

c. affordable [do you have enough money to pay for your accommodation and all the other things you need?] 
3. Did anyone help you get this place?

4. Will you stay in this place a while, or are you looking to live somewhere else? [location, with whom, tenure type] Is someone helping with that?

5. Do any conditions of your release affect where you can live?

6. When did you last leave prison?

7. Thinking back, where did you live immediately after leaving prison? Are you still in that place? [location; with whom; tenure type]. Was this accommodation secure, appropriate and affordable?

8. When you left prison, did anyone help you with your housing? Can you say:

a. who [which agencies, family... ] helped?

b. what did they do, when, and for how long?

c. how did different agencies work together with you? [referrals, info sharing, gaps, duplication]

d. what helped most?

e. what would have helped, but you didn't get it?

9. How important was it then to get housing sorted out? Were you dealing other things that were important to get sorted out? [health, income, family, social connections, cultural connections, sexuality/gender/identity]

10. How many moves have you made since leaving prison?

11. Have you participated in any programs since leaving prison? [case work, rehabilitation, counselling, employment services]

12. Do you have employment? If so how did you get it?

13. Have you been well since leaving prison? How would you describe your health?:

- not a problem - minor problem - moderate problem - serious problem

14. Have you used drugs or alcohol since leaving prison? How would you describe your use?:

- not a problem - minor problem - moderate problem - serious problem?

15. Have you had contact with police since leaving prison?

16. Thinking even further back, where did you live immediately before entering prison? [location, with whom, tenure type]

17. Has a past housing issue affected your housing since being released [listed on a tenancy database/blacklist, no references, social housing debt, previous unsatisfactory social housing tenancy]?

18. If you have been in prison before this current time, were your experiences finding housing different to this time? Can you explain why?

19. What do you think have been the main barriers to getting and keeping suitable housing (if that has been your experience) [e.g. no affordable housing, drug use, disability, health, stigmatisation, lack of funds, no one to help ....]?

20. What do you think have been the main helps and supports in getting and keeping suitable housing (if that has been your experience) [availability of affordable housing, good support, family help, being in a rehab program, employed...]?

21. Are there some key messages you would like policy makers to hear about your experience of exiting prison? 


\section{AHURi}

Australian Housing and Urban Research Institute Level 12, 460 Bourke Street

Melbourne VIC 3000

\section{Australia}

+61396602300

information@ahuri.edu.au

ahuri.edu.au

(?) twitter.com/AHURI_Research

f facebook.com/AHURI.AUS

in Australian Housing and Urban Research Institute 